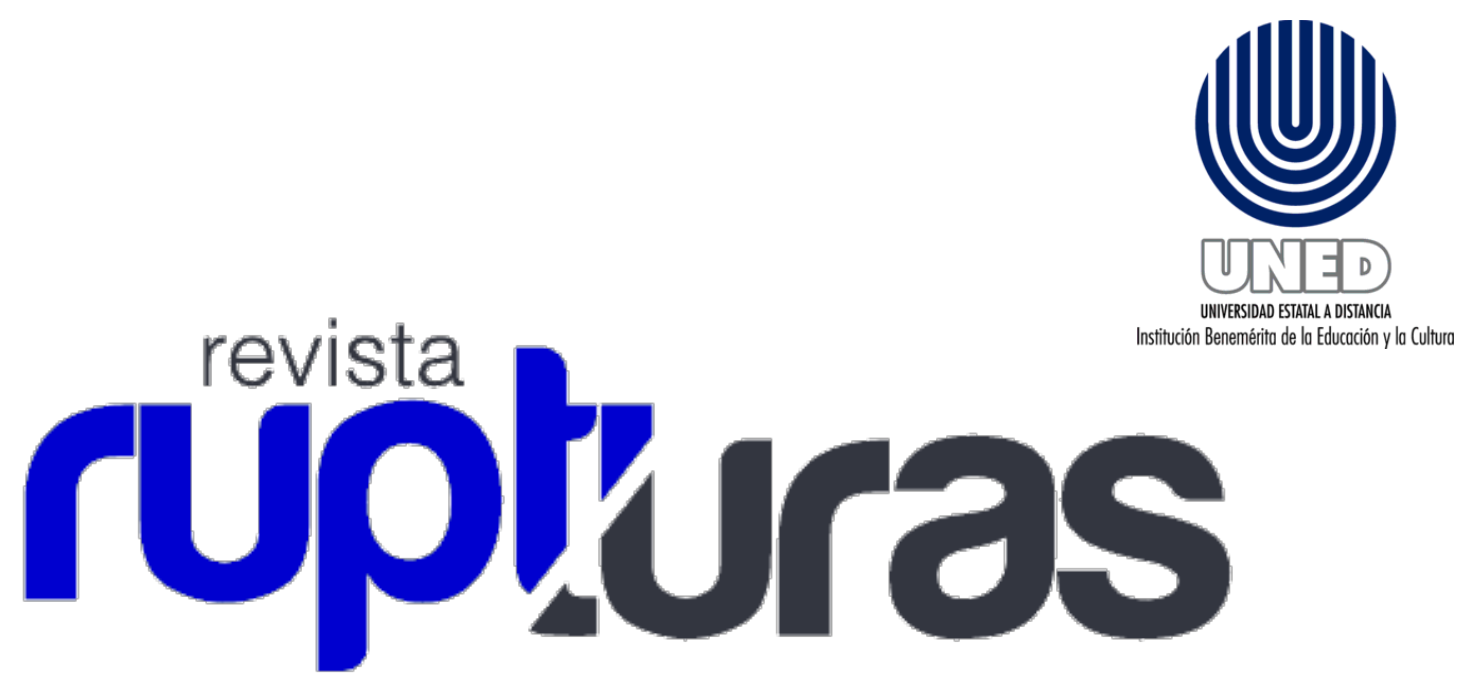

Revista Rupturas 5(2), San José, Costa Rica, Julio-Dicembre 2015. ISSN 2215-2466 http://investiga.uned.ac.cr/rupturas/

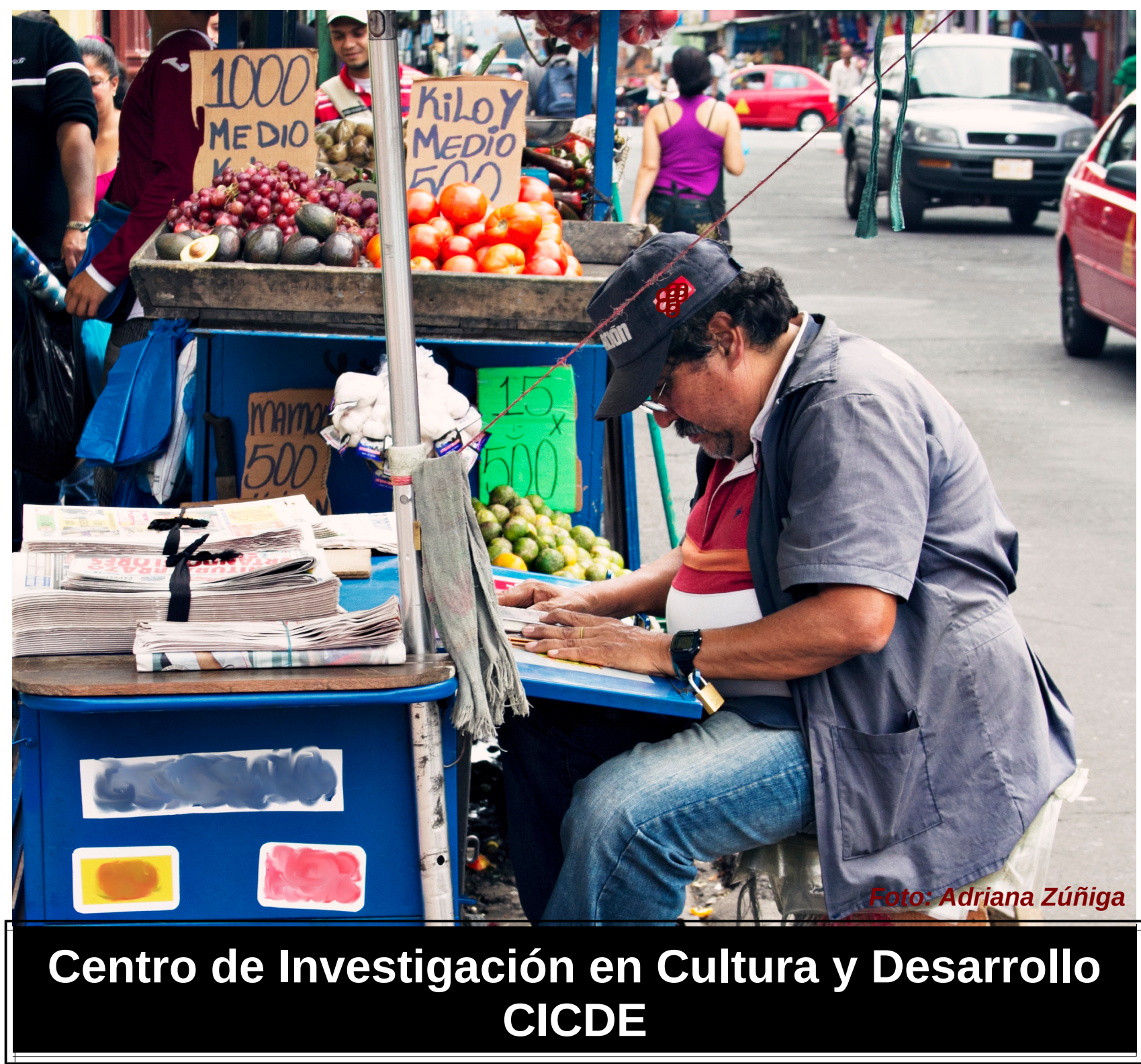


Revista Rupturas, Volúmen 5 Número 2

Centro de Investigación en Cultura y

Desarrollo (CICDE)

Universidad Estatal a Distancia (UNED)

San José, Costa Rica

Jul-Dic 2015 


\section{Contenido}

Presentación

\section{Artículos}

Trabajando con población migrante en Costa Rica: reflexiones sobre la relación entre organizaciones de ayuda y las bases para la acción colectiva / Working with Migrant Population in Costa Rica: Reflections on the Relationship between Aid Organizations and the Foundations for Collective Action

Silvia Azofeifa Ramos, Carmen Caamaño Morúa, Anna Matteucci Wo Ching

Reformas curriculares 2006-2014: del ajuste pedagógico neoliberal a la reinstauración del modelo pedagógico socialdemócrata / Curricular Reforms 2006-2014: From the Neoliberal Pedagogical Adjustement to the Restoration of the Social Democrat Educational Model

César Toruño Arguedas

Revisitando las ONG como objeto de estudio: consideraciones para una aproximación crítica inicial / Revisiting NGOs as Research Focus: Considerations Towards an Initial Critical Approximation

Alex Guevara Meza

Apuntes relativos a la producción del conocimiento científico, dilemas y posibilidades en la investigación social / Outlines Related to the Production of Scientific Knowledge, Dilemmas and Possibilities in Social Research

Andrey Badilla, Julio Solís Moreira

Reseña

¿Hacia un capitalismo rentificado y patrimonializado? A propósito del libro "El capital en el siglo XXI" de Thomas Piketty / ¿Hacia un capitalismo rentificado y patrimonializado? A propósito del libro "El capital en el siglo XXI" de Thomas Piketty

Luis Paulino Vargas Solís

\author{
Consejo científico internacional \\ Clara Arenas Bianchi \\ Amalio Blanco Abarca \\ José Luis Benítez \\ Amparo Marroquín Parducci \\ Ricardo Melgar Bao \\ Catalina Toro Pérez \\ Margarita Vannini \\ Jaime Hernández García
}

iv
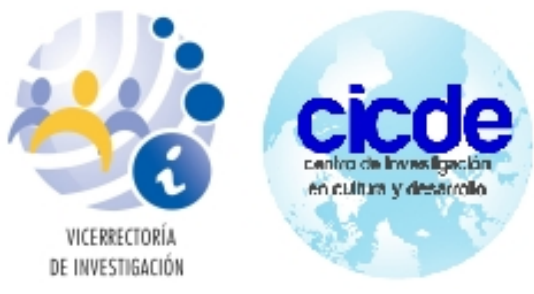

1

21

49

105

Consejo editorial

Luis Paulino Vargas Solís

Silvia Rodríguez Cervantes

Cristina D'Alton Kilby

Dagoberto Núñez Picado

Laura Guzmán Stein

Rodrigo Quesada Monge

Mario Zúñiga Núñez

Mirta González Suárez

Jaime Delgado Rojas

\section{Editor Académico y} Coordinador

Orlando Amarís Cervantes

revista.rupturas@gmail.com

\section{Editor Técnico \\ Pablo Díaz González}

Revisión filológica

Programa de Producción de Material Didáctico Escrito

(PROMADE)

\section{Diagramación \\ Pablo Díaz González}

Portada

Adriana Zúñiga Saborío
Centro de Investigación en

Cultura y Desarrollo (CICDE)

cicdeuned@gmail.com

Revista Rupturas

Volumen 5, Número 2

http://investiga.uned.ac.cr/revist

as/index.php/rupturas/

revista.rupturas@gmail.com

Julio-Diciembre 2015

ISSN: 2215-2466 


\section{Presentación}

Para el Centro de Investigación en Cultura y Desarrollo (CICDE) es una gran satisfacción presentar el segundo número del quinto volumen de la Revista Rupturas. En esta oportunidad se presentan cuatro aportes originales e inéditos que, desde diferentes áreas del conocimiento, tratan problemáticas de actualidad. Es de destacar la participación de dos artículos cuya autoría es externa a nuestra universidad. Esto último nos compromete más a consolidar la revista como un espacio académico riguroso y plural, que, cada vez más, convoque a investigadores de otras universidades y entidades dedicadas a la investigación social, tanto nacionales como de la región centroamericana.

En el caso del primer artículo intitulado Trabajando con población migrante en Costa Rica: reflexiones sobre la relación entre organizaciones de ayuda y las bases para la acción colectiva se presentan, mediante una crítica reflexión que se alimenta de las contribuciones de las organizaciones involucradas, los obstáculos para trascender la visión humanitaria alrededor de la regularización hacia posibilidades de acciones colectivas por parte de la población migrante. Igualmente las autoras exploran y profundizan las causas de este fenómeno.

El segundo artículo Reformas curriculares 2006-2014: del ajuste pedagógico neoliberal a la reinstauración del modelo pedagógico socialdemócrata expone, mediante la construcción conceptual de ambos formatos educativos, distinciones necesarias para su comprensión agregando la detección de contradicciones que prevalecen en el juicio apresurado que realizan sectores del progresismo nacional sobre la administración de Leonardo Garnier durante su paso por el Ministerio de Educación entre el 2006 y el 2014.

En el tercer trabajo, Revisitando las ONG como objeto de estudio: consideraciones para una aproximación crítica inicial, se discute, por primera vez en una revista académica costarricense, acerca sobre la Cooperación Internacional en América Central y en particular Costa Rica. Dicho análisis ensaya una categorización que facilita la exposición de hallazgos acudiendo a una copiosa bibliografía y al análisis de fuentes primarias. La pertinencia de este artículo bien cabe para los investigadores que estén aproximándose a este tema de estudio como para aquellos y aquellas que construyen su estado de la cuestión en investigaciones de posgrado.

Con respecto a la cuarta contribución, Apuntes relativos a la producción del conocimiento científico, dilemas y posibilidades en la investigación social, este artículo presenta a los lectores de Rupturas un trabajo original en el cual un profesional en Ciencias Políticas y otro en Sociología decantan su experiencia alrededor de la realización en talleres para la promoción de la investigación social entre estudiantes del sistema a distancia de la UNED. Es rescatable la labor de síntesis de este trabajo que recopila la metodología alrededor de este proceso pedagógico que pretende promover la actividad científica. 
Por otra parte en este número presentamos en nuestra sección Reseña un trabajo del Dr. Luis Paulino Vargas donde crítica razonadamente el último libro de Piketty. Este comentario se titula ¿Hacia un capitalismo rentificado y patrimonializado? A propósito del libro "El capital en el siglo XXI" de Thomas Piketty y fue expuesto en una actividad apoyada por la editorial del Fondo de Cultura Económica y el Centro de Investigación en Cultura y Desarrollo (CICDE).

Reafirmamos que Rupturas es un espacio académico que se construye desde un esfuerzo colectivo aspirando a la excelencia y el mayor rigor académico. Creemos que esa es la mejor forma de garantizarnos y merecer la confianza de nuestros lectores así como de investigadores e investigadoras que someten sus trabajos a nuestra consideración.

Orlando Amarís Cervantes

Editor Académico

Revista Rupturas

Centro de Investigación en Cultura y Desarrollo (CICDE)

Vicerrectoría de Investigación

UNED 
Revista Rupturas, Volúmen 5 Número 2 Centro de Investigación en Cultura y Desarrollo (CICDE) Universidad Estatal a Distancia (UNED) San José, Costa Rica Julio-Diciembre 2015 


Trabajando con población Working with Migrant Artículo recibido:
migrante en Costa Rica: Population in Costa Rica: 1 de abril del 2014.
reflexiones sobre la relación Reflections on the Relationship Evaluado:
entre organizaciones de ayuda between Aid Organizations and 19 de mayo del 2014.
$\begin{array}{lll}\text { y las bases para la acción the Foundations for Collective Aceptado: } \\ \text { colectiva } & \text { Action. } & 1 \text { de junio del } 2014 .\end{array}$

RESUMEN

ABSTRACT

En este artículo reflexionamos sobre las funciones de las organizaciones de ayuda a migrantes y sus posibilidades de desarrollar acciones políticas colectivas. A través de los seminarios de migración y subjetividad del Instituto de Investigaciones Sociales de la Universidad de Costa Rica con profesionales que trabajan en las ONG para la atención a inmigrantes, se pudo hallar que la priorización de labores asistenciales en las organizaciones, la lucha por el financiamiento externo, y las diferencias en el enfoque de la temática migratoria son algunos de los obstáculos para la acción política colectiva. Los esfuerzos de algunas de estas organizaciones se enfocan básicamente en la resolución de necesidades inmediatas como la regularización, mientras que el fortalecimiento de la población migrante como sujetos políticos parece secundario y este es un aspecto hacia el cual se propone dirigir el trabajo con la población migrante.

Palabras Clave

KEY WORDS

Migración; ONGs; asistencialismo; acción colectiva; participación

In this article we analyze the roles of migrant support organizations, and the opportunities to develop collective political action. Through the Seminars of Migration and Subjectivity at the Instituto de Investigaciones Sociales, Universidad de Costa Rica with professionals working in NGOs for migrants' advocacy we found prioritization of care work in organizations, the struggle for external funding, and differences in approach regarding migration issues are some of the obstacles for bringing more vitality to collective political action. The efforts of some organizations tend to focus on solving immediate needs such as regularization; in the meantime, strengthening migrants as political subjects seems secondary. We propose this as the goal when working with migrant population.

Migration; NGOs; welfarism; collective action; participatio

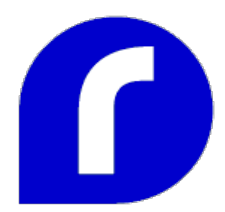

\begin{abstract}
Silvia Azofeifa Ramos
Bachiller en Psicología de la Universidad de Costa Rica. Es investigadora del Instituto de Investigaciones Sociales de la Universidad de Costa Rica; se desempeña en proyectos relacionados con población migrante, refugiada e indígena. Correo electrónico: silvia.azofeifa@gmail.com
\end{abstract}

\section{Carmen Caamaño Morúa}

Psicóloga y Doctora en Estudios Culturales Latinoamericanos, Caribeños y de los Latinos en Estados Unidos, State University of New York at Albany, Estados Unidos. Dirige el Instituto de Investigaciones Sociales (IIS) de la Universidad de Costa Rica.

Correo electrónico:

carmen.caamano@ucr.ac.cr

\begin{abstract}
Anna Matteucci Wo Ching
Psicóloga y Bachiller en Artes Plásticas de la Universidad de Costa Rica. Labora como investigadora en el Instituto de Investigaciones Sociales de la Universidad de Costa Rica y como artista visual independiente.

Correo electrónico:

anna.matteucci@ucr.ac.cr
\end{abstract}




\section{Trabajando con población migrante en Costa Rica: reflexiones sobre la relación entre organizaciones de ayuda y las bases para la acción colectiva}

\section{Introducción}

El presente artículo corresponde a reflexiones que surgen a partir del Seminario Migración y redes de apoyo: Entre la subjetividad y la acción colectiva, un seminario de Extensión Docente que desarrollamos en el Instituto de Investigaciones Sociales de la Universidad de Costa Rica. Dicho seminario se trabajó con dos grupos durante el primer semestre del año 2013, y a la vez, constituyó la segunda parte del que desarrollamos durante 2012 denominado Migración y Subjetividad: Trabajando con población migrante, a partir del cual concluimos, entre otras cosas, que la mayor parte de las personas que llevan a cabo trabajo con población migrante son mujeres, y sus tareas en las organizaciones son usualmente asistenciales. Esto convierte sus labores en jornadas laborales que se extienden indefinidamente con actividades reproductivas que consumen su tiempo y energía.

Es de esta manera que las funcionarias de organismos no gubernamentales, organizaciones religiosas y voluntarias, terminan formando parte de "cadenas globales de cuido" (Carcedo, Chaves y Lexartza, 2011; Azofeifa, Caamaño y Matteucci, 2012) que no logran revertir las bases estructurales del capitalismo globalizado. Por lo anterior, decidimos proponer el segundo seminario, cuyo objetivo principal era explorar la posibilidad de desarrollar acciones políticas colectivas que trascendieran las tareas de lobby que ya muchas de estas organizaciones realizan. 


\section{Acción política y acción colectiva}

De acuerdo al pensamiento de Arendt, explicado por Vargas (2009), podemos comprender la acción política como la actividad mediante la cual se puede construir y transformar el mundo a partir de la participación de la comunidad. Para que esto sea posible es necesaria la existencia de un espacio público en el que las personas puedan actuar, expresarse y deliberar libremente. Para Arendt (2005), la acción es entonces la actividad política por excelencia en una sociedad plural. En el caso de la población inmigrante y, en particular, aquella cuyo estatus migratorio es irregular, nos encontramos con importantes obstáculos para acceder a esa participación de manera formal. Lo anterior en tanto dicha participación se garantiza en un Estado-nación, a partir de la noción de ciudadanía, si bien algunas personas se organizan para garantizar la satisfacción de sus necesidades básicas con la mediación de diversas instituciones de ayuda.

Según Sassen (2006), lo anterior evidencia que la ciudadanía es básicamente un proyecto normativo, mientras que la membresía social es más bien comprehensiva y abierta. Sin embargo, al menos en el caso de Costa Rica, la discriminación y la xenofobia limitan esa membresía social. Es por ello que en el seminario planteamos buscar formas de acción política más contundentes y significativas para la población migrante. No obstante, encontramos varios obstáculos que trataremos de discutir en este trabajo.

Entre los obstáculos más importantes se encuentran las labores asistenciales, la rivalidad entre las organizaciones de apoyo a la población migrante debido a la lucha que se da entre ellas por el financiamiento externo de las agencias de cooperación, en un contexto de crisis económica mundial, y las diferencias entre organizaciones acerca del enfoque para abordar la temática migratoria. Por otro lado, parecieran predominar los esfuerzos dirigidos a la regularización de la población migrante, lo cual, si bien responde a un deseo de protección y a una necesidad, tiene varias consecuencias, entre ellas, la dificultad de visualizar a la población no regularizada como sujetos políticos, además de impedir la visualización de la labor en el marco de un contexto más amplio y "desde abajo" (Rauber, 2012).

Nuestro análisis se dirige hacia la necesidad de un enfoque que promueva el fortalecimiento de la labor en redes por parte de las diversas organizaciones que trabajan con población migrante, y la participación de dicha población como sujetos políticos, independientemente de su condición migratoria. Esto implica una participación que va más allá de la concepción formal sobre lo que es hacer política e incluye lo que Hardy-Fanta (1993) descubrió ya hace años al entrevistar a mujeres latinas activistas en Estados Unidos. Para estas activistas, hacer política es "hacer conexiones entre la gente, conexiones entre problemas privados y asuntos públicos, y conexiones que llevan a la consciencia política y a la acción política" (p.3). 
Es debido a esta imperiosa necesidad de trascender al plano político que pensamos en acciones colectivas, entendiendo por estas "el capital social formado por redes de reciprocidad, cooperación voluntaria y compromiso que contribuye a la formación de la comunidad" (Vargas, 2003, p.529). En estas redes de reciprocidad, se pretende prescindir de estructuras jerarquizadas y burocráticas para apelar a la horizontalidad entre los y las participantes involucradas y permitir que los aportes de cada quien sean recibidos "de primera mano" por los demás miembros.

Pero además de pretender formar redes de trabajo con quienes se encuentran de por sí realizando acciones constantes a favor de la población migrante, es importante también dar un paso más allá y pensar en formas de involucrar a la población en cuestión que, en este caso, es la población inmigrante en Costa Rica, así como a la población costarricense que se ve involucrada en las acciones colectivas como sujeto receptor del mensaje. Lo anterior se liga al paradigma de "los nuevos movimientos sociales" (Melucci, 2001, en Rodríguez, 2002) que se caracterizan por invadir la cotidianidad, politizar la vida cotidiana y politizar aspectos que tradicionalmente han estado supeditados a la vida privada o la intimidad, con lo cual una acción tal como migrar, en otro tiempo se hubiera considerado un asunto privado que atañe única y exclusivamente a ese sujeto que migra, pero que con la forma en que los movimientos sociales se articulan hoy en día, pasa a ser una lucha política de aquellos que se oponen a las injusticias y violaciones que se han naturalizado en los procesos de migración.

Melucci (1996, citado en Rodríguez, 2002) lo explica muy bien al definir lo que él llama identidad colectiva. Esta es "una definición interactiva y compartida producida por un número de individuos (o grupos, en un nivel mayor de complejidad) respecto de las orientaciones de su acción y el campo de oportunidades y constreñimientos en el que tal acción tiene lugar" (Rodríguez, sección La perspectiva de los nuevos movimientos sociales y el hiato tecnológico, parr. 7).

Estas acciones colectivas contemplan lo que para Touraine (1992, citado en Vargas, 2003) es la definición de un movimiento social en sí: "es una acción colectiva orientada a la implementación de valores culturales centrales contra los intereses e influencias de un enemigo definido en términos de relaciones de poder. Un movimiento social es una combinación de conflictos sociales y de participación cultural" (p. 530). En este caso, ese enemigo común a quien se dirigirían las acciones serían los medios de comunicación masiva e instituciones oficiales del gobierno que favorecen la xenofobia al compartir datos imprecisos y sesgados sobre la presencia de extranjeros en Costa Rica. Debido al poder que ostentan tanto los medios de comunicación colectiva como las instituciones oficiales, inevitablemente influencian la opinión pública a una velocidad a la que las ONG por sí solas e individualmente les cuesta seguir el paso. 
Es importante resaltar que las acciones colectivas no solo se encauzan políticamente, sino que se manifiestan culturalmente también, y su peso se encuentra en la acción en tanto logran simbolizar significados, conceptos, redes y distintos aspectos de la vida social general (Rodríguez, 2002). Esto tiene especial importancia en el caso de los seminarios de migración y subjetividad, los cuales al retomar el modelo reflexión-afecto-reflexión-acción lo hacen a través de la simbolización en un espacio en que se abordan los afectos que acompañan este tipo de trabajo, pero sin que resulte amenazante para la subjetividad de los y las participantes (Azofeifa, Caamaño \& Matteucci, 2012).

Por último, retomamos la propuesta de Rodríguez (2002) de que para estudiar los movimientos sociales y acciones colectivas actualmente, debemos ser capaces de estudiar la movilización individual a través de los procesos de construcción identitaria, de emociones, empatías y las diversas solidaridades que pueden emerger. Este planteamiento es coherente con la metodología que proponemos en los seminarios, en donde los afectos median no solo el posicionamiento con respecto al tema y la población implicada, sino también en relación con la interacción que se tiene, incluso en un plano profesional, con esas personas a las que se atiende día a día en las ONG.

\section{Contexto neoliberal y el trabajo de las ONG}

La inserción capitalista en las diferentes regiones del mundo ha ido desplazando a grandes cantidades de población, convirtiéndolas en la mano de obra flexible y móvil que genera los grandes flujos migratorios. Al mismo tiempo, las instituciones globales en el marco del capitalismo han ido generando, "desde arriba", propuestas de atención, regularización y control de las personas migrantes, en constante tensión con los gobiernos de los Estadosnación, las organizaciones y ciudadanía locales. En la mayor parte de los casos, las poblaciones migrantes resultan objeto de políticas, procedimientos y asistencia que responden a agendas institucionales diversas emanadas desde alguna "ciudad global" (Sassen, 2006), tal y como lo estudia Sefanie Kron (Kron, 2011) y cuyas características requieren un estudio y análisis profundo que va más allá del alcance de este artículo.

En los seminarios realizados quisimos retomar el tema de la subjetividad en las migraciones $\mathrm{y}$, al abordarlo, fue ineludible hacer un reconocimiento desde la teoría de género y darnos cuenta de que las personas que se acercaron al seminario eran en su mayoría mujeres para quienes hablar de afectos, valores, mitos, estereotipos, entre otros, vinculados a la migración fue más bien fácil. El grupo por sí mismo se preguntó “¿Cómo hacer que se consideren las emociones y los afectos?". 
Dentro del modelo económico en el que está inserto el país, se priorizan los objetivos económicos y para esto, se hace un uso político de los afectos, incentivando el miedo y la paranoia para justificar el control social, y principalmente el control de las fronteras. Por otra parte, el debilitamiento institucional, vinculado a políticas neoliberales, afecta tanto a la población migrante como a la costarricense en ámbitos como la salud, el trabajo y la educación, generando frustración y malestar que son encauzados a través de discursos de miedo hacia expresiones de agresión y a responsabilizar a las personas migrantes como las principales causantes de dicho desgaste institucional.

La parte difícil de las sesiones de trabajo vino cuando quisimos abordar la situación de las personas migrantes como sujetos políticos más allá de su condición de regularidad o irregularidad migratoria. Todavía más difícil resultó para las participantes en el seminario pensarse a sí mismas realizando acciones políticas más contundentes que hacer lobby, ya que sus acciones se enmarcan dentro de las directrices establecidas por sus organizaciones y los objetivos que deben cumplir según los acuerdos de financiamiento, a partir de agendas establecidas a nivel global y concordantes con organismos internacionales tales como el Banco Mundial y la Organización Internacional para las Migraciones (OIM), o religiosos, como la Iglesia Católica.

\section{Perspectivas sobre las migraciones y la identidad nacional}

Durante el seminario se logró hacer una reinterpretación de la migración interna en Costa Rica, viendo que esta también puede generar discriminación y rechazo, especialmente por parte de la población del Valle Central hacia personas de otras regiones del país, dejando al descubierto que no es necesario ser una persona extranjera para sufrir un trato diferenciado. Sin embargo, en la población nacional aparece una especie de negación de las propias experiencias de migración, debido a que se comprende la migración -la mayoría de las veces- como la llegada de personas extranjeras al país. Esto no permite apropiarse de las experiencias propias de migración y emigración cercanas como parte del espectro migratorio. Se desprende de esta reflexión que es necesario reconocer la experiencia propia y recuperarla como parte de una historia colectiva que responde a múltiples factores ya que, directa o indirectamente, todos y todas somos migrantes.

Este tipo de negación de experiencias propias de la migración resalta también la diferencia como un elemento inimaginable dentro de la sociedad costarricense, debido a que se ha manufacturado la "igualdad" y la homogeneidad costarricense como un elemento identitario por el que, además, se debería sentir orgullo.

La solidaridad y las relaciones de poder son factores que se encuentran presentes en la relación entre migrantes y que se discutieron durante las sesio- 
nes del seminario. Una de las participantes señala: "No siempre ser migrante va a sensibilizarme a las otras personas migrantes". Sin duda, el capitalismo es el marco que encierra relaciones de poder en que se naturaliza la explotación, la competitividad e individualismo y las relaciones de poder jerarquizadas por categorías como etnia, género, clase social y generación.

A partir de esta reflexión, las participantes concluyen que es fundamental incorporar el derecho y respeto a la diversidad en la educación, y romper con el nacionalismo metodológico (Wimmer, y Schiller, 2002). Dicho nacionalismo intenta ocultar la pluralidad de la población; además de colocar los valores propios como superiores a los de los demás, propiciando la asimilación, entendida esta como una pérdida de culturas diversas para asumir la cultura hegemónica.

Finalmente, se cubre la problemática de la legislación y la manera en la cual las nuevas leyes tienen una visión de la migración como tema de seguridad nacional, y dirigen sus acciones hacia el cierre de fronteras, obstaculizando que el país sea un receptor intercultural, tal como proclama la misma Ley 8764 de Migración y Extranjería. Este tipo de leyes vulnerabiliza a los y las migrantes, imponiendo altos costos para los trámites que se requieren para regularizar su permanencia en el país, asegurando así la mano de obra barata y situaciones de explotación de estas personas.

El análisis de discursos y acciones con respecto a las personas migrantes fue parte del trabajo realizado en los seminarios, y para esto se contrapuso el discurso del anterior Vice-Canciller de la República, señor Carlos Roverssi, generado en una actividad realizada en San Marcos de Tarrazú. También se analizó "El Tren de las Moscas" (Prieto \& López, 2010), documental que muestra cómo un grupo de mujeres llamadas Las Patronas, por pertenecer a la comunidad de La Patrona en México; reparten raciones de comida y agua a migrantes mientras viajan sobre un tren de carga conocido como "La Bestia", que recorre el territorio Mexicano hasta llegar a la frontera entre México y Estados Unidos.

En el caso del discurso de Carlos Roverssi, las participantes analizan que el canciller difunde un imaginario de Costa Rica como "el paraíso perdido de Adán y Eva" (Roverssi, 2011), por lo que, si se abrieran las fronteras "todos los centroamericanos se vendrían todos para Costa Rica" (Roverssi, 2011). También vincula la migración con la criminalidad y el crimen organizado al hablar de "migraciones raras, venezolanos, colombianos, maleantes, africanos de la parte ecuatoriana, no sabemos a qué vienen, serán de mafias organizadas del mundo, o del narcotráfico" (Roverssi, 2011), apelando así al tema de seguridad nacional. El discurso se dirige a los afectos desde el miedo y la paranoia para reforzar la idea de que es necesario el ingreso selectivo a través de las fronteras, una migración "revisada con lupa" (Roverssi, 2011). Además, asocia la crisis de la Caja Costarricense de Seguro Social (CCSS) al uso que la población migrante hace de esta, ignorando que, según los da- 
tos del Censo del 2011, el aporte financiero a la Caja por parte de los migrantes nicaragüenses tan solo en el 2008 fue de 45.350 millones de colones, mientras que el costo de la atención en salud que recibieron fue de 3 millones de colones menos (Sandoval, citado en Chavarría, 2013). Otro punto que sobresale del análisis de este discurso oficial, es que hace referencia a poblaciones indígenas como individuos ajenos al resto de la población costarricense, como personas en condición de extranjeras.

En el caso del documental sobre Las Patronas, se hace evidente que en estas mujeres existe una práctica mediada por los afectos solidarios y una fuerte sensibilización hacia las personas migrantes como seres humanos con derechos, sin importar su procedencia ni condición migratoria. Las participantes concuerdan que es en las iniciativas comunitarias donde se ven acciones reales de lucha por los derechos fundamentales, y no tanto así por parte de personajes políticos que, en su mayoría, dan chocantes discursos políticos que más bien denotan una enorme falta de compromiso con los Derechos Humanos. Ante esta reflexión Las Patronas señalan que es necesaria la humanización de la política pública; una participante afirma que las personas migrantes: "necesitan comer pero también cambio en la política".

\section{La necesidad de romper el estado de cosas mediante otro tipo de participación}

La discusión anterior llevó a un sentimiento generalizado de impotencia en los grupos participantes, ya que se hacía difícil intentar pensar en estrategias para convencer al sector político de que es necesario generar cambios y, en este caso específico, para garantizar los Derechos Humanos de las personas migrantes. "¿Cómo hacemos?" es la pregunta sin respuesta, pues según afirman: sensibilizar es un trabajo muy duro que primero requiere romper con las discusiones teorizadas y descripciones basadas en textos para conocer y escuchar a la población migrante en sí misma. Esto porque otra de las fallas del quehacer de las organizaciones e instituciones es la falta de representación de las personas migrantes en espacios públicos y políticos donde se toman decisiones que inciden directamente sobre sus vidas. La falta de representación responde a una lógica de desigualdad, la cual no solo se da en la distribución de los bienes, sino que es un contexto institucional que limita la capacidad de participar (Phillips, 1996).

Todas las participantes coinciden con que para lograr una transformación, es necesario romper con nuestras propias prácticas y cuestionar la perspectiva desde la cual abordamos los problemas, especialmente en aquellos y aquellas en quienes predomina una visión "vallecentralista", ignorando las dinámicas de otras regiones. Esto requiere un auto-análisis de nuestro propio discurso, que permita reconocer nuestro lugar de poder desde donde sea que 
cada uno(a) se posicione, una participante plantea: "¿Cómo analizar yo mi lugar de poder?, ¿Cómo analizar yo mi discurso?, ¿Cómo es recibido este?"

Algunas participantes comentan que también es necesario aprender a negociar con el poder y con las figuras que lo ostentan a pesar de que no se compartan los discursos que difunden. Además, hay que tener presente que las transformaciones sociales y los cambios culturales pueden lograrse a través de una lucha constante desde las esferas cotidianas. Uno de los participantes señala que la presencia en movimientos sociales y en lugares de discusión pública es un acto político, por lo que participar en actos que denuncian la injusticia y el abuso es importante y entre las participantes se concuerda la necesidad de "empoderarnos" como sociedad civil para exigir cambios y el respeto a los Derechos Humanos.

Durante el seminario, se consideró prioritaria la oficialización de discursos alternativos y cifras reales en tema migratorio, que puedan reflejar el impacto real que tiene la población migrante en el país, en lugar de basarse en prejuicios para formar la opinión pública. Por ejemplo, la Ley de Migración y Extranjería 8764 responsabiliza a la persona migrante para que se asegure, cuando este es un Derecho Humano que el Estado debe garantizar para todos sus habitantes.

El grupo además comenta su malestar y frustración al sentir que se hace una lucha individual, y que los esfuerzos que se hacen por mejorar las condiciones de las personas migrantes resultan insuficientes ante un contexto más grande que hace caer el trabajo realizado. Así, se habla de que se requieren estrategias para empoderar a la población migrante pero, “¿Cómo nos empoderamos nosotras mismas? ¿Cómo empoderar a las organizaciones para que hagan cambios?"

De lo anterior, se llega a la discusión sobre "lo personal" y "lo privado", entendiendo este último como el lugar donde las tareas de cuidado son fundamentales y están mediadas por los afectos. En esta discusión, las participantes recalcan que lo personal es político, pero enfatizan que "sola no se puede", refiriéndose a que cualquier esfuerzo individual que no se articule colectivamente queda tan aislado como si no hubiera tenido lugar. Es importante que se visibilice el trabajo que se hace desde las organizaciones.

Las participantes señalan como una prioridad para trabajar con población migrante y generar una transformación política, la división de tareas y estrategias, pero también atender las necesidades inmediatas. Se debe encontrar la manera de equilibrar ambos enfoques sin que se pierda el rumbo en el proceso. Ante esta necesidad de equilibrio se preguntan "¿Cómo puede ser una ONG estratégica para no reproducir el asistencialismo?" Algunas participantes acusan a las organizaciones como tales, de "tibieza", lo cual se refleja cuando se hacen foros para solicitar rendición de cuentas. Se señala una gran falta de articulación y trabajo en conjunto, y apuntan a que se debe ins- 
tar a las personas migrantes no solo a solicitar y exigir el respeto a sus derechos, sino también a definir aquello que están pidiendo y el proceso para hacerlo.

Como actividades estratégicas para poner en marcha nuevas prácticas y acciones conjuntas, las participantes resumen que se debe:

- Manejar las redes que se tienen.

- Buscar la incidencia política.

- Automatizar algunos trámites.

- Dar seguimiento del tema migratorio en campañas políticas y medios de comunicación.

\section{Del trabajo asistencial individual a la práctica política}

Al discutir más a fondo la posibilidad e imposibilidad de organización y articulación que existe entre las organizaciones que trabajan con población migrante, la resignación se identifica como un obstáculo que ha tomado fuerza, lo cual genera un sentimiento de que se trabaja de manera aislada y en soledad, resultando en la noción de que "Ante la pérdida de solidaridad, se naturaliza un 'no se puede hacer nada"', actitud que según reflexionan se debe en gran parte al neoliberalismo, como un proceso cultural en el que se fomenta la competencia y el individualismo antes que la solidaridad y por ende resulta aún más difícil tener confianza y organizarse. Además, comentan que este es un asunto estructural de nuestro país y se preguntan "¿por qué no articulamos? ¿Por qué no integramos?".

Otro de los temas fundamentales a abordar es el miedo; señalan las mismas personas participantes, "también hay un tema de miedo y vulnerabilidad", y es a partir de ello que surge la interrogante "¿Cómo combatir el miedo para lograr una mayor acción política?" El grupo propone los siguientes puntos:

1. Solidaridad: hay gente que puede dar la cara y hay gente que no, por ejemplo, migrantes ya regularizados podrían ayudar a quienes aún no se han regularizado, hablar por ellos y canalizar la lucha por sus derechos para así contrarrestar la vulnerabilidad de aquellas personas que temen reclamar sus derechos por falta de documentos, o por temor.

2. Resistencia: a nivel individual se pueden generar transformaciones a través de resistencias en lo cotidiano, se habla de la infrapolítica (Scott, 1985) como estrategia para sostener la dignidad. 
3. "Guerra de guerrillas": acción de salir a un espacio público, manifestar algo, y luego retirarse para protegerse.

4. Medios alternativos de comunicación: buscar espacios para visibilizar la injusticia y contrarrestar los discursos xenófobos y de exclusión que se canalizan en medios de comunicación hegemónicos.

La comunicación es señalada como un factor primordial para la articulación interinstitucional, sin embargo, las participantes consideran que: "falta cobertura y comunicación efectiva entre instituciones". Es urgente la comunicación en medios alternativos, pero también entre las mismas instituciones para saber qué es lo que hacen otras personas y para visibilizar la injusticia y también la valentía. Es a través de iniciativas de comunicación y de unión de esfuerzos que las organizaciones han obligado a la Dirección General de Migración y Extranjería (DGME) a prestar atención a temas de Derechos, según dicen ellas. Sin embargo, la desconfianza persiste cuando se trata de esta institución, pues las participantes cuestionan las intenciones de la DGME cuando comunica en medios de comunicación oficiales casos de explotación laboral y se plantean: “¿Cuál es el mensaje? ¿Qué hay detrás?".

Finalmente, surge una interrogante que consideramos clave en la articulación de nuevas propuestas y acciones políticas, pues al conocer el caso de movilizaciones masivas de migrantes en EEUU y en Europa (Sans Papiers) (BBC News, 2002), las participantes concuerdan con que ese empoderamiento de la población migrante es absolutamente necesario, pero al mismo tiempo se considera: "¿Por qué no ha surgido un movimiento así en Costa Rica?" Un punto importante discutido durante el seminario, es que para muchas participantes hay una baja en la autoestima de las personas migrantes, producto de los constantes atropellos a sus derechos y las muestras abiertas de discriminación por parte de la población en general y las instituciones públicas.

Para Sassen (2006), las poblaciones inmigrantes en las "ciudades globales" y también en ciudades de menor escala se convierten en actores políticos informales, al igual que las multinacionales. Según esta autora, se puede pensar las ciudades como el espacio donde se materializan las contradicciones de la globalización del capital y donde se da la reinvención de ciertos componentes de la política, y esto permite prácticas ciudadanas informales que se van constituyendo nuevas formalizaciones de pertenencia política, como es el caso de las prácticas de las personas inmigrantes, en particular, mujeres amas de casa y madres (Sassen, 2006).

Uno de los planteamientos en el seminario implica una vuelta al feminismo o al menos su capacidad de articulación más allá de la diversidad de clase, de nacionalidad, de etnicidad, entre otras, como una posibilidad para unir fuerzas desde los puntos en común. Además, se habla de la necesidad de apren- 
der a trabajar con identidades flexibles y cambiantes, y no caer en la trampa de pensar que las personas y los grupos son estáticos, y que por ende todas tienen las mismas necesidades. La vuelta al feminismo en tanto teoría política y praxis que promueve la igualdad resulta interesante a la luz de la observación de Sassen sobre el papel de las mujeres como sujetas políticas en tanto al tener que facilitar el acceso a los servicios públicos para sus familias deben interpelar a múltiples instituciones y así se convierten en activistas, lo cual contradice la idea de que las mujeres madres y amas de casa que se mueven en ámbitos privados no participan en la vida política (Sassen, 2006).

\section{Perspectivas de acción en red y sus limitantes}

Al solicitar a las participantes que representaran gráficamente la relación existente entre múltiples organizaciones que trabajan con población migrante en el país, pudimos también comprender algunas otras dificultades que tienen para ir un poco más allá del trabajo de lobby que realizan. Uno de los subgrupos representó a una nebulosa, en donde verdaderamente no entienden las relaciones entre las organizaciones. No obstante, tienen claro que existe tensión entre muchas de estas aunque señalan que también existen espacios de diálogo permanente. Tal es el caso de la Red Nacional de Organizaciones Civiles para las Migraciones (REDNAM) y el Foro de Mujeres Migrantes. También se resalta el peso del Ministerio de Seguridad, el ente que le dicta a la Dirección General de Migración y Extranjería (DGME) a quién dar permisos y cuáles resoluciones de refugio aceptar y cuáles no; y una vez más se palpa la falta de representatividad de las personas migrantes cuando las organizaciones de la población nicaragüense aparecen separadas en la representación de la red institucional.

Uno de los subgrupos, por su parte, organiza a los diversos actores según su acción y se puede observar claramente cómo la DGME impacta lo que hacen todas las organizaciones. También se observa a la Organización Internacional de las Migraciones (OIM) como una organización fantasma (Kron, 2011), y se discute que el Foro Permanente es un espacio diplomático donde todos participan. Sin embargo, luego en las Redes se cuestiona y critica al Foro.

Puntualizan a la organización ideal como aquella en la que se pudiera mejorar el diálogo y cuyo objetivo primordial sea el bienestar de la población beneficiaria. Consideran que algunas veces las ONG compiten por la visualización del impacto del trabajo que realizan, lo cual según las participantes hace que las discusiones se dirijan siempre a los mismos puntos sin darles solución. 


\section{Propuesta para un nuevo orden de cosas}

Según lo desarrollado en los seminarios, podemos identificar que las relaciones capitalistas de competencia y la división del trabajo en las organizaciones claramente establecen dificultades para que se cambie la situación de opresión que aqueja a la población migrante. Primeramente, encontramos que el trabajo asistencial no favorece la constitución de sujetos políticos, en tanto se limita a satisfacer necesidades inmediatas. Estas se enmarcan dentro de las tareas asignadas a organismos no gubernamentales o religiosos en el marco de mandatos de organismos financieros internacionales o de iglesias de diferentes denominaciones y las y los funcionarios deben de dar cuenta de que se cumplan estos mandatos.

En el contexto de la crisis mundial, la competencia entre las organizaciones y, por tanto, la competencia por demostrar resultados de la asignación de dichos recursos, desaparecen las personas migrantes en su capacidad de transformar la situación en la que se encuentran como sujeto colectivo, pues se individualizan sus necesidades y no se favorece su participación.

En este sentido, las luchas por la regularización y el lobby que se hace desde las organizaciones para lograr cambios en las leyes son importantes. Sin embargo, estas se priorizan y se colocan como el requisito primero para la construcción de sujetos políticos entre la población migrante. Esto es problemático pues, siguiendo a García Linera en su prólogo al libro de Isabel Rauber (2012):

El Estado es una herramienta que puede ayudar, pero que la vitalidad del postcapitalismo radica en la propia sociedad, radica en la capacidad de articulación de la propia sociedad (...) La vitalidad viene desde las propias organizaciones sociales, que pueden ocupar el Estado, transformarlo y construirlo, pero no resumen ni concluyen toda su fuerza en el Estado (p. 11).

Si bien no nos encontramos en el postcapitalismo en Centroamérica, coincidimos en que, para llegar a un momento que se le parezca, es necesario fortalecer las organizaciones sociales. La falta de participación directa de personas migrantes tiene sentido en tanto que la carencia de documentación profundiza la exclusión y el miedo a la deportación se constituye en un factor desmovilizador. De ahí que pensar en protestas masivas de migrantes al estilo de los Sans Papiers en Francia (EFE, 24 de abril de 2008), o de las marchas de migrantes de los últimos siete años en Estados Unidos (Univisión, 2013) se aleja de la situación de esta población en Costa Rica. Sin embargo, podemos aprender de otras experiencias. Por ejemplo, en el caso de inmigrantes latinoamericanos en Inglaterra analizado por Peró (2011), encontra- 
mos que la mejor manera de conseguir derechos laborales no es seguir el prevaleciente modelo de organización multicultural impulsado por la sociedad que recibe y formando organizaciones comunales étnicas con estatus apolítico/caritativo, sino mediante la organización de formas más politizadas y confrontativas alrededor de asuntos materiales y mediante organizaciones de clase.

Además, nos encontramos con una dificultad para visibilizar y acompañar el trabajo de lobby que realizan diferentes organizaciones que luchan por el bien de la población migrante, pues este depende en mucho de la anuencia de los medios de comunicación hegemónicos para publicar sus puntos de vista. Al mismo tiempo, estos medios de comunicación continúan difundiendo imágenes denigrantes y criminalizantes de personas migrantes, o como lo llama Edgerton (2008) "distorsiones socioculturales", al referirse a "creencias que promueven las instituciones sociales para mantener la estructura del poder y las relaciones sociales" (p. 8). (Hernández, 2013; Chinchilla, 2013 y Amenábar, 2013). Esto hace muy difícil que se reconozca la participación de las personas migrantes en la lucha por sus derechos, siendo precisamente esa, una de las formas de discriminación con la cual se ejerce poder sobre aquella, excluyéndole del acceso a servicios públicos, espacios, igualdad de trato, entre otros. "Se puede afirmar que la discriminación es un proceso sistemático y sostenido de repudio de los otros por ser distintos, negándoles un lugar como interlocutores de la historia y como sujetos de derechos" (Araya y Villena, 2008, p. 20).

En el transcurso de los seminarios impartidos, hemos ido visualizando la necesidad de transformar los mecanismos que legitiman y reproducen la exclusión, que además sostiene de alguna forma la indocumentación que, a su vez, resulta en la negación de los derechos civiles, laborales y humanos de la población migrante. Para ello, es necesario también atacar aquellas prácticas violatorias de estos derechos y también los discursos prejuiciosos que legitiman la discriminación. Sin embargo, estas tareas deben implicar la participación de la población migrante como ente activo en la defensa de sus derechos sin que esto implique generar una mayor vulnerabilidad. Partimos de que la impotencia genera indefensión y que la violación sistemática de derechos humanos afecta profundamente a las personas (Smith, 2009) y a la sociedad misma.

Para Rauber (2012), la horizontalidad necesariamente requiere de aceptar la diversidad y se debe partir de esta para la articulación de otras realidades posibles:

Implica aprender a articular la pluralidad sobre bases de equidad y complementariedad. Es una propuesta raizalmente intercultural, que supone aceptar el incorporar las diferencias en aras de construir una 
totalidad sociocultural compleja que en vez de anular la diversidad la presuponga y exprese. Lejos de buscar el aplanamiento de la sociedad y la unicidad del pensamiento, esta nueva lógica horizontal (supone y) se encamina hacia la coexistencia y el derecho de todos y todas a existir, pensar y actuar (vivir) acorde con sus identidades y cosmovisiones, es decir, de un modo propio, diferente (p. 11).

Un mundo horizontal no puede desarrollarse si una parte importante de la población se encuentra excluida. Así, nuestro siguiente paso es un trabajo de intervención que se oriente desde una perspectiva de infrapolítica (Scott, 1985) para generar campañas de transformación de legislación, procedimientos y normativas que son discriminatorias de la población migrante, que denuncien el irrespeto a los derechos humanos, civiles y laborales de las personas, y que ataquen los prejuicios, mitos y estereotipos que legitiman la exclusión.

Scott (1985), al analizar las prácticas de resistencia de campesinos cuya vulnerabilidad impide una organización colectiva y evidente en contra de quienes detentan el poder, hace una crítica al concepto de ideología y falsa conciencia. Para él, las personas saben que están siendo manipuladas y explotadas, pero se defienden haciendo aparecer en discursos o textos públicos que están de acuerdo con su propia dominación. Por otro lado, mediante discursos o textos privados, estas mismas personas muestran el rechazo a quien ejerce el poder sobre ellos y ellas, no solo mediante el lenguaje, sino en prácticas que van desde el arrastrar los pies, disimulo, falsa aceptación, sabotaje, y demás. (Scott, 1985). Si bien estas prácticas resultan espontáneas y no implican organización colectiva, el hecho de que sean textos compartidos solamente con quienes mantienen una situación similar de subalternidad puede ir multiplicándolas y constituyendo un marco de entendimiento y acción que, eventualmente, produzca un movimiento significativo para producir cambios.

Así, nos planteamos la existencia de tres ámbitos de acción: las instituciones, la población civil costarricense y la población migrante. En estos, apuntamos a la generación de discursos contrahegemónicos que cuestionen la discriminación y la xenofobia existentes en el país, apuntando a nuevas relaciones sociales en el marco de la solidaridad, la cooperación y la aceptación de la diferencia y el respeto a la dignidad de todas las personas mediante campañas que surjan de la misma población migrante, de organizaciones que trabajan con ellos y ellas, de la población civil a través de redes sociales, ocupación de espacios públicos e institucionales. La idea es construir nuevos sentidos comunes para impactar a los medios de comunicación tradicionales y, a través de ellos, a las personas que toman decisiones políticas partiendo de 
las experiencias de la población migrante con la xenofobia y la discriminación que, a su vez, presionen por cambios en políticas públicas y legislación que facilite la inclusión social. Con esto, podríamos pensar como Sassen (2006) que se puede producir una reinvención de la ciudadanía como práctica y como proyecto.

\section{Conclusiones}

A lo largo de este trabajo hemos ido presentando el proceso de reflexión desarrollado en el Seminario Migración y redes de apoyo: Entre la subjetividad y la acción colectiva, impartido en el Instituto de Investigaciones Sociales de la Universidad de Costa Rica durante el año 2013 a dos grupos de personas, en su mayoría mujeres funcionarias de organizaciones que trabajan con población migrante y estudiantes.

En el proceso de reflexión colectivo surgieron discusiones acerca de cómo se enmarcan las migraciones en Costa Rica dentro de un contexto aversivo contra el cual es necesario establecer estrategias colectivas. Sin embargo, existen muchos impedimentos para hacerlo, así como para lograr la participación de las personas migrantes como sujetos políticos independientemente de su situación migratoria.

Entre las dificultades es necesario considerar la construcción identitaria costarricense, los intereses políticos del gobierno y la no incorporación de la migración como parte de la historia de las y los costarricenses, aspectos que facilitan los discursos xenofóbicos y la legitimación de la discriminación. Luchar contra esto para generar transformaciones implica analizar también la forma en que las organizaciones no gubernamentales enfrentan el tema de las migraciones en un contexto en el que el trabajo colectivo se dificulta debido a la competencia y los diferentes enfoques existentes al abordar la tarea que les compete.

Finalmente, responder a las necesidades inmediatas de la población es necesario, pero la labor no puede limitarse a eso pues, de lo contrario, los sujetos que reciben la ayuda siguen perpetuándose como víctimas y no como sujetos políticos capaces de generar transformaciones. Es desde ellos y ellas que deben partir los discursos contrahegemónicos para para luchar en contra de la xenofobia y la discriminación. 


\section{Bibliografía}

Amenábar, A. V. (24 de setiembre de 2013). Nicas invaden mares ticos por petróleo. Recuperado el 18 de Enero de 2014, de Diario Extra: http://www.diarioextra.com/Dnew/noticiaDetalle/121377

Araya Jiménez, M., \& Villena Fiengo, S. (2008). Hacia una pedagogía del encuentro cultural: discriminación y racismo (1 ed.). San José, Costa Rica: Editorial Universidad de Costa Rica.

Arendt, H. (2005). La condición humana. Barcelona: Paidós.

Azofeifa Ramos, S., Caamaño Morúa, C., \& Matteucci Wo-Ching, A. (setiembre de 2012). Migraciones, género y subjetividad: El trabajo con población migrante en Costa Rica. Ponencia presentada en VII Jornadas de Investigación del Instituto de Investigaciones Sociales. San José, Costa Rica.

BBC News. (20 de Agosto de 2002). Immigrants stage sit-in in Paris church. Recuperado el 10 de Noviembre de 2013, de BBC News World Edition: http://news.bbc.co.uk/2/hi/europe/2205064.stm

Carcedo, A., Chaves, M. J., \& Lexartza, L. (2011). El papel de las migrantes nicaragüenses en la provisión de cuidados en Costa Rica. Santo Domingo: ONU Mujeres.

Chavarría Hernández, D. (15 de Mayo de 2013). Migrantes sin papeles enfrentan trabas para acceder a salud y educación técnica. Recuperado el 28 de Mayo de 2014, de Semanario Universidad: http://www.semanariouniversidad.ucr.cr/component/content/article/2117 -Pa\%C3\%ADs/9943-migrantes-sin-papeles-enfrentan-trabas-paraacceder-a-salud-y-educacion-tecnica-.html

Chinchilla Salazar, D. (19 de junio de 2013). Lo acuestan de 5 tiros en la cara. Recuperado el 20 de Marzo de 2014, de Diario Extra: http://www.diarioextra.com/Dnew/noticiaDetalle/73133

Edgerton, L. (2008). La noticia como recurso didáctico: una propuesta educativa (1 ed.). San José, Costa Rica: Editorial Universidad de Costa Rica.

EFE. (24 de abril de 2008). Francia rechaza una regularización masiva en respuesta a la huelga de 'sin papeles'. Recuperado el 10 de Noviembre de 2013, de elmundo.es: http://www.elmundo.es/elmundo/2008/04/24/internacional/1209025159. html 
Hardy-Fanta, C. (1993). Latina Politics, Latino Politics: Gender, Culture, and Political Participation in Boston. Philadelphia: Temple University Press.

Hernández, C. (14 de Agosto de 2013). OIJ allana vivienda de colombiano en Ciudad Quesada por supuesta estafa con propiedades. Recuperado el 18 de Enero de 2014, de La Nacion: http://www.nacion.com/sucesos/OIJ-colombiano-Quesada-supuestapropiedades_0_1359864099.html

Kron, S. (2011). Gestión migratoria en Norte y Centroamérica: Manifestaciones y contestaciones. Anuario de Estudios Centroamericanos (37), 53-85.

Peró, D. (2011). Migrants' practices of citizenship and policy change. En C. Shore, S. Wright, \& D. Peró (Edits.), Policy worlds: Anthropology and the analysis of contemporary power (págs. 244-263). Nueva York: Berghahm Books.

Phillips, A. (1999). ¿Deben las feministas abandonar la democracia liberal? En C. Castells (Ed.), Perspectivas feministas en teoría política (págs. 81-97). Buenos Aires, Argentina: Paidós.

Prieto Tassier, N., \& López Castillo, F. (Dirección). (2010). El tren de las moscas [Película]. Veracruz, México.

Rauber, I. (2010). Revoluciones desde abajo. Gobiernos populares y cambio social en latinoamerica (4 ed.). Buenos Aires: Peña Lillo/ Ediciones Continente.

Rodríguez, I. (Junio de 2002). El efecto de las TIC en la organización de la acción colectiva: la virtualización de los movimientos sociales. Recuperado el 25 de Mayo de 2014, de Universitat Oberta de Catalunya:

http://www.uoc.edu/web/esp/art/uoc/irodriguez0602/irodriguez0602.html

Sassen, S. (2006). Territory, Authority, Rights. From Medieval to Global Assemblages. Kindle edition.

Scott, J. C. (1985). Weapons of the weak, everyday forms of peasant resistance. New Haven: Yale University Press.

Smith Castro, V. (2009). Experiencias de discriminación social de inmigrantes nicaragüenses en Costa Rica: reacciones afectivas y atribuciones causales. Interamerican Journal of Psychology, 44(2), 368-381.

Univision. (21 de setiembre de 2013). Marcha por la reforma migratoria en Los Angeles. Recuperado el 20 de Marzo de 2014, de Univision.com: 
http://noticias.univision.com/article/1680408/2013-09-

21/inmigracion/reforma-migratoria/marcha-por-la-reforma-migratoria-enlos-angeles\#ixzz2frJGBcPH

Vargas Bejarano, J. (Diciembre de 2009). El concepto de acción política en el pensamiento de Hanna Arendt. Eidos: Revista de Filosofía de la Universidad del Norte (11), 82-107.

Vargas, J. G. (Octubre-Diciembre de 2003). Teoría de la acción colectiva, sociedad civil y los nuevos movimientos sociales en las nuevas formas de gobernabilidad en Latinoamerica. Espacio Abierto, 12(4), 523-537.

Wimmer, A., \& Schiller, N. G. (2002). Methodological Nationalism and Beyond: Nation-State building, migration and the social sciences. Global Networks: A Journal of Transnational Affairs, 2(4), 301-334. 
Revista Rupturas, Volúmen 5 Número 2 Centro de Investigación en Cultura y Desarrollo (CICDE)

Universidad Estatal a Distancia (UNED)

San José, Costa Rica

Julio-Diciembre 2015 


\section{Reformas curriculares 2006- 2014: del ajuste pedagógico neoliberal a la reinstauración del modelo socialdemócrata}

RESUMEN

El presente artículo analiza las reformas curriculares implementadas en Costa Rica en el período comprendido entre los años 2006 y 2014, bajo la premisa de que estas responden a una reinstauración del Modelo Pedagógico Socialdemócrata vigente en el país entre 1957-1985. Para el desarrollo de dicho estudio se construye una definición desde un currículo crítico que enmarca el proceso de creación de una nueva interpretación de los períodos que integran la historia educativa posindependencia para examinar las características del Modelo Pedagógico Socialdemócrata y el Ajuste Pedagógico Neoliberal. Finalmente se indaga en las reformas implementadas en el período en estudio para debatir las implicaciones de la premisa desarrollada en el artículo para los sectores progresistas del sistema educativo.

Palabras Clave

Currículo; socialdemocracia; neoliberalismo; progresismo
Curricular Reforms 2006-2014: From the Neoliberal Pedagogical Adjustement to the Restoration of the Social Democrat Educational Model

ABSTRACT

The present essay makes an analysis of the curricular reforms implemented in Costa Rica in the period between 2006 and 2014, under the premise that these answer to the establishment of the Social Democrat Educational Model, which was active in the country between 1957 and 1985. To perform this analysis, a definition is built from the critical curriculum that frames the creation process of a new interpretation of the periods that integrate the educational history post-independence so that, afterwards, there is an analysis of the Social Democrat Educational Model features and the Neoliberal Pedagogical Adjustment, to finally enquire on the implemented reforms in the period under study and discuss the implications of the premise developed in the essay for the progressive sectors of the educational system.

KEY WORDS

Currículo; Social Democracy; Neoliberalism; Progressivism
Artículo recibido: 30 de enero del 2015. Evaluado:

2 de marzo del 2015.

Aceptado:

15 de marzo del 2015

Máster en Planificación Curricular, en la Universidad de Costa Rica. Asesor Nacional en Currículum, Consejo Nacional de Enseñanza Superior Universitaria Privada del Ministerio de Educación Pública de Costa Rica. Coordinador Proyecto Sortilegios Educativos. Correo electrónico: cesartoruno@gmail.com

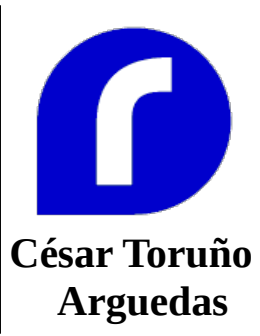




\section{Reformas curriculares 2006-2014: del ajuste pedagógico neoliberal a la reinstauración del modelo pedagógico socialdemócrata}

\section{Introducción}

El 19 de febrero del año 2014, a menos de dos semanas de finalizadas las elecciones nacionales cuyo resultado deparó una segunda ronda entre el candidato del Partido Liberación Nacional (partido en el poder desde el 2006) y el candidato del Partido Acción Ciudadana (partido de oposición), el periódico La Nación (periódico emblema del principal grupo de medios de comunicación del país e históricamente ligado con un proyecto hegemónico conservador y capitalista), publicó un editorial denominado "Ocho años de avance educativo" (La Nación, 2014) en el cual no solo reconocen los esfuerzos de la administración Garnier Rímolo y las mejoras en el sistema educativo, sino que indican que estos esfuerzos "alumbran el camino por seguir".

El editorial permite, al menos, dos interpretaciones desde una posición crítica al proyecto hegemónico implementado en Costa Rica. La primera establece que este editorial es una legitimación del grupo económico-político ligado al proyecto hegemónico neoliberal, en el tanto las reformas educativas comprendidas entre el 2006 y el 2014 forman parte del Ajuste Pedagógico Neoliberal; esta interpretación (del sistema educativo sometido al proyecto hegemónico neoliberal) ha sido ampliamente aceptada y repetida por diversos sectores con posiciones contrarias o críticas a dicho modelo económico. 
Sin embargo, existe una segunda interpretación en la que el editorial representa un punto de inflexión en la política educativa costarricense posterior a la década de 1980; en tanto, simbólicamente, los grupos hegemónicos explicitan el respaldo a una propuesta educativa socialdemócrata que difiere, en aspectos medulares, del Ajuste Pedagógico Neoliberal impulsado desde la década de 1980, y la cual es una actualización del modelo educativo socialdemócrata vigente en Costa Rica desde 1957 hasta 1985.

El presente ensayo asume la segunda premisa, para lo cual se realizará una construcción conceptual del currículo desde una pedagogía crítica, que sirve como marco de interpretación a una nueva propuesta de división de la historia educativa elaborada a partir de la construcción del currículo como área técnica de la pedagogía y herramienta de estructuración, control y seguimiento de la estructura educativa. Posteriormente, se profundizará en lo que el presente artículo denomina Modelo Pedagógico Socialdemócrata (incluyendo un apartado del Ajuste Pedagógico Neoliberal) como referente histórico y educativo para el análisis de las reformas implementadas durante las administraciones de Leonardo Garnier Rímolo (2006-2010 y 2010-2014) para establecer las implicaciones que tendría esta premisa (las reformas curriculares 2006-2014 como una reinstauración del Modelo Pedagógico Socialdemócrata) para el sector educativo progresista.

\section{El currículo y la pedagogía crítica: un producto contextual para la interpretación crítica}

El currículo es un producto cultural (Apple, 1997), un espacio de investigación y de redes de poder (Kemmis, 1998) donde hay visiones, ideologías intereses ocultos (Torres, 1998). Es una organización del conocimiento oficial (Apple, 1996a; 1996b) y una estructuración de un modelo cultural mediante el sistema educativo (Gimeno, 2001), escenario entre las resistencia y el proyecto hegemónico (Gimeno, 1998; Torres, 2001) y estructurado, durante gran parte del siglo XX, a los intereses de los poderes económicos capitalistas (Gimeno, 1997) y contra las clases populares (Freire, 1984); por tanto, se trata de una forma de estructurar, sistematizar, controlar, ordenar y evaluar el sistema educativo a partir de condicionantes históricas, sociales, culturales, políticas y económicas.

Al mismo tiempo, el análisis curricular entraña una compleja acción dialéctica de interacciones entre sociedad, cultura y educación. Se entiende esta última como un escenario eminentemente político (Freire, 1990) con posibilidades de resistencia (McLaren, 1995), un lenguaje de esperanza (Giroux, McLaren; 1998) y organización comunal (Freire, 1997) donde es posible la visibilización de las redes de poder y el papel asignado al sistema educativo en diferentes proyectos hegemónicos tanto explícitos como parte del Currículo Oculto (Torres, 1998). Es relevante en particular el estudio de este último en la era de la 
globalización y el neoliberalismo (Torres, 2001), economías de libre mercado, transnacionales y transformación de las políticas de Estado (Apple, 1996a, 1997).

Por tanto, el análisis del currículo costarricense y sus posibilidades de mejora debe asumir el reto de develar esos contextos, redes de poder y los fines asignados para generar una comprensión real de la estructura educativa. Esto a partir de la pedagogía crítica en tanto, en "la teoría tradicional del currículo, no se tiene conciencia de los tipos de conflicto que se dan en las escuelas en relación a diferentes formas de conocimiento" (Giroux y McLaren, 1998, p. 80).

Como bien afirma Giroux (2006, p. 205), "Ias escuelas no son ideológicamente inocentes, y tampoco son simplemente reproductoras de las relaciones e intereses sociales dominantes", por lo cual resulta necesario realizar los análisis para develar el papel del Estado, los grupos de presión y la estructura política en la estructuración del sistema educativo para establecer la interacción en la construcción de condiciones para la producción y adquisición del aprendizaje (Giroux, 1997).

Por lo tanto, a partir de la pedagogía crítica, se concibe que el currículo como un producto cultural no neutral, objetivo o técnico aislado de los procesos socioeconómicos; por el contrario, es la manifestación explícita de un proyecto cultural, social, político y económico que se estructura contextual e históricamente determinado dentro de la interacción dialéctica Sociedad-Sistema Educativo que, a su vez, genera marcos conceptuales y reguladores para la conformación tangible e intangible del sistema escolar y que, por lo tanto, se configura como un escenario de resistencias al proyecto hegemónico vigente.

En el marco de la anterior conceptualización, el presente ensayo abordará un análisis del currículo costarricense en interrelación con el contexto socio histórico, económico y cultural, estableciendo una nueva división de la historia educativa que permitirá analizar el Modelo Pedagógico Socialdemócrata, sus características y su influencia en el sistema educativo en la actualidad como primer paso para la denuncia y construcción de un modelo pedagógico ligado con el progresismo educativo.

Resulta necesario acotar que, para efectos del presente ensayo, el progresismo educativo se comprende como aquel grupo de personas ligadas al sistema educativo cuyas tesis de acción-reflexión son antimperialistas y están contra el proyecto político-económico neoliberal denunciando y resistiendo los poderes fácticos. Este grupo promueve modelos vivenciales-participativos de democracia. Además sus tesis cuentan con propuestas para la eliminación de la desigualdad social y marcos culturales e institucionales para la igualdad, la inclusión y la solidaridad. Asimismo, son ellos constructores de un currículo democrático así como de una redistribución del poder educativo que apunta a la construcción de medidas para asegurar al estudiante como cons- 
tructor activo del proceso de aprendizaje (coherente con una propuesta de mediación dentro del constructivismo y socioconstructivismo). A la vez dichas tesis de acción-reflexión defienden a los(as) docentes como intelectuales transformadores en un sistema educativo pensado desde y para la integralidad; todo esto dentro de los marcos de la pedagogía crítica.

\section{Nueva interpretación de la historia educativa: una división por modelos curriculares}

La comprensión del sistema educativo costarricense se ha realizado desde una división histórica-contextual ligada a una fragmentación histórica; en estos casos resulta referente el estudio realizado por Dengo (2011) y el realizado por Molina (2007), este último establece tres períodos de la Educación Costarricense, a saber: municipal-eclesiástico (1821-1885), el centralizadosecular (1886-1939) y el universitario-pedagógico (1940 en adelante). No obstante, la posición curricular esbozada en líneas previas exige la lectura de la división de la historia de la educación en relación con su funcionalidad dentro de un proyecto económico-político dominante.

Por lo tanto, el presente estudio dividirá la historia del sistema educativo costarricense a partir del desarrollo y consolidación de un modelo curricular, correlacionado al contexto socioeconómico y cultural de la sociedad. A partir de esta visión, la historia educativa se divide en tres grandes etapas: a) Originaria (1821-1885), b) Técnico-Liberal (1886-1956) y c) Modelo Socialdemócrata (1957-actualidad), este último con un período de Ajuste Pedagógico Neoliberal (1986-2005).

Las características de la educación costarricense entre 1814 y 1914 han sido estudiadas por Camacho (2005). Para el caso del presente artículo, podemos caracterizar la primera etapa, posindependencia, a partir de una ubicación temporal desde 1821 hasta 1885, con un sistema educativo a las órdenes de una economía agraria, aliada y controlada por el conservadurismo religioso (destacando el Concordato de 1852 el cual le confiere una alta cuota de poder a la iglesia Católica sobre el sistema educativo costarricense). Había en ese momento una organización centralizada, dedicada a la enseñanza de destrezas y conocimientos básicos (matemáticas y español para la interacción social y económica de la época) así como de valores patriarcales-religiosos y operacionalizada en la educación primaria, principalmente entre primer y tercer grado de la escuela.

La segunda etapa, Técnico-Liberal, se extiende desde 1886 (aprobación de la reforma educativa liberal) hasta 1956 (año previo a la aprobación de la Ley Fundamental de Educación). Se caracteriza por la vinculación del sistema educativo al proyecto liberal y su objetivo de formación de ciudadanos productivos con cultura universal, defensores y participantes activos del sistema 
democrático. Esta etapa contó con la ampliación de la matrícula en primaria (tanto niños como niñas) y la feminización del cuerpo docente de primaria (Molina y Palmer, 2000).

El currículo y la educación, en general, adquieren por primera vez un papel protagónico y estructurado en un proyecto hegemónico ligado a la consolidación del Estado nacional costarricense y el proyecto Liberal, por lo que el currículo evoluciona a la inclusión de nuevas asignaturas (como Cívica) y contenidos de la "cultura universal", la laicidad como principio organizador de la administración y de la selección de contenidos, ampliación de la oferta y la cobertura de la educación secundaria y, por último, a una profesionalización en la formación docente, siendo referente la creación de la Escuela Normal.

La tercera etapa del sistema educativo, Modelo Pedagógico Socialdemócrata, se extiende desde 1957 (aprobación de la Ley Fundamental de Educación) hasta nuestros días, con un Ajuste Pedagógico Neoliberal entre 1986 y el 2005. Durante la primera etapa de este período, 1957- 1985, el sistema educativo estuvo vinculado al Estado Desarrollista impulsado por el Partido Liberación Nacional constituyéndose en un gran movilizador social sustentado en la concepción de una educación para la formación de ciudadanos comprometidos con su patria, comunidad y productividad, solidarios y productoconstructores de una herencia cultural (fines de la educación establecidos en la Ley Fundamental de Educación). Se muestra en esta etapa un crecimiento en la cobertura de la educación secundaria y universitaria, esta última con la expansión de la cobertura de la Universidad de Costa Rica (creada en 1940) y creación de la Universidad Nacional (1973), el Instituto Tecnológico de Costa Rica (1971) y la Universidad Estatal a Distancia (1977).

Con respecto a esta propuesta curricular, se crearon o reforzaron las asignaturas de las ciencias sociales (Estudios Sociales y Filosofía), las artes (Música y Artes Plásticas) y la vida cotidiana (Educación Física, Hogar y Artes Industriales), se priorizó la ampliación de la oferta en secundaria con la inclusión de la educación técnica. Por otra parte, la profesionalización docente se da desde las universidades públicas (mejorando el dominio de contenido y técnicas para la mediación del aprendizaje) y se inicia una restructuración de la organización administrativa para responder a un nuevo currículo sustentado en los principios de Tyler (1973).

El Modelo Pedagógico Socialdemócrata sufrió las consecuencias de la crisis de 1978-1982 y el debilitamiento del Estado Interventor-Empresario, lo cual se tradujo en el surgimiento de una subetapa del sistema educativo, el Ajuste Pedagógico Neoliberal. Se puede considerar subetapa en tanto no logra consolidarse como un modelo educativo pero ejerce cambios en elementos fundamentales del Modelo Educativo Socialdemócrata. A continuación, se abordarán las principales características del Modelo Educativo Socialdemócrata desarrollado pos Guerra Civil y hasta el primer quinquenio de la década de 
los ochenta, esto como referente histórico de la reinstauración del modelo después del año 2006.

\section{Modelo Pedagógico Socialdemócrata}

La década de 1940 estuvo marcada por las reformas legales, administrativas y sociales ligadas a las Garantías Sociales y la lucha de la oligarquía contra dichas garantías, sumada a la organización de grupos insatisfechos con el transcurrir del país en una economía agroexportadora y liberal. Entre estos grupos destacó el Centro para el Estudio de los Problemas Nacionales. En el caso de dicho Centro, como afirma Miranda (2010), desde la década de 1940 propulsó una reforma educativa en primaria para adaptar los currículos a las zonas urbanas y rurales, mientras que en secundaria se optaba por una formación humanista complementada con orientación científica e incorporación de la educación vocacional.

Al finalizar la década, y como producto de la reconfiguración de fuerzas posGuerra Civil, el grupo hegemónico agroexportador-liberal fue sustituido por un grupo emergente representado por el Centro para el Estudio de los Problemas Nacionales (grupo Intelectual), el Ejército de Liberación Nacional (brazo armado) y, finalmente, por el Partido Liberación Nacional (brazo político que unificaría a los anteriores, a los grupos de la sociedad civil y a los pequeños partidos centristas). Como establece Rovira (2000, p.63), el Partido Liberación Nacional toma el poder en "una sociedad típicamente agro-exportadora que enviaba al exterior café, bananos y un poco de cacao y tenía que importar gran parte de todo lo que consumía". Frente a esa realidad, el Partido Liberación Nacional y grupos aliados, implementan el modelo desarrollista de intervención estatal (vigente entre 1949 e inicios de la crisis económica de la década de 1980), sustentado en la ideología socialdemócrata.

Rovira (2000) caracteriza al proyecto socialdemócrata a partir de sus esfuerzos para la diversificación de la producción; la participación de otros sectores en la producción; la relación del cooperativismo y pequeña propiedad; el Estado como organizador del sistema económico e impulso de la industrialización; la modernización del aparato estatal capitalista (creación de instituciones); la consolidación de una economía mixta; la consolidación de la clase media y de la nueva burguesía. En relación con este último apartado, Rovira (2000, p. 69) indica que un punto esencial de este modelo es "su política económica estructurada globalmente para diversificar la producción, fortalecer otros sectores y ramas de la economía e ir creando así nuevos grupos burgueses. Alrededor de esto es que gira todo lo demás".

Con respecto al sistema educativo, el estudio de García (2011) establece que al iniciar la década de 1950, Costa Rica tenía 975 centros de formación primaria (con una media de estudios en zonas rurales de 2,2 grados y en las 
ciudades de 4,3 grados), $2 \%$ de la población económicamente activa era docente, el alfabetismo promedio alcanzó el promedio de $78,76 \%$ de la población (en las ciudades era de 91,88\%), además existían 13 centros educativos de secundaria y $12 \%$ de la población había terminado estudios secundarios.

Además, el estudio de García (2011) aporta evidencia de que antes de 1950 se había dado la creación de colegios privados con un claro elemento segregador entre los hijos de la burguesía, clases medias y clases populares, así como el surgimiento, desde la década de 1930, de centros para la formación de oficios y profesiones como la Escuela de Comercio Castro Carazo, el Colegio Superior de Inglés y Ciencias Comerciales Manuel Aragón y la Escuela de Comercio de Limón. Estos dos elementos son aceptados en el Modelo Pedagógico Socialdemócrata (MPS), permitiendo la permanencia y leve expansión de los centros educativos privados e institucionalizando la formación para el trabajo mediante la creación del Instituto Nacional de Aprendizaje (INA) y la ampliación de la educación técnica, esto último en el marco de la inserción costarricense en el Mercado Común Centroamericano.

De esta manera, el MPS se le debe comprender como el instrumento cultural utilizado por el nuevo grupo dominante para legitimarse (mentalidad del colectivo) mediante la creación de un ciudadano acorde con la nueva estructura política y por medio de la formación de estudiantes en el marco de las nuevas expectativas culturales, ciudadanas y productivas, sin obviar su papel como un instrumento indispensable en la política de distribución de la riqueza dentro del esquema socialdemócrata de movilización social (ascenso en el nivel socioeconómico que podría tener una persona o familia a partir de una intervención del Estado). Como bien afirma Miranda (2010, p. 200), se define a la educación como "unidad ideológica para la configuración de la hegemonía política y cultural de orientación socialdemócrata y a la vez, de formación del ejército laboral de reserva calificada necesaria para las escalas laborales que requería el proceso de modernización capitalista".

El sistema educativo desde el MPS es consolidado a partir de la creación de la Ley Fundamental de Educación (1957) en tanto esta normativa establece los pilares de la estructura curricular vigente en Costa Rica hasta la actualidad. Entre los elementos más importantes están los siguientes: definición de la educación y el perfil de salida (es decir, las características que debe poseer cada estudiante al terminar la educación secundaria); estructuración por ciclos y asignaturas; institucionalización del Consejo Superior de Educación como ente rector del sistema con poder decisorio en el currículo nacional; y elementos básicos de la estructura administrativa. Adicionalmente, la educación es reformada en su función social en tanto, siguiendo a Fernández (2002), dentro del MPS esta se instituye en un instrumento de política de igualdad de oportunidades caracterizado por la inclusión, la educación compensatoria y especial, gratuidad en el sistema público o privado subvencionado y regulación para que no exista discriminación. 
EI MPS consolidó la gratuidad del sistema público de la Educación General Básica (ratificado en la Constitución Política) al tiempo que la educación compensatoria sustentó la creación de ofertas para adultos y alfabetización; la ampliación de la educación especial; la regulación de la educación privada; la ampliación de la inversión en infraestructura; la contratación docente para ampliar la educación secundaria; y las reformas curriculares para permitir un currículo con mayor sustento en la realidad costarricense; es decir, la realidad de un Estado con un proyecto económico intervencionista, el Modelo de Sustitución de Importaciones y la industrialización como objetivo de desarrollo.

EI MPS consolida, por primera vez en la historia del sistema educativo costarricense, un diseño curricular estructurado y fundamentado en el enfoque técnico, el cual mantendrá una vigencia parcial hasta nuestros días. Dicho enfoque, estructurado a partir de los aportes elaborados por Tyler (1973) para los Estados Unidos pos-Segunda Guerra Mundial, establece que el diseño del currículo se define a través de una serie de presupuestos como (a) el currículo es una organización de los procesos educativos para lograr una mejora en los procesos de enseñanza y aprendizaje; (b) se construye a partir de una serie de fundamentos y fuentes que establecen la concepción y relación del sistema educativo con la sociedad; (c) se construye a partir de la secuenciación del diseño curricular (selección de objetivos, selección y organización de las experiencias de aprendizaje y preparación de la evaluación); (d) el currículo es un área disciplinar, dentro de las áreas pedagógicas dirigido al estudio, diseño e implementación de las acciones y estrategias necesarias para convertir los conocimientos disciplinares y científicos en conocimientos para los estudiantes; (e) los fenómenos curriculares pueden racionalizarse, controlarse y medirse.

El enfoque técnico será complementado con un enfoque práctico sustentado en los postulados de Taba (1974) al crear una amalgama de enfoques curriculares propia de la realidad costarricense, por cuanto se debe comprender el currículo costarricense como una compleja red de elementos dinámicos y variantes que interactúan entre lo idealizado en documentos oficiales (enfoque curricular práctico ligado al constructivismo, del cual resulta referente la Política Educativa Hacia el Siglo XXI aprobada en 1994 y vigente a nuestros días) y la realidad de la contextualización curricular ligada al conductismo, la fragmentación de la organización administrativa-pedagógica y la priorización de los resultados, así como las demandas y proyectos específicos de grupos o personas ligadas a un enfoque sociocrítico.

Dicho lo anterior, podemos caracterizar el MPS como el modelo educativo implementado en Costa Rica posterior a la guerra civil (1948), ligado políticamente al Partido Liberación Nacional, sustentado en los preceptos de la Constitución (1949) y la división por ciclos y fines de la educación establecidos en la Ley Fundamental de Educación (1957), que asume la educación 
como instrumento de movilización social y distribución de la riqueza, con una función de educación integral (acercamiento a la cultura universal y desarrollo de una persona emocional y socialmente plena, según se puede inferir de los fines de la educación). Este modelo pedagógico está también ligado al nuevo modelo económico mediante la formación de mano de obra especializada (colegios vocacionales, colegios técnicos, inclusión de asignaturas como Mecanografía en el currículo de colegios académicos y el Instituto Nacional de Aprendizaje).

EI MPS se operacionalizó mediante el aumento de la inversión en educación; la conceptualización del dinero dedicado a educación como inversión; la ampliación de la cobertura en secundaria (objetivo de inclusión social, la movilización y construcción de legitimidad del proyecto político-económico); la nueva organización del Ministerio de Educación Pública (extrapolación empresarial del enfoque curricular técnico, correspondiente con la visión fragmentada y dirigida a maximizar el control-evaluación del producto educativo); el aumento de la estructuración de los procesos educativos (programas de estudio, materiales didácticos y otros); la fragmentación del conocimiento por asignaturas; los programas de equidad (para la inclusión y permanencia de estudiantes de estratos económicos medio-bajo y bajo); y la ampliación de la oferta académica según necesidades del nuevo modelo económico.

EI MPS postula la premisa de la importancia estratégica de la educación pública tanto para el Estado como para la sociedad y los individuos y su coherencia con la distribución de la riqueza desde el ideario socialdemócrata, por lo que logra constituir a la educación en una institución cultural impulsora de la narración que legitima el proyecto socioeconómico y defiende al proyecto hegemónico contra posibles resistencias tangibles o intangibles. Esto último adquiere relevancia en el marco de la abolición del ejército y la construcción del mito del "ejército de educadores"; una narración construida para visibilizar la importancia estratégica de la institución educativa.

\section{Ajuste Pedagógico Neoliberal}

Al finalizar la década de 1970, el Modelo de Estado Desarrollista o Interventor enfrentó una profunda crisis, cuyas causas y características trascienden el presente ensayo, pero su consecuencia intangible más importante fue la crisis de legitimidad (Miranda, 2007) del Modelo de Estado e, inherentemente, de los postulados argumentados por la socialdemocracia costarricense en las tres décadas anteriores.

Como consecuencia de la crisis económica y de legitimidad, junto al ascenso de las corrientes político-económicas de corte neoliberal impulsadas desde Estados Unidos, América Latina inicia la restructuración política y económica (con implicaciones socioculturales) denominado como Estado Neoliberal (Li- 
chstenztejn, 1988). Costa Rica implementa entonces las reformas dirigidas a la apertura comercial (Hidalgo, 1998) cuyas medidas económicas generaron un daño social e institucional (Korten, 1997), que todavía no ha sido reparado en aspectos como la desigualdad social, la exclusión de sectores populares, la disminución de la clase media y los mecanismos de movilidad social, la precarización laboral y otras que, en el fondo, constituirían una crisis de legitimidad que alcanzaría al propio modelo hegemónico (Vargas, 2002).

A nivel educativo, el modelo neoliberal introdujo una serie de reformas para el cambio de la concepción de la ciudadanía (Hindes, 2002) además del acercamiento de la formación al capitalismo y globalización (Miranda, 2001). A lo anterior se suma la disminución de las partidas dedicadas al área educativa aduciendo eficiencia presupuestaria (Pérez y González, 1991). Sin embargo, el presente ensayo delimita estas reformas bajo la denominación de Ajuste Pedagógico Neoliberal (Toruño, 2010, 2011) caracterizado por:

a) Una reforma económica singularizada por un cambio de concepción del dinero destinado a educación (de inversión a gasto); asimismo por la disminución de la inversión; la desregulación del sistema para impulsar la apertura (directa e indirecta) y ampliación de la cobertura de instituciones educativas privadas y la promoción de instituciones subvencionadas; la limitación en la contratación docente y en la infraestructura (generando un sobre poblamiento en las aulas); la priorización de inversión en área educativas "rentables" como Educación Técnica; y el aumento de la cantidad de días lectivos (y su correlación con una supuesta mejora en la calidad), entre otras

b) Una reforma institucional para aumentar eficiencia y eficacia, lo cual se tradujo en la creación-desarrollo de oficinas para el Control y la Calidad (en el caso de Evaluación) además de la profundización de la segmentación-especialización en oficinas centrales y las asignaturas de currículo. A lo anterior se añade la inserción de procesos de desarrollo-seguimiento-evaluación propios del sector privado. Se adiciona a esto, la creación de una oferta de modalidades educativas para "maximizar" los logros educativos y proyectos de Municipalización de la Educación (el principio de la descentralización ha sido fundamental dentro de la propuesta neoliberal iberoamericana) que han sido archivados por las resistencias sociales y políticas a esta medida.

c) Una reforma curricular que implicó cambios en contenidos y asignaturas dirigidas a la formación de un Consumidor-Trabajador (ser humano en la sociedad de consumo) en sustitución de la formación ciudadana (vivencia democrática). Se introdujeron también exámenes en sexto año, noveno año y bachillerato para verificar la calidad de la formación dada-recibida; se amplió la oferta técnica y se reorganizaron los contenidos-mediación para aumentar la "eficiencia" de los procesos educativos. Todo esto en coherencia con la Pedagogía por Objeti- 
vos (Gimeno, 1997) y la construcción de un productor-consumidor más que de un ciudadano (Toruño, 2010).

Sin embargo, a pesar de los esfuerzos de determinados sectores políticoeconómicos, el Ajuste Pedagógico Neoliberal no logró sustituir el Modelo Pedagógico Socialdemócrata, en tanto no implementó elementos básicos de una propuesta pedagógica neoliberal (Torres, 2001) como lo son la privatización o semiprivatización de gran parte de las instituciones educativas ni la desconcentración o municipalización del sistema educativo. De igual manera tampoco se desarrolló un sistema curricular fundamentado en las corrientes conservadoras ni se crearon ofertas educativas con sistemas de ingreso diferenciado (por ejemplo, educación técnica en zonas urbano marginales y científicos en zonas de clase media-alta). No se concretó un sistema flexible para la contratación de los trabajadores del sistema educativo (eliminación de la posibilidad de ser propietario en un puesto por tiempo indefinido, aumento de jornadas laborales, sistema de pago según evaluaciones, aumento de cantidad de estudiantes por grupo y eliminación de pluses como anualidades y carrera profesional) ni se eliminaron las asignaturas "inútiles" en la sociedad de mercado como tampoco las "distorsiones" provocadas por los programas de equidad.

Lo anterior no omite los impactos negativos del Ajuste Pedagógico Neoliberal para el sistema educativo costarricense entre los que se debe destacar el debilitamiento de la educación integral (en tanto se priorizó la enseñanza técnica, el inglés y la informática); la caída y el estancamiento de las tasas de cobertura en secundaria posterior a la crisis de la década de 1980; el cambio en lo conceptual del dinero dedicado a la educación como un gasto social; la disminución de los "gastos" en infraestructura, mobiliario y programas de equidad; la implementación de un sistema de evaluación segregador (pruebas nacionales en sexto, noveno y undécimo año) y conservador (introducción de la evaluación de la conducta y la correlación con las notas académicas); la sobrepoblación de centros educativos (producto de una baja en la inversión en infraestructura); el debilitamiento de los programas de equidad (menos inversión y disminución de la cobertura); la ampliación de la contratación interina dentro del Magisterio Nacional y el debilitamiento de su sistema de derechos-garantías. Un caso referente fue la afectación al régimen de pensiones que desembocó en uno de los mayores movimientos magisteriales en el año 1995, finalizando con la derrota del movimiento huelguístico y generando una década de debilitamiento y deslegitimización de las organizaciones sindicales magisteriales frente a sus bases. 


\section{La reinstauración del Modelo Pedagógico Socialdemócrata: el currículo oculto y explícito de las reformas}

Dos décadas después de iniciar su implementación, el Estado Neoliberal degeneró en una crisis de legitimidad política marcada por el aumento de la desigualdad, la conservación de índices de pobreza y la disminución de la movilidad social característica del Estado Interventor (principalmente entre 1950 y 1970) y la correlación entre el manejo del Estado y los intereses de sectores privados visibilizados en escándalos de corrupción.

El agotamiento del modelo partidario, la lucha contra el Combo del ICE en el año 2000, el aumento del abstencionismo, la ruptura del bipartidismo, la crisis política generada por el escándalo de corrupción que envolvió a líderes políticos entre el 2003 y 2005, la crisis de legitimidad de las instituciones democráticas y la lucha-polarización sobre el TLC con Estados Unidos demostraron que, en términos de Habermas (2008), nuestro sistema sufría una crisis de legitimidad y como crisis sociopolítica con fundamento cultural, la respuesta posible era en el marco de una reformulación de la formación ciudadana.

En este escenario, de crisis de legitimidad y polarización, asumió la Presidencia de la República Óscar Arias Sánchez (2006-2010), quien designó a Leonardo Garnier Rímolo como Ministro de Educación y quien fue ratificado durante la presidencia de la señora Laura Chinchilla Miranda (2010-2014). La administración de Leonardo Garnier (2006-2010, 2010-2014) realizó una serie de reformas dirigidas a la reformulación de la formación ciudadana, sin embargo, como se analizará en el siguiente apartado, este proceso implicó una transformación de la política educativa para dar paso a una reforma reinstaurativa del Modelo Pedagógico Socialdemócrata (MPS), que realiza rupturas conceptuales (educación como derecho e inversión) y reguladoras (asignaturas, contenidos, presupuesto y otras) con respecto al Ajuste Pedagógico Neoliberal imperante en las dos décadas anteriores.

Todo proceso de reforma curricular posee un currículo oculto (Torres, 1998) integrado por redes de poder invisibles (Gimeno, 1998), visión de la educación, propósitos del sistema, proyectos hegemónicos, ciudadanía esperada, entre otros. La visibilización del currículo oculto de una reforma enfrenta el desafío de que los análisis, generalmente, no cuentan con respaldo documental que permita el estudio de aspiraciones, ideales y redes de poder manifiestas fuera de los documentos oficiales.

En el caso de las reformas impulsadas bajo la administración de Leonardo Garnier, se puede realizar un análisis de las aspiraciones, concepción de ciudadanía y funciones educativas a partir de los artículos escritos por él como parte su columna semanal en el periódico la Nación, titulada "Sub-versiones". Estos escritos fueron elaborados entre el 2002 y abril de 2006 (período previo a su llegada al Ministerio de Educación Pública), en su calidad de figura pública relacionada con el Partido Liberación Nacional, publicados en un dia- 
rio ligado, tanto por el abordaje noticioso como por la red de negocios de sus accionistas, con el proyecto político-económico neoliberal y sin la posibilidad real, en el momento de escribir los textos (con excepción del último artículo vinculado al tema educativo, publicado en abril de 2006), de ejercer influencia sobre las reformas educativas en Costa Rica.

En sus textos, Garnier establece una ruptura con el discurso neoliberal de mercantilización de la educación y su priorización de la formación de mano de obra, rescatando la necesaria formación integral (con énfasis en lo artístico) al indicar que es necesario,

juntar la economía y el arte, la economía y la música, la economía y la plástica, la economía y... cualquier tipo de manifestación cultural, pero no en un sentido mercantilista miope... sino, por el contrario, entendiendo y atendiendo el carácter de bien eminentemente público que, por diversas razones, tiene la creación artística (Garnier, 2002a).

En ese artículo, se le da carácter de "transformadora" a la experiencia de disfrute y apreciación del arte, finalidad que será plasmada en las Reformas de Ética, Estética y Ciudadanía en Música y Artes Plásticas y en la creación del Festival Estudiantil de las Artes (FEA), ambas realizadas entre el año 2008 y 2009. Además, tanto el artículo como las reformas revalorizan el arte dentro del proceso educativo y plasman un anhelo del MPS (formación integral con el uso del arte como recurso indispensable), el cual alcanzó su mayor preponderancia durante el primer quinquenio de la década de 1970.

En segundo lugar, frente a la polémica suscitada a raíz de las declaraciones de autoridades del Ministerio de Educación Pública anteriores a su administración contra la asistencia de todos los niños(as) al comedor (en tanto el dinero no era suficiente y se debía priorizar a quienes en verdad lo necesitaban), Garnier (2002 b) reitera la crítica a la educación con el objetivo prioritario de la formación de mano de obra e introduce el tema de la convivencia al afirmar que:

La educación, para serlo, tiene que ir mucho más allá de la mera adquisición de conocimientos para la vida laboral. También debe enseñar a vivir -"aprender a comer de todo" como dijo una maestra- y, sobre todo, aprender a convivir, aprender que somos de los mismos, que la comida y la educación que compartimos es un derecho, no un privilegio ni una limosna. 
Lo anterior devela tres conceptos básicos del currículo oculto de las reformas realizadas durante su gestión: la educación para la convivencia, la educación para la vida y la educación pública como un derecho. Estos tres elementos constituyen la base del ideario pedagógico del MPS plasmado en la Ley Fundamental de Educación, principalmente referente a los fines del sistema educativo.

Amerita mención especial el caso de la educación para la convivencia, en tanto Garnier (2006) afirmó que:

Hemos cerrado y menospreciado los espacios para el juego, para el arte, para el deporte, para la música, para el teatro, para el campamento, para el entretenimiento, para la conversación, para la tertulia - hoy chat -, para el jolgorio, para la amistad. Hemos confundido jugar o divertirse con vagabundear. Al hacerlo, hemos ido minando aquello que más llena, que más vivifica, que mejor ocupa y apasiona a los jóvenes y, de paso, lo que más limita y evita la violencia, lo que la hace más absurda e innecesaria. Hemos cerrado los espacios de la ética y la estética, los espacios donde se aprende qué es bueno y correcto, qué es bello, bonito, entretenido.

La elaboración conceptual de una educación para la convivencia rompe con la visión tradicional-conservadora (una educación para obedecer y aprender) y neoliberal (una educación para el trabajo e individualizada), reivindicando las posturas progresistas en el área educativa vinculadas a la educación vivencial, construcción de vínculos, el espacio lúdico y la comprensión de los aprendizajes más allá de los contenidos disciplinares. Sin embargo, la ruptura más importante se realiza con la conceptualización de Violencia-Convivencia, asumiendo como prioridad la construcción de una convivencia desde el disfrute, la expresión, el encuentro y la ética-estética. La inclusión de este eje pedagógico constituye un paso adelante con respecto al MPS de las décadas anteriores y permite acercamientos con las posiciones del progresismo educativo del país al iniciar el siglo XXI.

En relación con la educación pública como derecho, se incluye la educación como el espacio de formación para la convivencia democrática (Garnier, 2002d), con la globalización y sus retos (Garnier, 2002c). Se visualiza también la necesidad de una ciudadanía práctica que trascienda la simple repetición de contenidos (Garnier, 2005a), entrelazada con la necesidad de universalizar la educación secundaria. En este sentido, Garnier (2005b) señaló que es importante: 
Frenar el desgrane empezando por sus discontinuidades álgidas. Resolver las carencias de primaria que promueven el fracaso en secundaria. Avanzar hacia una secundaria que resulte atractiva y útil para los estudiantes. Elevar la motivación, la formación y capacitación docente. Mejorar la infraestructura y el entorno de aprendizaje. Atender a los sectores y regiones más rezagados o con problemas especiales. Usar la evaluación como medio correctivo y no como autopsia. Aprovechar las nuevas tecnologías para el aprendizaje y, en especial, para cerrar brechas. Fortalecer los programas exitosos... y cerrar otros; etc. Todo ello exige invertir más en educación.

Las anteriores reflexiones se fundamentan, aunque no se mencione explícitamente, en los postulados básicos asignados a la educación dentro del modelo socialdemócrata implementado en Costa Rica entre la década de 1950 y finales de la década de 1970, a saber: (a) acceso universal con amplia participación estatal; (b) educación como espacio de formación ciudadana (ligada a la convivencia, el aprecio de las manifestaciones culturales y la acción en el ámbito político); (c) integrada dentro de modelo productivo que promueva la distribución de la riqueza; y (d) movilizador social.

Por lo tanto, los textos escritos por el señor Garnier entre el 2002 y 2006 develan un currículo oculto ligado al proyecto socialdemócrata y a su modelo pedagógico, cuyas premisas básicas se oponen al Ajuste Pedagógico Neoliberal y su concepción de ciudadanía (Toruño, 2010). Sin embargo, este currículo oculto encuentra manifestaciones explícitas en las reformas implementadas en el período comprendido entre el año 2006 y 2014.

Entre el 2006 y 2008 se desarrolló la base curricular para la reforma Ética, Estética y Ciudadanía la cual generó nuevos programas de estudio, estrategias de mediación (constructivistas) y evaluación en Educación Cívica (2009), Educación Musical (2008), Artes Plásticas (2009) y Educación Física (2010); como también una priorización de asignaturas consideradas "especiales" o "secundarias" en el ideario neoliberal. Además, se crean los programas de Pensamiento Científico (2008), se hacen reformas en Ciencias de primaria dirigidas a la inclusión de mediación para la construcción del pensamiento científico, y Piensa en Arte (2009), esta última en Español e implicó la creación de una lección para construir habilidades comunicativas a partir del conocimiento, aprecio y disfrute del arte. En el mismo período se crean el Festival Estudiantil de las Artes (2008) y El Cole en Nuestras Manos (proyecto que sería la antesala del Programa Convivir. Este último será oficializado 
en el año 2011. Además, se consolidan-expanden los Juegos Deportivos Estudiantiles, la Bandera Azul Ecológica y los Gobiernos Estudiantiles.

Durante la segunda administración (2010-2014) se realizaron las reformas sustentadas en los principios de Ética, Estética y Ciudadanía. En secundaria se realizaron las reformas en Vida Cotidiana (2012), Artes Industriales (2013) y Afectividad y Sexualidad Integral (2012). Esta última fue convertida en la reforma educativa más polémica durante las últimas décadas por el rechazo del sector más conservador del país. A nivel de primaria se realizaron las reformas de Español (2013), Artes Plásticas (2013), Educación Musical (2013), Educación Física (2013) y Estudios Sociales y Cívica (2013); en Preescolar (2014) y, en primaria-secundaria, la reforma de Matemáticas (2012).

A partir de un análisis de contenido de los programas de estudio de estas reformas, se puede concluir que estas tuvieron como ejes del currículo oculto el desarrollo de una serie de competencias vinculadas con la formación ciudadana en el marco de una visión del MPS (incluso involucrando elementos de la discusión de la Tercera Vía) con la incorporación de la Convivencia como elemento innovador y plasmadas tanto en contenidos como en el desarrollo de actividades de mediación e implementación de estrategias de evaluación. Entre estas competencias se encuentran comunicación, disenso, consenso, deliberación, toma de decisiones, negociación, comunicación social y política, participación, representación, trabajo en equipo, responsabilidad individual y social, resolución de problemas, saber elegir y disfrute de la diversidad.

Además de estos ejes, la administración utilizó cuatro pilares como principios implícitos en la selección y organización de contenidos, a saber: Conocer, Apreciar, Disfrutar y Expresar. Las implicaciones de estos pilares trascienden los límites tácitos del presente ensayo, sin embargo resulta necesario ampliar los debates curriculares sobre esta temática, las posibles transformaciones en el diseño curricular y la posible innovación para el MPS al incluir estos pilares como referentes para la selección y organización de contenidos, para las actividades de mediación y para los proyectos extra académicos.

La posición del señor Garnier y las anteriores reformas académicas implementadas entre el año 2006 y el 2014 son coherentes con el MPS, el perfil de ser humano a formar dentro de ese modelo pedagógico y el planteamiento del Congreso Ideológico del Partido Liberación Nacional del año 2005, en el cual se indica:

El sistema educativo debe apoyarse en los avances de las diferentes ciencias, las demandas del país y los cambios del mundo. Los factores científicos, tecnológicos y sociales deben conjugarse con un sólido desarrollo de los valores humanos, las artes y las letras deben ser objeto de permanente promoción y difusión. Especial estímu- 
lo ha de brindarse a las manifestaciones creadoras del pueblo y a toda forma de cultura que emane de él. Asimismo, la formación ciudadana debe tener la primera prioridad en el proceso educativo para preservar los valores cívicos y éticos, ennoblecer la acción política y dignificar su ejercicio. La educación debe ser relevante, con un sentido vivo de actualidad y utilidad. Esto incluye la educación para la salud; educación para la convivencia, para la vida en comunidad; educación para la recreación física y espiritual; educación para una vida en armonía con la naturaleza y el medio ambiente (Partido Liberación Nacional, 2005, p. 54; el resaltado en negrita para fines del presente artículo).

Lo anterior permite visibilizar el tejido conceptual y orgánico que constituye el currículo oculto de las reformas en estudio y que será manifiesto en los cambios académicos y extra académicos realizados. Estamos, pues, ante un claro proyecto educativo entramado en la lógica curricular del MPS y las necesidades de construir nuevos pactos, consensos y legitimidades dentro del proyecto hegemónico; un proyecto que no se limita a las reformas de programas de estudio porque se extendieron también programas extra académicos y marcos reguladores del sistema educativo.

La reforma al Reglamento de Evaluación de los Aprendizajes (2008), un acompañante clave en la propuesta pedagógica de la reinstauración del MPS, implicó un cambio de concepción de la evaluación dentro del sistema educativo puesto que eliminó tanto las Pruebas Nacionales de Sexto y Noveno Año como la Repetición Anual (antes de la reforma, si un estudiante perdía una o varias materias tenía que repetir todo el curso lectivo). Se introdujo además el Adelantamiento de materias (sólo se repiten las materias no aprobadas y se cursan las materias del año escolar siguiente, por ejemplo si un estudiante perdió Matemáticas en octavo año, repetirá esa materia en el siguiente curso lectivo y llevará las demás materias de noveno año). Se eliminó también la obligación de aprobar el último trimestre (con la antigua normativa si un estudiante de educación tenía como calificaciones 90 en el primer trimestre, 80 en el segundo y en el tercer trimestre obtenía una nota inferior al promedio mínimo -70 en educación diversificada y 65 en Tercer Ciclo-, la materia sería reprobada). Igualmente, se suprimió la vinculación Nota de Conducta y Notas Académicas (si un estudiante obtenía una nota inferior al mínimo en Conducta, tendría que realizar un examen de Convocatoria en todas las asignaturas con calificación inferior a 80 y repetiría el curso lectivo en caso de no aprobar las pruebas). 
A nivel de asignaturas, la reforma al Reglamento de Evaluación de Aprendizaje introdujo el cambio en diversas materias para incorporar la evaluación por proyectos (un 30\% o 35\% de la nota final en cada trimestre), lo cual constituyó un paso operativo hacia la implementación de una mediación constructivista en el tanto que, por primera vez, actividades como proyectos, trabajos cotidianos y extraclase tenían mayor importancia evaluativa que el examen tradicional. Este último fue reducido a solo uno por trimestre con un $35 \%$ como porcentaje máximo.

Lo anterior rompe con uno de los ejes del Ajuste Pedagógico Neoliberal producto del deseo de control y supervisión extrapolado desde el sector empresarial y los anhelos de "normalización" moral de los sectores conservadores. Además, con estos cambios se introduce un cuestionamiento al status quo (repetir un año por una materia) que no había sido abordado por los sectores progresistas del sistema educativo. Sin embargo, no se puede asumir como una reforma dirigida a esa ruptura; en tanto se debe considerar también las implicaciones de mantener una mayor cantidad de estudiantes en el sistema educativo y disminuir los índices de reprobación, ambos motivos relevantes desde una administración política del sistema.

Las reformas académicas, extra académicas y de evaluación, durante el período 2006 a 2014, fueron acompañadas de un giro en el financiamiento de la educación, alcanzando la cifra del 7,2\% del PIB para el año 2013, siendo uno de los elementos referentes del cambio en la concepción de la inversión el rubro de infraestructura educativa y mobiliario. Según datos del MEP (2014), entre el 2002 y 2006 la inversión en infraestructura fue de 16995 millones y en mobiliario de 3235 millones, en estos mismos rubros entre el 2007 y el 2010 la inversión fue de 110464 millones y 8654 millones respectivamente, mientras que entre el 2011 y el 2014 fue de 135251 millones y 7441 millones respectivamente. A lo precedente se debe sumar la aprobación de un fideicomiso en el 2014 por un monto de 167 millones de dólares para la construcción de infraestructura educativa.

A nivel de los denominados Programas de Equidad, entre los años 2005 y el 2014, el Estado paso de invertir 11300 millones en el Programa de Comedores Escolares a 52500 millones de colones, con una cobertura de más de 673 mil estudiantes durante el año 2013. Con respecto a la inversión en transporte, en el año 2006 se dirigieron a este 5941 millones y en el año 2014 alcanzó la cifra de 24693 millones mientras que el sistema de becas de FONABE pasó de una cobertura de 139537 estudiantes en el año 2006 (con una inversión de 5694 millones) a 198236 en el año 2014 (una inversión de 46927 millones de colones).

Relacionado con las tasas de asistencia, cobertura y brechas educativa, destaca el caso del grupo etario entre 13 y 17 años el cual paso de un 76,4\% en el 2006 al $85,9 \%$ en el 2013, con una tasa de matrícula bruta de 90,5 en ese año, así como la disminución de la deserción nacional de un 13,2\% en el 
2006 a un 9,9\% en el año 2013. Sin embargo, el dato más importante radica en la disminución de la brecha en equidad educativa por ingresos; en tanto, la asistencia a la educación formal de la población entre los 13 y 17 años aumentó, en el quintil más bajo, de un $64 \%$ a un $79 \%$, mientras que en el quintil más alto el aumento fue de un $92 \%$ a un $93 \%$, disminuyendo la brecha educativa entre ricos y pobres de un 44\% en el año 2003 a un $20 \%$ en el año 2013. Todo esto es un reflejo de la preocupación del Estado por restaurar, al menos en el corto plazo, los índices de permanencia y cobertura registrados en el país durante la década de 1970 y, al mismo tiempo, se puede reconocer el incremento de cobertura educativa como un mecanismo para disminuir la crisis de legitimidad de la primera década del siglo XXI.

Por su parte, entre el 2006 y el 2014 se da un incremento significativo de los Colegios Técnicos, en tanto de un total de 882 centros educativos de secundaria (públicos, privados y subvencionados) que tenía Costa Rica en el 2013, 127 instituciones de ellos eran Colegios Técnicos Profesionales frente a los 696 académicos. Se evidencia también un aumento de la matrícula de 62 093 mil estudiantes en el 2006 hasta 95 mil estudiantes en el 2014, junto a la apertura de nuevas especialidades como las secciones nocturnas. Además, las asignaturas del área técnica también son reformadas. Estos esfuerzos son coherentes con el MPS y su objetivo de armonizar las demandas laborales con la formación especializada que debe brindar el Estado. La comprensión de la relación entre MPS y la formación de mano de obra para los sectores empresariales debe ser comprendida para aminorar el riesgo de la simplificación del fenómeno ligándolo única y exclusivamente a posturas neoliberales.

Las reformas y las acciones enunciadas anteriormente, e implementadas entre el 2006-2014, son pertinentes en el marco de los cuatro grandes retos establecidos por el Congreso Ideológico del Partido Liberación Nacional en el año 2005, a saber:

Un reto social, que consiste en hacer de la educación un instrumento eficaz para cerrar la brecha entre las clases sociales, crear nuevas oportunidades de ascenso social y suscitar la participación activa de todos en la solución solidaria de los problemas. Un reto económico, que consiste en que la educación haga posible que contemos con los recursos humanos idóneos para elevar la competitividad y productividad de la economía nacional de manera que nos podamos integrar exitosamente en la economía mundial. Un reto ético, para que la educación fortalezca aquellos valores y actitudes que le den a lo económico y lo social un sentido altruista, inspirador, incorruptible y 
humanista. Y un reto ecológico, para que la educación promueva y

reproduzca un desarrollo que armonice las relaciones entre el ser

humano y la naturaleza (Partido Liberación Nacional, 2005, p. 54).

Así, las reformas en las dos administraciones de Leonardo Garnier pueden ser asumidas como parte del Modelo Pedagógico Socialdemócrata, tanto en relación con las características del modelo entre 1957 y 1985 como con la reformulación implícita en el Congreso Ideológico del año 2005. Sin embargo, esta tesis contradice una lectura generalizada entre sectores progresistas costarricenses relacionada con la alineación neoliberal de la propuesta educativa posterior a la crisis de la década de 1980. Debido a lo anterior resulta necesario ampliar acerca de las implicaciones de esas reformas para los sectores progresistas.

\section{Las implicaciones del MPS para el sector progresista costarricense}

Las administraciones de Leonardo Garnier (2006-2010, 2010-2014) como Ministro de Educación Pública implicaron la reinstauración del MPS tanto en el diseño curricular (perfil de ser humano, las reformas académicas y extra académicas y reforma en evaluación) como en las políticas de inversión, su relación con el modelo económico y conceptualización-operacionalización del sistema educativo como herramienta de distribución de la riqueza y movilizadora social. A lo anterior es importante agregar sus posiciones sobre la importancia del arte en la educación, el centro educativo como centro de identidad, la necesidad de la educación sexual y de la afectividad, la educación para la libertad y la lucha contra el miedo y el verticalismo en el sistema educativo o conferencias con una narración educativa ligada a reivindicaciones históricas de la pedagogía crítica y movimientos progresistas. En su conjunto todos estos elementos representaron una posición pedagógica mucho más profunda de los postulados del MPS y difícilmente separables de las propuestas del progresismo educativo.

Adicionalmente, la administración Garnier Rímolo debe considerarse a raíz de la constitución de una nueva política de Estado en el área Educativa que, por primera vez en las últimas cuatro décadas, adquiere continuidad en la siguiente administración (2014-2018) a partir del análisis del Plan Nacional de Desarrollo Alberto Cañas Escalante 2014-2018 presentado por el gobierno del Partido Acción Ciudadana.

Para el Progresismo Educativo, la premisa de reconocer la administración Garnier Rímolo como una reinstauración del Modelo Pedagógico Socialdemócrata puede ser interpretada como una invisibilización del neoliberalismo 
vigente en el sistema educativo y una rendición frente al proyecto hegemónico. No obstante, aceptar la premisa desarrollada en el presente ensayo no implica invisilizar el modelo hegemónico Neoliberal impulsado en Costa Rica desde la década de los ochenta, en cambio exige no analizar la implementación de dicho modelo desde una posición reproduccionista.

La implementación de un proyecto hegemónico (con el respectivo modelo económico) es un proceso complejo de luchas entre los grupos de poder defensores de dicho modelo, los grupos de poder con intereses contrarios, los grupos de presión defensores de un determinado status quo y los grupos progresistas que poseen una agenda alternativa.

El presente ensayo reconoce la existencia del modelo Neoliberal al mismo tiempo que reconoce su implementación alejada de la narración oficial (y de sectores del progresismo costarricense) que caracteriza la implementación del mismo como homogénea y carente de oposición. El modelo Neoliberal no logró ser implementado uniformemente en Costa Rica al punto de que podría ser factible darle otra denominación a lo que comúnmente hemos denominado Estado Neoliberal en tanto, para lograr su viabilidad el grupo dominante, el grupo político representante del proyecto hegemónico, los grupos de presión y la sociedad civil establecieron pactos explícitos e implícitos, llegando a mantener dentro de la estructura del Estado Costarricense a instituciones y políticas públicas no coherentes con el modelo neoliberal. Por lo tanto, es posible observar al sistema educativo como escenario de resistencias (Bourdieu y Passeron, 2001) capaz de implementar un proyecto educativo no lineal con un proyecto hegemónico tampoco coherente con las premisas educativas brindadas desde un determinado modelo económico.

El progresismo educativo requiere visibilizar y cuestionar al modelo educativo imperante desde aristas mucho más complejas que el reduccionismo de una oposición radical a todo proceso educativo implementado en los últimos años bajo el supuesto de que responde a un modelo neoliberal. Lo contrario exige un amplio proceso de reflexión y acción para lograr distinguir la paja del trigo; es decir, comprender, valorar y utilizar determinados elementos del Modelo Pedagógico Socialdemócrata para la construcción de un Modelo Pedagógico Crítico, Revolucionario o Alternativo y suprimir aquellos elementos ligados con un conservadurismo o pertenecientes al Ajuste Pedagógico Neoliberal. Acá sería también oportuno generar un debate sobre la creación de la legitimidad institucional del modelo económico, así como de la disminución e institucionalización de los conflictos generados por las distorsiones del mercado y la verdadera educación brindada en la contextualización curricular; es decir, aquella educación construida en las aulas que puede ser opuesta al proyecto hegemónico o al proyecto educativo progresista.

Por último, el sector educativo progresista requiere establecer las primeras aproximaciones del diseño curricular del Modelo Pedagógico Crítico (u otro nombre que vaya a tomar según sus características), que vendría a sustituir 
al MPS con el fin de poder establecer las características educativas vitales a reformar, aquellas que serían pactadas, las que son necesarias a mediano plazo para la consolidación del nuevo modelo y las que se mantendrían, así como las acciones legales y políticas necesarias para su mantenimiento y expansión. Dichos elementos, de los que careció el Ajuste Pedagógico Neoliberal, han sido los que ahora el MPS ha logrado crear, consolidar y utilizar.

\section{Conclusiones}

Lo analizado en el presente artículo permite establecer la necesidad de realizar nuevas interpretaciones de la historia educativa más allá de la visión cronológica clásica. Ello posibilitará desarrollar análisis y propuestas a partir de elementos internos al sistema educativo; en este caso, la división a partir de la evolución del currículo costarricense como sistema de control ligado a un proyecto hegemónico.

Establecer una lectura histórica desde el currículo, comprendido como un hecho cultural que trasciende los programas de estudio, permite analizar crítica y contextualizadamente al modelo pedagógico. En el caso del presente ensayo, este analizó el Modelo Pedagógico Socialdemócrata (MPS) y el Ajuste Pedagógico Neoliberal (APN). En el primero se ha demostrado la existencia de marcos conceptuales (concepto de educación, visión, misión, función social y económica, concepción de docente y estudiante, perfil de salida del estudiante y perfil de ser humano) y reguladores (inversión en educación, índices de cobertura, programas de equidad, malla curricular, asignaturas, ofertas académicas y ampliación de la infraestructura) de la educación costarricense elaborados como parte de un proyecto económico pos Guerra Civil (Estado Desarrollista), además del desarrollo del currículo como área teórica y técnica funcional dentro de la nueva estructura educativa (construida a partir de la tecnificación extrapolada de los principios empresariales), una institución cultural clave para la movilidad social y la creación de una plataforma de legitimidad de los diversos procesos y acciones implementadas como parte del proyecto hegemónico.

Como resultado de la crisis económica, que afectó a Costa Rica a finales de la década de 1970 e inicios de la década de 1980, el proyecto de Estado Desarrollista pierde legitimidad social al tiempo que se presenta una reconfiguración de las élites económicas con un creciente sector ligado a la propuesta ideológica de un Estado Neoliberal. El presente ensayo concluye que el surgimiento del Modelo o Estado Neoliberal en Costa Rica no implicó la construcción de un Modelo Pedagógico Neoliberal, por el contrario, desarrolló un APN (1986-2005) constituido por reformas parciales a los marcos conceptuales y reguladores de la educación en el MPS. 
La reinstauración del MPS se construye a partir del debilitamiento del APN. EI quinquenio entre el año 2000 y 2005 fue el referente porque durante ese período se manifestaron luchas sociales y fracturas institucionales (surgimiento de nuevos partidos y aumento del abstencionismo) que obligan al Partido Liberación Nacional (PLN) a realizar un Congreso Ideológico en el cual se restablecen los pilares del modelo educativo impulsado como parte del MPS y que sería reflejado en las siguientes dos administraciones.

La designación del señor Leonardo Garnier Rímolo como Ministro de Educación Pública, en las administraciones del Partido Liberación Nacional 20062010 y 2010-2014, estableció las condiciones políticas para operacionalizar el currículo oculto socialdemócrata ya implícito en las algunas de las publicaciones semanales realizadas por el señor Garnier en la columna Sub/versiones en el periódico La Nación entre el año 2002 y 2005.

Lo anterior ha sido denominado, en el presente artículo, como reinstauración del MPS en el tanto que implica un reforzamiento de pilares de los marcos conceptuales y reguladores de la educación. En los marcos conceptuales se desarrolla la concepción de educación como herramienta institucional para la movilidad social y creación de legitimidad, la formación de una ciudadanía vinculada con la patria, las ciencias, el arte, la comunidad y la producción (Fines de la Educación). Además se reinstaura la función social del sistema educativo como integrador y formador de estudiantes para un modelo productivo que exige bilingüismo así como competencias técnicas y competencias para la vida. Con respecto a los marcos reguladores, se reforman los programas de estudio de diversas asignaturas y se desarrollan los programas extra académicos. Igualmente la inversión en infraestructura, mobiliario y los programas de equidad reciben los mayores aumentos porcentuales y nominales desde la década de 1970. Es pertinente agregar que la oferta educativa se diversifica, se amplía la cantidad de Colegios Técnicos Profesionales y reforman reglamentos-directrices emanadas durante la década anterior.

Asumir la tesis de la reinstauración del MPS implica, para el progresismo educativo costarricense, superar el análisis tradicional basado en la premisa lineal-reproduccionista de que un Estado Neoliberal posee un sistema educativo Neoliberal (lo que obliga a una oposición radical a todo proceso de reforma educativa). Lo aquí expuesto obliga a analizar la relación Proyecto Hegemónico- Estado-Modelo Económico-Sistema Educativo como una interacción compleja, dinámica e incluso opuesta, con escenarios de resistencia o incongruencias. Por lo tanto, las reflexiones y las acciones progresistas deben hilvanar los elementos constitutivos de su propuesta pedagógica con elementos del MPS, al tiempo que deben caracterizar claramente los elementos del APN que serán rechazados en su propuesta. 


\section{Referencias}

Apple, M. (1997). Política cultural y educación. Madrid: Morata.

Apple, M. (1996a). Educación y poder. Barcelona: Paidós.

Apple, M. (1996b). El conocimiento oficial. La educación democrática en una era conservadora. Madrid: Paidós.

Bourdieu, P; y Passeron, J. (2001). La reproducción. Elementos para una teoría del sistema de enseñanza. Madrid: Popular.

Camacho, J. (2005). Un siglo de educación costarricense: 1814-1914. San José: EUCR.

Dengo, M. (2011). Educación costarricense. San José: EUNED.

Fernández, M. (2002). Políticas socialdemócratas de igualdad de oportunidades educativas: las experiencias de González y Miterrand. Revista Española de Ciencia Política, 22, 39-65

Freire, P. (1997). Educación y participación comunitaria. En: Castells, M; Flecha, R; Freire, P; Giruoux, H; Macedo, D y Willis, P. Nuevas perspectivas críticas en educación. Barcelona: Paidós.

Freire, P. (1990). La naturaleza política de la educación. Cultura, poder y liberación. Barcelona: Paidós.

Freire, P. (1984). Pedagogía del Oprimido. Madrid: Siglo XXI.

García, I. (2011). Formación de la clase media en Costa Rica. Economía, sociabilidad y discursos políticos (1890-1950). Tesis no publicada de Maestría Académica en Historia, Universidad de Costa Rica, San José, Costa Rica.

Garnier, L. (2002a). El arte no es un queque. La Nación. Recuperado noviembre 22, 2014, de http://leonardogarnier.com/articles/subversiones/el-arte-no-es-unqueque-252

Garnier, L. (2002b). Comer Juntos. La Nación. Recuperado noviembre 22, 2014, de http://leonardogarnier.com/articles/subversiones/comer-juntos$\underline{236}$

Garnier, L. (2002c). Malestar de nuestro tiempo. La Nación. Recuperado noviembre 22, 2014, de http://leonardogarnier.com/articles/subversiones/el-malestar-de-nuestrotiempo-240 
Garnier, L. (2002d). Dar ganas de leer. La Nación. Recuperado noviembre 22, 2014, de http://leonardogarnier.com/articles/subversiones/darganas-de-leer-221

Garnier, L. (2004). Luces y Sombras. La Nación. Recuperado noviembre 22, 2014, de http://leonardogarnier.com/articles/subversiones/luces-ysombras-428

Garnier, L. (2005a). La ciudadanía es como el sexo. La Nación. Recuperado noviembre 22, 2014, de http://leonardogarnier.com/articles/subversiones/la-ciudadan-es-comoel-sexo-541

Garnier, L. (2005b). Universalizar la secundaria. La Nación. Recuperado noviembre 22, 2014, de http://leonardogarnier.com/articles/subversiones/universalizar-lasecundaria-580

Garnier, L. (2006). El único antídoto. La Nación. Recuperado noviembre 22, 2014, de http://leonardogarnier.com/articles/subversiones/el-nico-ant$\underline{\text { doto- } 607}$

Gimeno, J. (2001). El currículo: una reflexión sobre la práctica. Madrid: Morata.

Gimeno, J. (1998). Poderes inestables en educación. Madrid: Morata.

Gimeno, J. (1997). Pedagogía por objetivos. Obsesión por la eficiencia. Madrid: Morata.

Giroux, H. (2006). La escuela y la lucha por la ciudadanía. Pedagogía crítica de la época moderna. México, D.F: Siglo XXI.

Giroux, H. (1997). Cruzando límites. Trabajadores culturales y políticas educativas. Barcelona: Paidós.

Giroux, H; \& McLaren, P. (1998). Sociedad, cultura y educación. Madrid: Niño y Dávila Editores.

Habermas, J. (2008). Facticidad y validez. Sobre el derecho y el Estado democrático de derecho en términos de teoría del discurso. Madrid: Trotta

Hidalgo, A. (1998). La forzada apertura comercial y el modelo neoliberal de desarrollo en Costa Rica. Revista de Ciencias Sociales, 78-79, 61-74.

Hindes, B. (2002). La ciudadanía neoliberal. Revista Mexicana de Ciencias Políticas y Sociales, 45, 107-131. 
Kemmis, S. (1998). El currículo: más allá de la teoría de la reproducción. Madrid: Morata

Korten, A. (1997). Ajuste Estructural en Costa Rica. Una medicina amarga. San José: Departamento de Ecuménico.

La Nación. (2014).Ocho años de avance educativo. La Nación. Recuperado noviembre 20, 2014, de http://www.nacion.com/opinion/editorial/anosavance-educativo_0_1397660230.html

Lichstenztejn, S. (1988). Políticas económicas neoliberales en América Latina. Revista Centroamericana de Economía, 8(9), 125-148.

McLaren, P. (1995). Pedagogía crítica y cultura depredadora. Políticas de oposición en la era posmoderna. Barcelona: Paidós.

Ministerio de Educación Pública. (2014). Memoria Institucional 2006-2014. La educación subversiva. Atreverse a construir el país que queremos. San José: s.e.

Miranda, G. (2010). La fundación del Partido Liberación Nacional y el origen del proyecto político educativo socialdemócrata en Costa Rica. Una aproximación hermenéutica crítica. Revista de Ciencias Sociales, 130, 185-213.

Miranda, G. (2007). Política curricular, crisis de legitimación y hegemonía neoliberal. Una visión desde la sociología de la educación critica. Revista de Ciencias Sociales, 115, 13-34.

Miranda, G. (2001). Capitalismo global y cambio educativo. Los fundamentos estructurales e ideológicos de la política educativa neoliberal. Revista Educare, 4(7), 13-42.

Molina, I. (2007). Educación y sociedad en Costa Rica: de 1821 al presente (una historia no autorizada). Diálogos Revista Electrónica de Historia, 8(2), 149-356.

Molina, I; \& Palmer, S. (2000). Educando a Costa Rica: alfabetización popular, formación docente y género (1880-1950). Costa Rica: Porvenir.

Partido Liberación Nacional (2005). V Congreso Nacional Daniel Oduber Quirós Una Costa Rica Integrada por las Oportunidades. San José: s.e.

Pérez, M. y González, Y. (1991). De la crisis financiera al proyecto neoliberal: la educación superior en Costa Rica. Káñina, XV, 341-348.

Rovira, J. (2000). Estado y política económica en Costa Rica: 1948-1970. San José: EUCR. 
Taba, H. (1974). Elaboración del currículo. Buenos Aires: Troquel.

Torres, J. (2001). Educación en tiempos del Neoliberalismo. Madrid: Morata.

Torres, J. (1998). El currículo oculto. Madrid: Morata

Toruño, C. (2010). Fundamentos curriculares de la ciudadanía en un Estado Neoliberal: el caso del sistema educativo costarricense. Actualidades Investigativas en Educación, 10 (2), 1-25.

Toruño, C. (2011). ¿Es neoliberal la reforma en el MEP? Diario Digital El País. Recuperado diciembre 01, 2014, de http://www.elpais.cr/frontend/noticia_detalle/3/39612

Tyler, R. (1973). Principios básicos del currículo. Buenos Aires: Troquel.

Vargas, L. (2002). Costa Rica, 1985-1997: liberalización y ajuste estructural o la autodestrucción del neoliberalismo. San José: EUNED. 


\section{Revisitando las ONG como Revisiting NGOs as Research objeto de estudio: Focus: Considerations consideraciones para una Towards an Initial Critical aproximación crítica inicial Approximation}

RESUMEN

Este trabajo se propone evidenciar la relevancia de retomar la reflexión en torno al tema de las ONG, desde la agenda de investigación académica de las ciencias sociales costarricenses. En el primer apartado se expone una serie de elementos que justifican su importancia, realizando para ello una aproximación cuantitativa al fenómeno llamado "oenegeísmo"; asimismo, se realiza un primer acercamiento al estado del arte generalizado sobre el tema, deteniéndonos brevemente en los referentes costarricenses que se identifican en la Universidad de Costa Rica. En un segundo apartado se realiza un reconocimiento de los principales debates y discusiones que prevalecen, aprovechando también para problematizar algunas de las referencias históricas a las que tradicionalmente se hace alusión en la mayor parte de la bibliografía. En el último apartado se ensaya una definición amplia, crítica y plural de la noción de "ONG"; aunado a lo cual se pasa revista (y se intenta ponderar) a las principales tendencias de clasificación y tipificación que se conocen a lo interno del universo de las ONG.

\section{Palabras Clave \\ Organizaciones No Gubernamentales; asociaciones internacionales privadas; Costa Rica}

ABSTRACT

This work aims to demonstrate the importance of resuming reflection on the subject of NGO's from the academic research agenda of the Costa Rican social sciences. The first section addresses a number of elements that justify its importance by carrying out a quantitative approach to the phenomenon called "oenegeísmo". There is also an initial approach to the state of the art on the subject, briefly looking at the Costa Rican referents that can be identified in the University of Costa Rica.The second section allows us to recognise the main debates and discussions that prevail on the issue and using this opportunity, we show the problem some of the historical references have, which are traditionally mentioned in the bibliography. In the last section, in order to lay down some foundations to continue the discussion, we present a broad, critical and pluralistic definition of "NGO", while it reviews (and aims to ponder on) the main trends in classification and grading that are internally known the universe of NGO's.

\section{KEY WORDS}

Non-Governmental Organizations; private partnerships; Costa Rica
Artículo recibido:

19 de enero del 2015.

Evaluado:

5 de febrero del 2015.

Aceptado:

26 de marzo del 2015.

Licenciado en Trabajo Social por la Universidad de Costa Rica; investigador ad-honorem del Centro de Investigación en Cultura y Desarrollo (CICDE) de la Universidad Estatal a Distancia (UNED) y funcionario del Departamento de Gestión Humana del Poder Judicial de la República de Costa Rica. El autor investiga desde el 2006 temas sobre las ONG, Organizaciones de la Sociedad Civil, Tercer Sector y Cooperación Internacional desde enfoques críticos. De manera voluntaria, como parte de su vinculación con el CICDE, el autor realiza una investigación concreta sobre las ONG en Costa Rica.

Correo electrónico: guevarameza@gmail.com

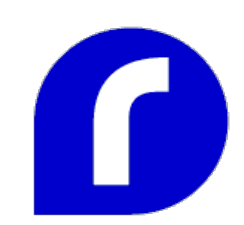

Alex Guevara Meza 


\section{Revisitando las ONG como objeto de estudio: consideraciones para una aproximación crítica inicial}

\section{Introducción}

A primera vista, la presencia de las llamadas Organizaciones No Gubernamentales (ONG) dista mucho de ser un suceso nuevo. En el ámbito latinoamericano, al menos, ya desde finales de los 80 había quienes consideraban que estas organizaciones formaban "parte del paisaje social" de la región (Spoerer, 1988); y en los años 90, tanto en Europa como en Estados Unidos, no dudaban en calificar al fenómeno como una "verdadera revolución asociativa mundial", que podía llegar a ser "la más grande innovación social del siglo XXI" (Salamon et al, 2001). En épocas más recientes, además, desde la palestra de las mismas ONG se reconoce que, por ejemplo, en nuestra subregión centroamericana, las organizaciones no gubernamentales representan uno de "los cuatro jinetes del neoliberalismo" que -junto al narcotráfico, las pandillas y las iglesias evangélicas- "trotan a sus anchas en la tierra arrasada del desempleo, del subempleo, de la amplia gama de empleos por cuenta propia, inciertos y efímeros (...) porque Centroamérica, como todo el mundo, vive en la era del declive del trabajo asalariado". (Rocha, 2011, p. 1).

Más allá de estas valoraciones divergentes, es un hecho que la innegable y manifiesta proliferación exponencial de las ONG durante las últimas dos décadas del siglo pasado, así como (y sobre todo) el cambiante y multifacético 
papel que han venido jugando (en conjunto o individualmente) desde entonces en cada sociedad, sí son (o deberían ser nuevamente) objeto de estudio de especial interés en la agenda de investigación de las ciencias sociales; y con mayor relevancia desde el ámbito académico.

La afirmación anterior toma mayor sentido si, lejos de naturalizar o mimetizar el papel y la funcionalidad actual de estas organizaciones, reconociéramos con la debida rigurosidad científico-social la particularidad y las implicaciones de su puesta en escena, así como su protagonismo indiscutible en ciertos procesos sociales vinculados directamente al ejercicio de profesiones como sociología, psicología, ciencias políticas, trabajo social, ciencias de la comunicación y administración pública; ocupaciones cuyos graduados y graduadas no podemos ignorar que las ONG constituyen, hoy por hoy, uno de nuestros potenciales empleadores. $Y$ es que en efecto, desde hace algunos años estas organizaciones representan -cuando menos- una de las primeras aproximaciones al ejercicio de las disciplinas en mención; ya sea en el marco de una práctica académica, o en la experiencia (a modo casi de "iniciación") del primer espacio de trabajo remunerado en el que empezamos a desempeñarnos.

Por otra parte, la relevancia de retomar críticamente el estudio de las ONG como parte de la agenda de investigación académica de las ciencias sociales debería remarcarse, aún más, si nos percatamos de que al día de hoy no son pocos los países -tanto del Norte como del Sur- donde buena parte de las ONG han pasado a ser pieza fundamental del andamiaje de la política pública dirigida a ciertos sectores sociales o poblaciones específicas.

En relación a este último aspecto, debería al menos llamarnos la atención como investigadores e investigadoras el hecho de que en un país como España, por ejemplo, -cuyo tercer sector ${ }^{1}$ revela un tamaño levemente por debajo de la media internacional, según Ruiz, et al (2001)- el Estado destina por ley el 0,52 \% del Impuesto Sobre la Renta de Personas Físicas (ISPF) para la subvención de las ONG que participan como co-gestoras de servicios sociales (Rossel, 2010). Similarmente, en países de la región latinoamericana como Uruguay, un estudio de la CEPAL demuestra que para el 2005, el 86\% de las organizaciones del tercer sector declaraban mantener convenio con el Estado en la gestión total o parcial (co-gestión) de servicios sociales y asistenciales (Gerstenfeld y Fuentes, 2005). Y en Costa Rica, por su parte, para el último trimestre del 2014, tan solo en el área de niñez y adolescencia, el Patronato Nacional de la Infancia transfirió a las ONG y "otras entidades sin fines de lucro" un monto de poco más de dos mil quinientos millones de colones (exactamente: $₫$ 2.546.811.716,55; según datos institucionales oficiales) (PANI, 2015).

Las lista de justificantes podría extenderse ampliamente si quisiéramos buscar más razones que fundamenten nuestra argumentación en torno a la necesidad de retomar el tema de las ONG como objeto de estudio; sin embar-
1. Termino que junto al de "tejido asociativo", "sector no lucrativo", "espacio público no estatal", entre otros; es utilizado para referirse, genéricamente, al conjunto de organizaciones compuesto por las ONG y otras organizaciones de la sociedad civil. 
2. Rocha se refiere a los norteamericanos James Petras y Henry Veltmeyer. go, ya con solo estos pocos elementos a los que hemos hecho alusión, deberíamos convencernos de que el tema tiene dimensiones e implicaciones nada despreciables. Esto último, tanto con respecto a los aportes que la academia está llamada a brindar, a efectos de esclarecer ciertas complejidades y procesos sociales como el que tiene que ver con las ONG; asimismo, con respecto a las oportunidades de empleo y las condiciones laborales a las que podemos aspirar como trabajadores y trabajadoras (intelectuales) salariadas, una vez finalizada nuestra formación académica y profesional básica.

Por todo lo anterior, es que consideramos que cualquier estudio acerca del papel de las organizaciones en cuestión no puede ser unilateral, sino que debe analizar, dialécticamente, los múltiples factores que determinan su presencia, funcionamiento y legitimidad social. Sobre todo, debe partir del reconocimiento de que estas organizaciones no han desempeñado la misma función, y tampoco el contexto histórico a nivel político y cultural en el que han operado ha sido estático e inmutable. Además, vale tener en cuenta en primera instancia que, como afirma O'Neill (2004), es preciso reconocer que estas organizaciones, metafóricamente, "son como los hongos: los hay sanos y nutritivos y los hay venenosos y fatales".

Así las cosas, en la misma lógica que propone Torres-Rivas (2001) al referirse a la relación que existe entre la sociedad civil y la vida política de un determinado Estado, consideramos que el papel y la funcionalidad de las ONG no responde a un patrón normativo. Por el contrario, está determinado por una multiplicidad de factores dentro de los que resalta la naturaleza de la sociedad política (instituciones estatales, partidos políticos, cultura participativa, normas, y valores propios de la cultura simbólica) y la tradición asociacionista que predomina en dicho territorio. En los países dependientes o "en desarrollo", por su parte, el papel y la funcionalidad de las ONG se encuentra tensionado y determinado por el comportamiento de la cooperación internacional para el desarrollo, la vertiente del desarrollo económico y social que privilegie el país, así como la trayectoria democrática del régimen político, entre otros muchos elementos. En tal sentido, como afirma Rocha (2011) al replicar a dos de los críticos más radicales de las ONG2: "aunque sólo la ceguera interesada podría regatear la mucha razón que hay en el cuestionamiento (...) a la trayectoria política -con destino apolítico y apolitizante- de las ONG, a su condena sin reservas cabe oponerle un bloque de evidencias y un enfoque histórico divergente".

Consideramos por tanto que, al día de hoy, es inaceptable -y en todo caso poco consecuente desde el punto de vista científico- ignorar o por el contrario naturalizar y considerar "parte del paisaje social" a las ONG. No obstante, creemos que a la hora de ocuparnos de ellas en tanto objeto y problema de estudio es igualmente reprochable caer en descalificaciones a priori; reproducir generalizaciones que no reconocen la singularidad de cada contexto y momento histórico; e igualmente, ignorar de manera deliberada algunas evi- 
dencias concretas que, de manera inevitable, denotan algunos efectos positivos (transitorios o permanentes) del accionar de las ONG.

Por tales razones - y al margen de cualquier ingenuidad o perversión político ideológica que ignore la naturaleza y dinámica del nuevo imperialismo y sus implicaciones para los países dependientes-, proceder en la labor investigativa de espaldas a los aspectos antes señalados es ser cómplices de la simplicidad que caracteriza a buena parte de los análisis sobre el tema; los cuales, además, ignoran la complejidad del fenómeno, y terminan reforzando visiones unilaterales o ideologizadas acerca del papel de las organizaciones en cuestión.

El presente artículo se propone retomar la reflexión desde la agenda de investigación de las ciencias sociales costarricenses en torno al tema de las ONG. El trabajo se divide en tres apartados, y en ellos están vertidos, sintéticamente, los resultados preliminares de la investigación que el autor viene desarrollando de manera permanente desde distintos espacios y contextos académicos en donde ha tenido la oportunidad de desarrollar dicha actividad, paralelo a su labor de funcionario público.

Para lograr su propósito, este artículo inicia con una breve introducción que no pretende más que realizar un primer llamado de atención. Ya en el contenido, en el primero de los apartados se presenta una serie de elementos que pretenden abonar a la identificación de los justificantes que sostienen la necesidad de retomar desde la academia este tema de estudio. Se recurre para ello a un intento de cuantificación del fenómeno llamado "oenegeísmo", a efectos de dimensionar el problema de estudio; asimismo, se realiza una aproximación general al estado del arte, deteniéndonos brevemente en los referentes costarricenses que se identifican en la Universidad de Costa Rica.

Intentando ilustrar la complejidad del asunto, en el segundo apartado del artículo nos detenemos en la presentación de algunas de las discusiones y debates principales que existen respecto al tema, aprovechando para problematizar algunas de las referencias históricas a las que tradicionalmente se hace alusión en la mayor parte de la bibliografía. Asimismo, se discute el carácter ambiguo y polisémico de la denominación bajo la cual se conoce a estas organizaciones de las que aquí se habla. En el último apartado, con el propósito de dejar sentadas algunas bases para continuar con la discusión, se ensaya una definición amplia, crítica y plural, al tiempo que se pasa revista (y se intenta ponderar) a las principales tendencias de clasificación y tipificación que se conocen a lo interno del universo de las ONG. 
3. La predominancia e influencia de las organizaciones "Sin Fronteras" (Médicos, Veterinarios, Periodistas, Policías, Payasos, etc.) en Europa y Estados Unidos, denota la aparición de un fenómeno en sí mismo (el llamado "sinfronterismo")

\section{Elementos para (re)dimensionar un problema de estudio que ha venido diluyéndose}

\section{Breve panorama sobre la trayectoria y legitimidad social de las ONG}

En términos generales, la importancia en sí de las ONG pareciera estar fuera de duda para el sentido común de ciudadanos y ciudadanas alrededor del mundo. Es casi imposible identificar país o región, actividad humana o institución social donde estas organizaciones no estén presentes. Podría decirse, incluso, que en el imaginario social de las sociedades contemporáneas, el "buen hacer" de estas organizaciones alcanza el reconocimiento casi "natural" por parte de la ciudadanía.

Y es que en poco menos de 40 años, a partir de su "explosivo resurgir" (Cernea, 1989), estas organizaciones han llegado a constituirse en una importante referencia (cuando no, en sinónimo directo) a la hora que se evocan conceptos y términos como el de sociedad civil o participación ciudadana; cuando se piensa en la idea de cooperación internacional; o cuando se invocan valores como la solidaridad y el humanitarismo.

Precisamente en el campo de la acción humanitaria, un reflejo del reconocimiento que se le ha dado a las ONG a nivel mundial lo ilustra el hecho -entre muchos otros- de que para el año 1999, la organización Médicos sin Fronte$\operatorname{ras}^{3}$ (una de las más reconocidas internacionalmente en su campo) recibió el Premio Nobel de la Paz, "por su pionera labor humanitaria en varios continentes". Es de recordar, sin embargo, que ya desde 1977, Amnistía Internacional había recibido el mismo premio por "su campaña contra la tortura" (Derechos Humanos, 1997).

Más allá de estos ejemplos puntuales, es innegable que el conjunto de las ONG -como afirma Balbis (2001)- al día de hoy han ganado visibilidad, reconocimiento y legitimidad ante gobiernos, agencias de cooperación (internacionales y locales), organismos intergubernamentales de talle mundial y regional; y muy visiblemente, en años recientes, ante los medios de comunicación y la opinión pública en general (López-Rey, 2004; 2006 a; 2006 b; y 2006 c).

A estas organizaciones sociales se les reconoce hoy día no solo por su tradicional y primigenio accionar en el referido terreno de la ayuda humanitaria -encarnada, por ejemplo, en organizaciones tan reconocidas, antiguas y emblemáticas como Oxfam, Caritas, Manos Unidas o la misma Amnistía Internacional-; además de esto, desde finales de la década de los 70 , el reconocimiento público por su labor se debe también al papel que se considera han jugado de manera destacada en el desarrollo de los países del llamado Tercer Mundo. 
Y es que, en efecto, en el campo del desarrollo strictu sensu, a nivel local o nacional, la mayoría de autoridades de los países alrededor del mundo valoran a las ONG prácticamente en los mismos términos que al Estado y al sector privado. Y en el escenario más amplio de las relaciones internacionales, por su parte, las ONG son consideradas -nada más y nada menos- "uno de los tres principales agentes involucrados en las diversas fases de los proyectos de desarrollo" (Tussie y Tuozzo, 1997); justamente al lado de los gobiernos y los organismos multilaterales.

Por citar un ejemplo también de esto último, podríamos destacar que el protagonismo de las ONG en este campo del desarrollo ha sido tanto que, en Centroamérica -para no ir muy lejos- a inicios de la década de los 90 se les delegó a las ONGs hondureñas la ejecución completa del Fondo de Inversión Social de su país (Irías, 1996); un tipo de programa que los Organismos Financieros Internaciones (OFIs) utilizaron como instrumento de compensación, luego de verse fuertemente presionados a prestar atención y a destinar recursos para aminorar los nefastos efectos sociales que dejó tras de sí la implementación de los Programas de Ajuste Estructural (PAE's) impuestos por ellos mismos en todo Latinoamérica.

Por cierto que este tipo de fondo de financiamiento -también llamado Fondo Social de Emergencia- fue de uso general por aquella época en la mayor parte de los países en los que se operaban los PAE, siendo paradigmáticamente conocido -y uno de los primeros- el caso del Fondo Social Boliviano de Emergencia. Dicho fondo funcionó temporalmente desde 1986 y hasta mediados de los 90, y se convirtió en el receptor de un monto cercano al cuarto de millón de dólares -procedentes del exterior-; de los cuales poco más del $30 \%$ fue administrado por las ONG. Estas últimas, además fueron las responsables de todo el dinero que se destinó para apoyar actividades productivas, así como de la mitad de los recursos orientados a proyectos de asistencia social (Arellano-López y Petras, 1994; Petras, 1997 b).

\section{De difícil cuantificación, pero de dimensiones definitivamente considerables}

En lo referente a cifras que de alguna manera permitan dimensionar la presencia de este fenómeno -que algunos/as han llamado "oenegización" (Rabotnikof, 2001; García Linera, 2011 y 2012; Rocha, 2011; entre otras y otros)es difícil llegar a conocer (tan siquiera por aproximación) el número de las ONG que actualmente operan en el mundo. En cuanto a este aspecto, las estimaciones varían significativamente de acuerdo a las fuentes y a la ubicación de estas en uno u otro lado del debate que este tema suscita, así como por la concepción de ONG que se adopte (Palladino, 2006). 
4. Las estimaciones más recientes se realizan con respecto al "tercer sector" o a la "sociedad civil" en general, lo cual rebasa el universo de las ONG en sentido estricto.
5. Organismo autónomo del gobierno de los EE.UU, fundada por el Congreso en el año 1969 "para canalizar la asistencia para el desarrollo hacia sectores pobres organizados de América Latina y el Caribe".
Pese a lo anterior, se pueden encontrar coincidencias generales en las estimaciones (lamentablemente no tan recientes como quisiéramos) ${ }^{4}$ que indican que para inicios del año 2000 se registraban en el mundo no menos de 100.000 de estas organizaciones. De este monto, aproximadamente 50.000 se ubicaban en el Tercer Mundo y recibían un total de más de 10.000 millones de dólares por parte de instituciones financieras internacionales y de entidades oficiales y locales europeas, estadounidenses y japonesas (Petras, 1997a; Pi i, 2006; Petras, 1997 b, 1997 c, Petras y Veltmeyer 2002 y 2004).

\section{Algunos datos generales a nivel de la región latinoamericana}

En América Latina, Bombarolo et al, (1992) y García-Huidobro (1989) coinciden en que, de acuerdo a una recopilación de directorios de las ONG realizada por la Inter-American Fundations (IAF) ${ }^{5}$, ya para finales de 1990 existían en la región alrededor de 11.000 ONG. Según estos mismos autores, a finales de la década de los 80 , la proliferación de las ONG en la región motivó una cantidad considerable de esfuerzos investigativos orientados a conocer el número de organizaciones que trabajaban en Latinoamérica, así como las actividades específicas a las que estas se dedicaban.

Así entonces, a partir de los datos generados por los estudios en mención, los autores señalan que en una muestra de tan solo 10 países (Argentina, Brasil, Colombia, Ecuador, Guatemala, Honduras, México, Paraguay, Perú, República Dominicana y Uruguay), en aquel momento se registraban casi 4.000 organizaciones no gubernamentales; todas estas, fundadas entre finales de la década de los 80 e inicios de los 90. Más recientemente, según Rocha (2011), para el 2004 las agencias europeas colocaban en América Latina una parte significativa de su cartera total de proyectos: Misereor puso 43.5 de sus casi 100 millones de euros; Cordaid 17.4 de 150; Hivos 16.2 de 65; Intermon 11.6 de 25; Trocaire 9 de 37; Diakonia 10 de 28; e IBIS 7.3 de 20.6. (p. 36).

\section{En la subregión centroamericana}

Si nos vamos al plano subregional, por ejemplo, el fenómeno de las ONG tampoco pasa desapercibido. Los mismos autores arriba mencionados (Bombarolo et al, 1992) señalan, por ejemplo, que durante la década de los 80 , Centroamérica experimentó igualmente una explosión de ONG. Para estos autores, el fenómeno incluso fue impulsado por los gobiernos del área, los cuales contaban para ello con cuantiosas sumas de financiamiento proporcionadas, sobre todo, por la Agencia de los Estados Unidos para el Desarrollo Internacional (US-AID) y una buena cantidad de agencias europeas. 
Particularmente esta subregión, como lo indica Rocha (2011), fue terreno fértil para el surgimiento de las ONG durante el periodo de la posguerra, y especialmente, durante la época de conflictos armados que anegaron a los países centroamericanos de sangre, dolor y destrucción. Según este autor, a partir de las insurrecciones locales, numerosas ONG internacionales -y las contrapartes locales fundadas por las primeras-, desarrollaron de manera progresiva innumerables y encomiables tareas; sobre todo en labores de búsqueda de personas desaparecidas durante y tras los conflictos bélicos, así como en lo relacionado con los movimientos migratorios derivados del conflicto y que terminaron siendo un estímulo para la proliferación y fortalecimiento de las ONG en países fuera de la subregión como México (Aguayo, 1992; CODEHUCA, 1994; Contreras, 1998; Reuben, 1991). Tales acciones, sin embargo, no por ello dejaron de ser cuestionadas por la contribución al declive del trabajo asalariado y a la precarización del empleo (Rocha, 2011), aunado a la crítica tradicional por su cortoplacismo, la tendencia a la despolitización y la gran dependencia del financiamiento externo -común a la generalidad de las ONG.

Es importante destacar además que en la mayor parte de los países del istmo se hizo evidente con meridiana claridad el paralelismo entre el proceso de achicamiento del Estado y la explosión de las ONG; en este sentido, en algunos casos, el propio gobierno transfería recursos humanos e infraestructurales hacia las ONG, siendo así que:

Antiguos cuadros medios (...) del Instituto Nacional Agrario en Honduras [por ejemplo] montaron ONG especializadas en desarrollo rural y en toda la gama de temas agrarios y ambientales. Fiscales guatemaltecos, hastiados de la corrupción estatal, se parapetaron en ONG especializadas en derechos humanos, desde cuyas barricadas impugnan los abusos del sector público. En Nicaragua [por su parte] (...) a veces instituciones estatales se convirtieron en ONG: el Centro de Investigaciones y Estudios de la Reforma Agraria (CIERA) fue adjudicado íntegro (...) para que lo convirtiera en el Centro de Investigación y Promoción para el Desarrollo Rural y Social (CIPRES) (...) [por su parte] exfuncionarios del Instituto Nicaragüense de Estudios Territoriales (INTER) crearon el Centro Humboldt, especializado en desastres naturales (...) y así podríamos continuar con temas de educación, salud agrarismo (Rocha, 2011, p. 36). 
6. Existen tres grandes formas de cooperación internacional: multilateral (como la de los organismos intergubernamentales como el BID o la ONU); la cooperación bilateral (de gobierno a gobierno) y la llamada "cooperación privada o solidaria", en la que suele enmarcarse a un número importante de ONG de tendencia religiosa o laica.
Cabe anotar, por otra parte, la particularidad de la subregión en lo referente al caso nicaragüense (Rocha, 2011; Morales, 2010; Reuben, 1991; entre otros/as). O'Neill (2004), por ejemplo, advierte que solo dos países en el mundo han logrado ser "niños bonitos", mimados por la cooperación multilateral, bilateral y privada ${ }^{6}$ (ONG), Mozambique y Nicaragua:

Desde 1979 -cuando se comenzaron a guardar estadísticas- hasta 2003, Nicaragua ha recibido en donaciones de la cooperación bilateral, de gobierno a gobierno, por 14 mil 681 millones de dólares (...) es el país más favorecido por la cooperación en toda América Latina. En el año 2003, el 28\% del PIB (...) provino de la cooperación. Es el porcentaje más alto en todo el continente. En Honduras, el país más próximo en geografía y en pobreza (...) la cooperación aporta sólo el 6\% del PIB. En El Salvador, la proporción es el 2\%. En México, Perú, Ecuador y países del Cono Sur, no llega ni al 1\%. (...) De la cooperación solidaria [por su parte] durante los años 80 no hay datos confiables; [sin embargo] a partir de los años 90 -cuando todas las organizaciones con presencia en Nicaragua están obligadas a informar al gobierno de sus recursos- ya hay datos. En el año 2000, por ejemplo, la cooperación privada, la de las ONG internacionales, aportó 152 millones de dólares. En 2003 se redujo: 90 millones de dólares (...) No son datos totalmente exactos, porque hay muchos ONG que no tienen oficinas en Nicaragua -Misereor o CORDAID, por citar dos-, pero que sí envían contribuciones significativas. Estimo, pues, que el dato real para 2003 es de 130 millones de dólares (párr. 11 y 26).

Tal y como se desprende de la cita anterior, es claro que Nicaragua, históricamente, ha sido destino privilegiado de la acción de las ONG; y esto, principalmente, por parte de agencias de cooperación y de las ONG (del Norte) europeas y norteamericanas. En este sentido, resulta ilustrativo, por ejemplo, que ya desde el año 1990, de un total aproximado de 300 ONG de los países de la OCDE que ejercían su labor en Centroamérica, casi la mitad (48\%) desarrollaba proyectos en Nicaragua, orientándose la mayoría de estos a apoyar, en aquella época, la política oficial del país (Morales, 2010). En años más re- 
cientes, un estudio que realizó, en el 2005, una agencia de cooperación austriaca encontró que:

Aparentemente existen aproximadamente 1,800 ONG en Nicaragua, alrededor del 20 por ciento de la ayuda a Nicaragua (USD 200 millones) es canalizada a través de ONG. La plataforma de ONG más importante es la Coordinadora Civil, que cuenta con unos 300 miembros y se involucra en el diálogo político con el gobierno de Nicaragua y con los donantes. En general, la sociedad civil nicaragüense de la cual las ONG son la columna vertebral- sigue siendo considerada muy débil, fragmentada, altamente dependiente del apoyo externo, y con relativamente poca influencia en la política nacional. Sin embargo, la sociedad civil nicaragüense ha ganado fuerza y autonomía, y se ha convertido en una contraparte seria de los donantes internacionales y del gobierno nacional. Tradicionalmente, el enfoque de las ONG nicaragüenses ha sido la implementación de proyectos y la entrega de servicios a sus comunidades (Inbas y Lrsocialresearch, 2005, p.15).

Mientras tanto, ya para el año 2011, en una línea similar Rocha señala:

Hace pocos años el Ministerio de Gobernación hablaba de 4,360 asociaciones sin fines de lucro en Nicaragua y de muchas más sin personería jurídica. El Directorio de ONG apenas alcanzó a registrar los datos de 322 ONG en el año 2000. De ese limitado conjunto, únicamente el 6\% había surgido antes de 1980. La década de los 80 vio nacer el 22\%. En los años 90 tuvo lugar la explosión demográfica: $72 \%$ de las ONG que existían en el 2000 nacieron en la Nicaragua neoliberal (pp.35-36). 


\section{En el contexto costarricense}

Costa Rica, como se sabe, es el país de Centroamérica que junto a Panamá recibe el menor volumen de cooperación internacional para el desarrollo incluido, desde luego, el financiamiento que se canaliza por la vía de las ONG (Morales, 2010). Aunado a esto, históricamente, el marco contextual que ofrece al país para el desarrollo de las ONG es bastante diferente respecto al resto de la subregión, en tanto que, como afirma Reuben (1991):

si bien por una parte el Estado presenta un marco de tolerancia que facilita el surgimiento y desenvolvimiento de este tipo de organización y su relación con los grupos de base; por otra parte el Estado -por medio de la política social- ha ocupado espacios de trabajo que en otros contextos de la región han sido de dominio exclusivo o preponderante de las ONG (p. 262).

Ejemplo de esto último es el caso de los Fondos Sociales de Emergencia -que en Costa Rica lleva el nombre de Fondo de Desarrollo Social y Asignaciones Familiares (FODESAF)- y que a diferencia del resto de istmo (y de muchos países de la región latinoamericana en general) no es una estrategia u organismo transitorio, sino más bien permanente; al mismo tiempo, su financiamiento es con fondos públicos (garantizados por ley) y no con montos de la cooperación internacional.

Más allá de esta particularidad anotada respecto de nuestro país, en Costa Rica también es visible el fenómeno de las ONG. En tiempos neoliberales, cuando abundan los discursos de cuestionamiento a la eficiencia del Estado y la tendencia a la focalización, privatización y descentralización de la política social y asistencial, se han dado las condiciones para que las ONG resurjan y se fortalezcan en algunos campos. Así entonces, dentro de estos últimos, el campo medioambiental es el principal espacio de proliferación reciente de organizaciones no gubernamentales (nacionales e internacionales); seguido del ámbito de niñez y adolescencia, así como el de la asistencia social.

Referente a este último campo, en un estudio del 2008 sobre las ONG se detectó que son más de 500 las organizaciones que se encargan de operacionalizar la política asistencial del Estado costarricense. Dicha cantidad de organizaciones es la que se registra en el Departamento Instituciones de Bienestar Social (DIBISO) del Instituto Mixto de Ayuda Social (IMAS), unidad encargada de todos los asuntos relacionados con las ONG que se dedican a la atención de la población en situación de pobreza, pobreza extrema, riesgo social y abandono (Boza y Monge, 2008 y 2010). 
Por otra parte, cuantitativamente menos significativo -pero no por ello menos importante- es el caso de la política pública que el gobierno costarricense dirige a la atención y protección de la población menor de edad que vive en el país. En este ámbito, el Sistema Nacional de Protección Integral (SNPI), que la legislación nacional en la materia ordena establecer, contempla a la sociedad civil como un actor que integra dicho sistema. La sociedad civil participa en el SNPI organizada en dos grandes bloques: por un lado, la Coordinadora Costarricense de Organizaciones Sociales para la Promoción y Defensa de los Derechos de la Niñez y la Adolescencia (COSECODENI) ${ }^{7}$-formada en 7 . COSECODENI es una 1998, que agrupa aproximadamente 15 organizaciones de defensa de los de- plataforma que reagrupa a rechos de las personas menores de edad-; por otro lado, la Unión de Institu- referencia a la Convención ciones Privadas de Atención a la Niñez (UNIPRIN) -establecida en 1977, y sobre los Derechos del que integra a 56 ONG y asociaciones privadas (Ruíz, 2005; PANI-UNICEF, Niño, centrándose en el 2009).

el cabildeo y la incidencia política. Se vincula a varias Relacionado con lo anterior, destaca que en el Informe de Gestión Institucio- redes de carácter nacional, nal del Patronato Nacional de la Infancia (PANI) del año 2013, esta institución coordinadora Subregional rectora mantenía convenio con 65 ONG. Las cuales atendían cerca del 80\% de ONGs; Red

del total de población menor de edad a cargo de la institución; población que Latinoamericana de ONG y se ubica transitoriamente en alguna de estas ONG que hacen las veces de Suiza. "alternativa de protección" debido a la condición de riesgo social y vulnerabilidad que experimentan (PANI, 2013). Vale anotar a este respecto, que pese a la sensibilidad del tema de la protección integral de niños, niñas y adolescentes, y a la trascendencia que reviste la supervisión de la calidad de la atención integral hacia esta población vulnerable, datos arrojados por el propio PANI en el Informe de Gestión del año siguiente (20014) señalan modestamente que:

Para mejorar la calidad de vida de niños, niñas y adolescentes en alternativas de protección, el Departamento de Acreditación logró el fortalecimiento del equipo humano con 2 trabajadoras sociales más una psicóloga, se dieron 16 permisos de funcionamiento, se certificaron con calidad 3 organizaciones y se dio la supervisión de 65 ONG en donde se protegieron solo en el 2013 un total de 1766 niño, niña y adolescentes y se coordinó con 43 de atención diurna para un total de 3236 personas menores de edad. Además de supervisar la atención integral a 631 niños, niñas y adolescentes en la Red Nacional de Cuido (PANI, 2014, p. 46).

En cuanto a las ONG del área ambiental, sin temor a equivocarnos podemos afirmar que este es el ámbito de acción de las ONG en Costa Rica que me- 
nor atención ha recibido desde la actividad investigativa; lo anterior, pese a ser uno de los temas que vehiculizan mayor cantidad de cooperación internacional, tanto por el componente indentitario "ecológico", "verde" o "conservacionista" que supone la identidad nacional y la reputación que se tiene a nivel internacional (pese a los mitos que ello encierra), como por el contenido ideológico que puede esconderse detrás del tema ambiental en el contexto reciente de crisis ecológica y civilizatoria. Contexto este en que la sensibilidad social al respecto, valida casi sin cuestionar cualquier iniciativa que se autodefina "ecológica" o "conservacionista".

Es de destacar, además, que tal estado de cosas hace que con facilidad se pierda de vista y se carezca de criticidad respecto al trasfondo político de la estrategia global de la llamada "gobernanza ambiental" y que, a diferencia de otros temas donde la cooperación internacional y el estímulo a las ONG ha ocupado en alguna medida las agendas de investigación social; la cooperación internacional en medio ambiente no ha sido sometida al mismo escrutinio ni responde a los mismos mandatos de transparencia y fiscalización. En este sentido, es revelador lo que plantea un estudio reciente sobre cooperación internacional en medio ambiente:

Para ofrecer una idea general, la ayuda para el MA creció del 50\% entre 1998 y 2010. (...) Desde 1980 hasta finales del siglo XX, la ayuda medioambiental se incrementó sustancialmente, de aproximadamente \$ 3 mil millones en los '80 por año a cerca de \$ 10 mil millones en 1990. (...) a inicio de los años 2000 la ayuda verde se aproximaba a los 20 mil millones para llegar a más de 100 mil millones en 2011. (OECD/DAC-AidData, 2012). De estos 100 mil millones, más de la mitad se otorgó para proyectos generales ambientales (56 mil millones); la segunda parte se otorgó para proyectos de agua y saneamiento (33.2 mil millones) mientras la última parte (8.2 mil millones) se dio para proyectos con componente ambiental transversal a otros temas como biodiversidad, conservación natural, etc. (OECD Statistics CRS Bilateral y multilateral 2011). Los principales donantes de ayuda "verde" en la última década a nivel mundial han sido los países nórdicos europeos así como otros países de la Unión Europea y Japón. Estados Unidos ha bajado desde 1980 su influencia en temas ambientales a nivel mundial, si bien como veremos 
después, es el principal donante "verde" en América Latina (Lucate-

Ilo, 2014, p. 40-41).

En medio de este panorama, las ONG con presencia en Costa Rica que trabajan en el área ambiental, al parecer, han recibido poca atención por parte de la academia, pese a que, por ejemplo, solo en el Programa de Restauración de Tortugas Marinas (PRETOMA), se registran más de 40 organizaciones nacionales y 30 internacionales que brindan apoyo a dicho programa (Ver sitio web: http://www.tortugamarina.org/) y a que operen redes de articulación como la Fundación para el Desarrollo de la Cordillera Volcánica Central (FUNDECOR); la Fundación Costarricense para Protección de la Naturaleza en Guanacaste (FUNDECONGO) que agrupa una cantidad grande de organizaciones y que canalizan recursos financieros de cooperación internacional desde hace varias décadas. Asimismo, pese a que existan programas en el país como el Pago por Servicios ambientales (PSA) -implementado por el Fondo Nacional de Financiamiento Forestal (FONAFIFO)- o el Programa de Pequeñas Donaciones (PPD) del Programa de Naciones Unidas para el Desarrollo (PNUD), que además de recibir financiamiento internacional con un porcentaje considerado de donantes privados (dentro de los que se contemplan varias ONG del Norte), ponen a disposición de una cantidad copiosa de organizaciones de la sociedad civil (dentro de las que destacan las ONG locales) sumas de dinero considerables, de las cuales no se tiene mayor control.

\section{Contribuciones al Estado del Arte sobre ONG}

\section{Estudios pioneros poco explorados y escasamente analizados}

Desde los años sesenta y hasta aproximadamente el primer lustro del nuevo milenio, el rol de las ONG en la acción humanitaria, la lucha contra la pobreza, la movilización y participación social, la autogestión, etc., mereció una larga serie de estudios, tanto de parte del medio académico como de organismos intergubernamentales (ONU, UNRISD, FAO, OIT, UNESCO, PNUD, PNUMA, OMS; etc.). De igual manera - y más claramente a partir de la última década del siglo pasado-, se sumaron a los esfuerzos de investigación las mismas organizaciones que se autodenominan ONG (individualmente 0 desde la redes de articulación), así como sus cooperantes internacionales. Por otra parte, han venido multiplicándose las reuniones, declaraciones y resoluciones de carácter internacional que reconocen y promueven el rol de las ONG como actores del desarrollo humano; lo mismo que los foros de discusión, las iniciativas para la sistematización de experiencias, las redes internacionales y los proyectos para mejorar su gestión y sostenibilidad financiera. 
No obstante lo anterior, indiscutiblemente los trabajos dominantes sobre la cuestión de las ONG y de los sectores asociativos en general son de origen anglosajón -más específicamente, norteamericano-, siendo más recientes y escasos en los ámbitos francófono e hispano. Entre los primeros se destacan en especial los que actualmente se llevan a cabo por la International Society for Third-Sector Research (ISTR) en el seno de la Johns Hopkins University, aunque también otras prestigiosas universidades como Yale en los Estados Unidos y la de Manchester y la London School of Economics en Inglaterra cuentan con áreas especializadas en el estudio de las ONG y sobre todo de la sociedad civil en general.

En el ámbito latinoamericano, hasta entrado el siglo XXI, la escasa producción de análisis sistemáticos y de estudios empíricos sobre el tema -a excepción de los estudios realizados por, o con el impulso de, la Banca Multilateral de Desarrollo- reconoce empero algunos antecedentes desde los años setenta a nivel de ciertos países como Argentina, Perú, Bolivia, Chile, Ecuador, Nicaragua, y México inicialmente; así como Brasil, Uruguay, Colombia, y países de Centroamérica como Guatemala, Honduras, El Salvador, de manera más reciente. La mayor parte de los estudios que en general se logran ubicar fueron impulsados y desarrollados por organismos internacionales y agencias de cooperación con sede en la región. Muy especialmente por instituciones de integración regional en el caso centroamericano (IICA, OEA, OPS, IDHH), así como las iniciativas desarrolladas por las mismas organizaciones articuladas en redes, destacando entre estos últimos la copiosa cantidad de trabajos desarrollados desde la Asociación Latinoamericana de Organizaciones de Promoción (ALOP). Los centros académicos han tenido también un papel destacado (FLACSO, principalmente; y en menor medida y solo a partir del primer lustro del siglo XXI, CLACSO), siendo especialmente relevante la serie de estudios sobre el tema de las ONG y el desarrollo rural que FLACSO-Chile realizó entre mediados de los 80 e inicios de los 90; asimismo, el que realizara FLACSO-Argentina sobre la sociedad civil y la banca multilateral de desarroIlo, en la segunda mitad de los 90, y recopilados en Tussie, 1997.

En todos estos antecedentes, la mayoría de las veces las ONG son objetos de estudio en relación a los vínculos que estas establecen en cuanto a los temas de desarrollo rural (Hilhorst, 1983; Furche, 1982; Gómez, 1987 a; 1897 b; 1988; 1992 a, y 1992 b; Reuben 1987); desarrollo local (Cernea, 1989); concertación a nivel local; la educación popular o educación de adultos (Chateau y Martinic, 1989; García y Martinic, 1984; UNESCO-CAAL, 1988; García, 1989); el desarrollo urbano (Agurto y Piña, 1988; Piña, 1989); la autogestión (Padrón, 1981); los procesos de democratización; investigación o producción científica (Lladser, 1986; Catalán, 1987); las migraciones y los derechos humanos (Aguayo, 1992; CODEHUCA), la integración regional (Reuben, 1991; Enríquez, 1997a, y 1997b; Serbin, 1997; Monge, 1999), desarrollo sostenible (Corrales, Machado y Salgado, 1995); política públicas (Casey, 
1997) y de manera más reciente, la gobernanza (Balbis, 2001), el capital humano (Gerstenfeld, y Fuentes, 2005), entre otros.

Un vistazo a la investigación académica sobre el tema de ONG desde la Universidad de Costa Rica

El tema de las organizaciones no gubernamentales viene siendo estudiado, académicamente, en Costa Rica desde inicios de la década de los 90. Las investigaciones que incursionaron en la temática directamente se realizaron en su mayor parte desde las Ciencias Sociales, y en menor medida desde el Derecho y la Administración Pública. En el campo de las Ciencias Sociales, Trabajo Social es la categoría profesional que ha realizado mayor investigación, seguida por el Derecho y en otro ámbito, la Administración pública. Aunado a esto se registran unas pocas investigaciones desde las Ciencias Políticas, la Psicología, así como de Administración de Empresas; desde esta última profesión, con un enfoque que privilegia la "eficiencia" y "competitividad" de las organizaciones.

Como objeto de estudio directamente, las ONG aparecen en la mayoría de estas pesquisas mencionadas en estrecho vínculo con la gestión de la política pública, y muy especialmente, en lo que refiere a la participación de estas organizaciones en la gestión política social a nivel general (Calvo y otros, 1993), así también a nivel más específico en áreas tales como niñez y adolescencia (Alpízar, Carvajal y Cedeño, 2003; Ruiz, 2005; Hidalgo y Largaespada, 2009; Fonseca, Salazar y Valerio, 2009; Gutiérrez, Mora y Vargas, 2002), personas adultas mayores (Araya y Jiménez, 2005), asistencia social y grupos vulnerables (Boza y Monge, 2008) personas en situación de indigencia (Brenes y Chacón 2009).

Destaca, por otra parte, que desde el Derecho, las investigaciones en la temática se han dirigido a estudiar el estatus jurídico de las ONG, su papel en la protección de los derechos humanos, así como a la posibilidad acceder a los mecanismos de resolución de controversias en el marco del Derecho internacional de Inversión (Jiménez, 1996; Campos y Salazar, 1987; y Sauma, 2011).

En términos generales, el abordaje que predomina en estas investigaciones se caracteriza por su tendencia a privilegiar la descripción y definiciones de estas organizaciones, asimismo el análisis de la gestión interna, contemplando aspectos como la captación de recursos, las metodologías de intervención utilizadas y evaluación del trabajo realizado en comparación con las metas propuestas por la misma organización. En menor medida, los estudios identificados se han ocupado del marco legal en que se inscriben las organizaciones no gubernamentales. 
Hasta el momento en que surge en el contexto académico costarricense la primera investigación crítica específica sobre las ONG (Boza y Monge, 2008), la posición dominante que reflejaban tales investigaciones era de legitimidad (casi incuestionable) en torno a la imagen y funcionalidad de este tipo de organizaciones. En todos los estudios anteriores, se consideraba a este tipo de organizaciones como agentes aliados en la gestión de la pública -e incluso como ideales sustitutos en algunas áreas- considerándoseles como sinónimo de espacios alternativos a la acción estatal, y diferenciándose de este último en cuanto a las prácticas burocráticas, el clientelismo y en cierto grado su ineficiencia. En fin, se les atribuía (a priori) una supuesta naturaleza democrática, participativa, flexible, con capacidad de convocatoria entre la población y con la representatividad de grupos subalternos en los espacios de decisión gubernamental y en foros internacionales.

Cabe acotar, sin embargo, que pese al ambiente optimista de los estudios que se iniciaron en la temática, una lectura más atenta y crítica de estos permite advertir que la mayoría de las investigaciones reconoce que las ONG tienden a privilegiar una visión cortoplacista en la ejecución de sus actividades; cuentan con limitaciones (o del todo están imposibilitadas) para coordinar acciones entre sí o con otros entes (incluso públicos), tienen poco impacto en sus acciones, evidencian escasa supervisión y apoyo técnico financiero por parte de las autoridades sectoriales del campo en el que se desempeñan, entre otras.

Desde el discurso político nacional dominante, por su parte, paralelamente a partir de inicios de los 90 - y a tono con el discurso de los organismos de financiamiento internacional- se volvió recurrente la afirmación acerca de una supuesta relación directa (natural y deshistorizada) entre las ONG y valores como la solidaridad, la justicia y la cooperación, entre otros; además de atribuírseles actitudes como el compromiso social, la participación y la lucha por el "cambio social" (Valverde, 1996; Calderón y Prado, 1996; Bejarano y Víquez, 1996); posiciones claramente materializadas en el número especial (Vol. 4; No. 2) sobre el tema que publicara en 1996 la Revista Parlamentaria de la Asamblea Legislativa; República de Costa Rica.

A partir de la revisión general y esquemática de las investigaciones identificadas, así como de documentos y literatura local, se deriva claramente que las vinculaciones entre las ONG y el Estado es un hecho que en Costa Rica es evidente y no puede negarse. De entrada, es de destacar la relación con la institucionalidad pública y los intentos de regulación que existen, siendo que -precario o no- es posible verificar un marco jurídico que regula el nacimiento, funcionamiento y la disolución de una ONG. Es claro que mayoritariamente, como afirma Boza y Monge (2008), estas organizaciones son inscritas ante la Dirección de Registro Público bajo la forma de asociaciones o fundaciones, y a partir de este momento, legitiman formalmente ante el Estado costarricense su existencia 
La inscripción oficial ante la autoridad del ramo, define las posibilidades y límites objetivos en el marco de la institucionalidad costarricense, configurando así la naturaleza de dichas organizaciones. A pesar de su importancia, el vínculo o estatus jurídico de las ONG ha pasado casi inadvertido para las y los investigadores sobre el tema, inclusive para aquellos autores que depositan en las ONG fuertes esperanzas y deseos de cambio social.

En este nexo Estado-ONG la dimensión técnico-financiera es relevante. En la actualidad, existe un vínculo normado institucionalmente en relación con el financiamiento de actividades propias de las ONG, así como de disposiciones estatales para la supervisión técnica y profesional de sus labores cotidianas. Esta relación, sin embargo, es débil en lo que se refiere a la supervisión técnica, acompañamiento y seguimiento del Estado hacia la práctica de las ONG. Preocupa de hecho, que su vinculación parece reducirse a la transferencia de dinero para la ejecución de acciones sobre las que inclusive las máximas instituciones de asistencia social no ejercen el control dispuesto por la normativa pertinente (Boza y Monge, 2010).

\section{Consideraciones mínimas sobre el concepto y orígenes de las organizaciones no gubernamentales desde una perspectiva crítica}

\section{Debates sobre el concepto o denominación "ONG”.}

Son muchos los autores y las autoras que coinciden en reconocer la dificultad a la hora de establecer un concepto universalmente válido para las ONG (Bombarolo et al, 1992; Ortega, 1994; Casey, 1996; Herrera, 1999; Gadea y Gómez, 1999; Balbis, 2001; Palladino, 2006; Pi i, 1998; Diez, 2009). De acuerdo con Picas (2001), tal situación se da ya que -como cualquier efecto que resulta de la acción de "definir negando"- la propia "indefinición" de la denominación facilita más la identificación de lo que no es ("no gubernamental") que de lo que verdaderamente es. Efecto que si bien según Ortega (1994) fue conscientemente buscado por los propios creadores de la denominación, empero ha dado para que tal definición esté cargada de una gran ambigüedad y para que, aún al día de hoy, se preste para una variedad disímil de interpretaciones que lo que pareciera existir es una "ensalada de terminologías y un pupurrí de definiciones" donde coexisten:

Términos norteamericanos y anglosajones como los calificativos non-profit (no lucrativa o sin ánimo de lucro), community-based (comunitaria o basada en la comunidad), charity (caridad), voluntary (voluntario), independent (independiente) e informal y nombres colectivos como third party government (gobierno por terceros), third 
sector (tercer sector) y shadow government (gobierno en la sombra) (...); términos europeos como el francés économie sociale, los alemanes gemeinnützige (bienestar común) y gemeinwirtschaftliche unternehmen (economía común), el inglés non-statutory sector (sector no estatutario) y el equivalente a 'administración pública indirecta' de uso en Finlandia, Alemania, y Dinamarca (...); el australiano community services sector (sector de servicios comunitarios) y, por último, 'asociacionismo' de uso común en Cataluña y España (Casey, 1996, p. 177).

No es casual, por tanto, que al intentar definir las ONG atribuyéndoles características a modo de "valores absolutos", inmediatamente surjan las dificultades. Así pues, resulta muy difícil valorar si una entidad reúne o no algunas de estas características; especialmente cuando, bajo una denominación genéri$\mathrm{ca}$, muchas veces se intentan nombrar y homogenizar un conglomerado de instituciones o entidades con objetivos muy disímiles.

Ciertamente no todas ellas se pueden considerar como ONG, pero también es cierto que la propia definición de lo que es una ONG da pie a numerosas confusiones, ya que aprovechando la corriente de apoyo social hacia estas organizaciones cualquiera que emprenda una labor del tipo que sea, se autodenomina una ONG, sin reunir los criterios mínimos para ello, no solo desde el punto de vista formal sino también en su carácter funcional (Gadea y Gómez, 1999, p. 35).

En el contexto latinoamericano y caribeño, por su parte, ya desde el momento mismo del "explosivo crecimiento" de las organizaciones en cuestión durante la década de los 80's, Cernea (1989) reconocía claramente que:

De primera impresión, el término 'organización no gubernamental' parece engañosamente simple. Sin embargo, la naturaleza residual del término cubre una colección kaleidoscópica de organizaciones tan amplía, que cualquier definición simple de inmediato pierde todo significado. Es necesario reconocer que las ONG existentes pertenecen a diferentes categorías y que sus características se entrecruzan tan sólo parcialmente. El conjunto es suficientemente heterogéneo 
como para requerir distinciones analíticas internas en base a varios criterios. (p. 7)

Asimismo, en uno de los primeros estudios que intentaba compendiar las investigaciones o "catastros" que por aquella época se venían realizando en torno al tipo y cantidad de ONG en diversos países, se señalaba al respecto "todos los estudios coinciden en señalar en la dificultad que significa aludir con el término ONG tanto a instituciones con características y objetivos tan diversos como universidades, centros de investigación, partidos políticos, organizaciones gremiales, instituciones deportivas, de beneficencia, etc., como a las organizaciones dedicadas a 'promover y realizar proyectos de desarroIlo junto a sectores populares'." Bombarolo et al, 1992, p. 25). Y ya en el nuevo milenio, Balbis (2001) continuaba llamando la atención sobre este mismo aspecto:

Cualquier intento por clasificar o agrupar estas organizaciones bajo una denominación común difícilmente pueda llegar a dar cuenta de una realidad tan variada y diversa como la que ella representa. Muchas de estas organizaciones no tienen fines de lucro, por lo que en algunos casos se tiende a hablar de sector "sin fines de lucro" como aquel que engloba a todas las organizaciones con fines sociales o solidarios (...) Otras tantas entre ellas tienden a autoidentificarse como "no gubernamentales" por no depender de la administración del Estado; casi todas se definen como no partidarias o no religiosas remarcando el carácter independiente de su accionar; y un grupo importante entiende que es parte del llamado "Tercer Sector" (...) un término que se reconoce fue acuñado hace unas décadas por $\mathrm{W}$. Nielsen y que da por sobreentendida la existencia de otros dos sectores constituidos por el Estado y el mercado. Algunos autores otorgan a este Tercer Sector la capacidad mediadora entre los ciudadanos y el Estado, pero es claro que los contactos, vínculos y articulaciones entre los eventuales tres sectores cuestionan e interpelan las fronteras que pretendan marcarse entre unos y otros (p. 13-14). (cursivas del original) 
Así las cosas, y pese a todo lo anterior, lo cierto es que aunque el propio concepto o definición se revele poco práctico -incluso para los y las especialistas-, tal ambigüedad no ha impedido que las organizaciones no gubernamentales hasta "se pusieran de moda" en los medios de comunicación. Esta última circunstancia, sin embargo -parafraseando a Palladino (2006)- si bien revistió el significado de la denominación con una especial "aura" de alternativa frente a un imaginario colectivo cada vez más apático respecto a la política y las instituciones democráticas, ha venido resultando engañosa y peligrosa; precisamente porque en el contexto neoliberal (a diferencia de los años anteriores a la década de los 70s), estas organizaciones parecen ir cada vez por sendas menos representativas del interés general, aparte que no son pocos lo señalamientos respecto de que tienden también a la despolitización de ciertos sectores de la población.

\section{Los polémicos elementos supuestamente distintivos de las ONG: lo "no lucrativo" y lo "no gubernamental"}

Es evidente que si nos vamos al sentido o significado literal de la denominación "ONG", lo primero de lo que es posible percatarse es que "ONG" son las siglas de una denominación que basa su contenido o significado en dos elementos supuestamente distintivos que, por definición, son una negación: lo "no lucrativo" y lo "no gubernamental". Como es notorio, este último elemento aparece explícito en la propia denominación; mas el primero es una negación que más bien se da por sobreentendida.

El segundo de estos supuestos elementos distintivos que derivan de la denominación "ONG" -lo "no gubernamental"- es un aspecto que no ha sido objeto de una polémica significativa; lo anterior, sin embargo, no es sinónimo de una ausencia total de cuestionamientos, empero, al parecer es algo relativamente comprensible que las ONG en determinado momento tengan relación con las instancias gubernamentales en ciertas circunstancias y con fines muy específicos: a efectos de hacer valer ciertos derechos ciudadanos; sumarse a iniciativas públicas en afán de una adecuada democratización de procesos y una participación social amplia y plural; o simplemente, para que puedan ser sancionadas y legalizadas por el Estado y, entre otras cosas, para tener la posibilidad de acceder a fondos de financiamiento o beneficios y exoneraciones específicas de acuerdo al ordenamiento jurídico de cada país y al estatus que se les concede de acuerdo a este.

De hecho, en la época del neoliberalismo, la participación de las ONG en los proyectos de desarrollo -y más específicamente en la ejecución de política pública y social- pasó a ser un componente esencial de la condicionacionalidad del financiamiento para el desarrollo. 
Con la misma intención de negar todo lo que tenga que ver con el gobierno (en el sentido liberal), la negación de la orientación al lucro pretende distinguir a las ONG de otras organizaciones sociales; específicamente, de aquellas que no solo nacen de la iniciativa privada, sino que también (y principalmente) están motivadas por la obtención de beneficios económicos para sus propietarios o accionistas ${ }^{8}$ (Mesa, 1980). El significado más laxo de este elemento de la denominación supone que las organizaciones que se señalan como ONG no tienen (o no deberían tener) como finalidad última el lucro; y que además, los destinatarios de sus actividades serán otras personas, grupos o sectores de población distintos respecto a los miembros de la organización de que se trate.

Desde inicios de los 90 se consideraba que si bien las ONG no tenían como fin primordial la obtención de ganancias económicas, sino promover el desarrollo de los sectores populares, esto no excluía que sus miembros pudieran tener como meta de su trabajo su propio desarrollo y sustentabilidad económica y laboral. (Bombarolo et al, 1992)

No sucede lo mismo con el primero de los elementos distintivos que componen la denominación: "lo no lucrativo". Si bien se trata de un elemento que no aparece literalmente explícito en la denominación, es un aspecto que permanentemente ha sido discutido, y política e ideológicamente reprochado. Por tal razón, desde la perspectiva crítica que intentamos mantener en este trabajo es conveniente detenerse un poco en este aspecto.

Pero como se dijo antes, aquí también se han suscitado polémicas incluso desde el grupo de autores y autoras abanderados y abanderadas de las ONG; tal es el caso del destacado investigador uruguayo, el señor Jorge Balbis $^{9}$, quien ha llegado a cuestionarse lo siguiente:

(...) muchas de estas organizaciones [supuestamente] no tienen fines de lucro, por lo que en algunos casos se tiende a hablar de sector "sin fines de lucro" como aquel que engloba a todas las organizaciones con fines sociales o solidarios. Sin embargo, por ejemplo, las cooperativas promueven proyectos que benefician a la comunidad al tiempo que reditúan provecho para sus propios miembros así como, más y más organizaciones "sin fines de lucro" entran a jugar en el campo de la promoción de créditos, asistencia técnica a microempresas y otras actividades de tipo económico (p. 13-14).

Así entonces, lo razonable de cuestionarse por la validez actual del apelativo de "lo no lucrativo" como parte de los elementos distintivos e identitarios de
8. Tal es el caso de las empresas privadas y las modernas sociedades por acción.

9. Jorge Balbis es investigador especializado en las ONG, del Centro Latinoamericano de Economía Humana (CLAEH) de Montevideo; colaborador y consultor de varias ONG y organismos intergubernamentales vinculados al tema como la UNESCO. 
las ONG, queda aún más en evidencia cuando se aprecian posturas que no encuentran conflicto en obviar (o del todo nunca han considerado) esta supuesta cualidad de las ONG. Es este el caso, por ejemplo, de autores y autoras como la ingeniera industrial colombiana, María Cristina Rojas - asesora de planeación en el Ministerio de Hacienda de Colombia hasta agosto de 2013- quien sostiene abiertamente que "las fundaciones empresariales son instituciones híbridas porque hacen parte del sector empresarial y como tales están sujetas a la lógica del mercado, pero también son organizaciones de la sociedad civil que tienen que ver con lo social" (Rojas, 2000, p. 13).

Caso ilustrativo en esta misma línea es también el de Arango, Pérez y Sepulveda (2011), quienes en un intento de "construir el significado" contemporáneo de ONG, sostienen que estas organizaciones en definitiva aportan al desarrollo, y que su papel puede considerarse en tres dimensiones: política, social y económica. Estos autores y autora, para justificar la dimensión política, nos ofrecen un breve recuento de fuentes bibliográficas en donde se aprecia la afirmación de que las ONG pueden ser también consideradas, perfectamente, "empresas formales" o fundaciones empresariales:

En una dimensión diferente al fenómeno político, para algunos autores, las ONG pueden definirse dentro de la dimensión económica como empresas formales. Para Miranda \& Sepúlveda (2004), las ONG son empresas formalizadas que se ven afectadas por todas las variables de entorno que afectan a las empresas públicas y privadas. Por su parte, Fernández (2003: 58), manifiesta que éstas no sólo se rigen por la normatividad propia del mundo empresarial privado, sino que las acciones que emprenden se realizan desde la lógica privada. Los órganos de gobierno internos de las ONG son los encargados de decidir a qué tipo de población apoyar, qué clase de programas -medio ambiente, educación, derechos humanos, salud, etc.- favorecer según sus principios e ideologías, con el propósito de contribuir al interés común de una población definida (p. 51). (cursivas nuestras)

Pero los ejemplos anteriores no son aislados; estas citas textuales tan solo ilustran una tendencia que desde finales de los 90 e inicios del milenio en curso se aprecia en uno de los actores más influyentes en el debate -entre muchos otros- sobre la naturaleza y función de las ONG en la contemporaneidad. Hablamos aquí de la Organización de las Naciones Unidas y sus di- 
versas agencias; pero particularmente, las asociadas a sectores sociales o de derechos.

Este organismo intergubernamental no solo hizo las veces, como se sabe, de primer marco institucional donde se reconoció formalmente la existencia y funcionalidad moderna de las ONG (Rabotnikof, Riggirozzi y Tussie, 2000); además de esto, de manera ininterrumpida desde finales de los 70 , ha sido uno de los espacios que mayor influencia ha tenido en el proceso de determinación de la configuración actual y de la función que a nivel general cumplen las organizaciones no gubernamentales siendo que, por ejemplo, el Programa de las Naciones Unidas para el Desarrollo (PNUD) y el Programa de las Naciones Unidas para el Medio Ambiente (PNUMA) representan dos de los principales espacios -junto a los Bancos Multilaterales de Desarrollo (BMDs), como veremos más adelante- en los cuales las ONG han sido impulsadas y fortalecidas institucionalmente.

Ambos programas de la ONU -junto al sector privado empresarial y la sociedad civil (convertida en actor y reducida básicamente a las ONG) han impulsado el establecimiento de un "Pacto Mundial" (Global Compact), "un experimento ambicioso de colaboración de múltiples grupos de interés dirigido a incorporar los principios universales sobre derechos humanos, trabajo y medio ambiente en los mercados globales" (SustainAbility, 2005).

Es de destacar que en el marco de dicho "pacto" se parte del siguiente supuesto paradigmático e icónico respecto a la comprensión de las ONG, el cual refleja muy claramente la concepción de lo que los actores involucrados entienden con el término "organizaciones no gubernamentales", y asimismo, ilustra lo paradójico y contradictorio del principio de "lo no lucrativo":

La globalización es algo que va más allá de la expansión de los mercados. También es un proceso que difunde ideas y crea redes. Quizá más que ninguna otra institución, las organizaciones no gubernamentales, ONG, han aprovechado, e impulsado, estos cambios (...) En este momento, el sector no lucrativo tiene un valor de un billón (millón de millones) de dólares en todo el mundo. Como resultado, atrae una atención creciente, aunque no siempre favorable (...) Las Organizaciones No Gubernamentales (ONG), que tiempo atrás se oponían y actuaban al margen del sistema, se están integrando a él (...), de forma que esperamos un creciente interés por las prioridades de las ONG, sus estrategias, su rendición de cuentas sus modelos de negocios (...) pocas ONG destinan tiempo para pensar en 
las empresas, y menos aún a pensar en los mercados. A pesar de ello, tienen profunda influencia en ambos. La evidencia, por el contrario sugiere que es necesario que se comprometan e influyan en los mercados más directamente (...) ¿Cómo podemos civilizar el capitalismo a través de los mercados? (...) [esbozamos] cinco áreas de respuesta: campañas contra las empresas, inteligencia de mercados, compromiso de mercado, mercados inteligentes y trastornos de los mercados (SustainAbility, 2005, p. 01).

No es este artículo, el lugar ideal para detenerse mucho en el análisis de esta última cita. Para referirse a las implicaciones de este paradigma en la comprensión de lo que el "pacto" entiende por ONG, no solo se requiere un texto exclusivo, sino que se demanda profundizar en la investigación seria sobre este punto. No obstante lo anterior, no podemos dejar pasar la oportunidad, esquemáticamente, algunas inquietudes que ineludiblemente resultan de la lectura de dicha cita.

Así las cosas, es evidente que al referirse al "valor del sector no lucrativo", el extracto del texto no hace más que reafirmar y confirmar la argumentación que antes hacíamos al respecto de lo razonable (sino imprescindible) que resulta cuestionarse la validez del elemento distintivo de lo "no lucrativo" en el significado clásico de la denominación "ONG". Podría resultar incluso cínico que en la actualidad se pretenda hacer extensivo y universal la aplicación de dicho apelativo o principio a todo el conjunto de ONG.

Poco queda para decir al respecto cuando nos encontramos afirmaciones tan significativas y reveladoras como la que aparece en una nota al final del texto del cual hemos extraído la cita. En dicha nota se señala:

Un trabajo reciente del Center for Civil Society Studies de la John Hopkins University indica que, sin contar las congregaciones religiosas, el 'sector no lucrativo es una industria de 1.100 billones (millones de millones) de dólares', que tiene 19 millones de asalariados y representa la octava economía del mundo. (John Hopkins Center for Civil Society Studies: Global Civil Society - Dimensions of the Nonprofit Sector, John Hopkins, Baktimore, 1999). (SustainAbility, 2005, p. 57; nota al final No.2) 
Sin tomar partido aún en la discusión que suscita el tema que hemos venido tratando, y partiendo de lo planteado en estas últimas líneas, no resulta extraño que en algún momento un autor francés - citado por Picas (2001)- haya argumentado que existe algo así como una especie de "aristocracia de la ayuda"; un pequeño y selecto grupo de ONG (de entre decenas de miles de ellas que hay en total) que canalizan la mayor parte de la Ayuda Oficial al Desarrollo (AOD) ${ }^{10}$ que el Comité de Ayuda al Desarrollo (CAD) de la OCDE destina para el financiamiento de los procesos de Desarrollo por la vía no gubernamental ${ }^{11}$. Tampoco resulta del todo sorpresiva o exagerada la posición de un autor (de los más radicales, por cierto) del ala crítica del debate que suscita el tema de las ONG, el norteamericano marxista James Petras, para quien las ONG:

(...) se han tornado por doquier en el vehículo más reciente de movilidad ascendente para las clases ilustradas con ambiciones. Académicos, periodistas y profesionales en general han abandonado ocupaciones previas y escasamente remuneradas en movimientos izquierdistas en aras de una carrera lucrativa al frente de una organización no gubernamental, aportando consigo sus destrezas organizativas y retóricas y un cierto vocabulario populista. Desde su chalet o su piso en el extrarradio de un despacho lujoso en un edificio de oficinas, millares de directores de organizaciones no gubernamentales (...) pasan más tiempo en los lugares donde celebran sus conferencias internacionales (Washington, Bangkok, Bruselas, Roma, etc.) que con las aldeas enfangadas de su propio país. Se muestran más inclinados a ofrecer sumas en monedas fuertes a 'profesionales que se lo merecen' que a correr el riesgo de una manifestación de maestros rurales mal pagados (...); constituyen una nueva clase, no basada en la propiedad o en los recursos del Gobierno sino derivada de la financiación imperial y de su propia capacidad para controlar grupos populares significativos (Petras, 2002, p. 192-193).

Para finalizar este apartado, quisiéramos remarcar que es al menos prudente (sino del todo necesario) reconocer que es difícil de ignorar el hecho de que, desde hace algunas décadas, las ONG tienden a situarse cada vez más cerca de los organismos de poder tanto público como privados, mientras que, por otra parte, es posible notar que por momentos se alejan significativamen-
10.Aquellos flujos que las agencias oficiales -incluidos los gobiernos estatales y locales, o sus agencias ejecutivas- destinan a los países en desarrollo y a las instituciones multilaterales; pero que además: a) promocionen el desarrollo económico y el bienestar social y; b) sean de carácter concesional y contengan un elemento de donación de al menos el $25 \%$.

11. Según fuentes oficiales, para el periodo 2000-2009 los países miembros del CAD destinaron en promedio el $0,30 \%$ del PIB para la $A O D$, del cual existen partidas directas que se canalizan vía ONG y que corresponde a un $3 \%$ del total desembolsado. 
12. Tales como el Catholic Relief Service (CRS), fundado en 1943, que coordinaba la acción de las parroquias católicas, y el Church World Service entre las protestantes.

13. Se mencionan aquí: Rescue Commitee (IRC), fundada en 1940 por intelectuales y artistas; Cooperation for American Remittances to Europe (CARE), creada en 1945, especializada en el envío de paquetería a las zonas en guerra; World Vision, organización de orientación cristiana, que surge en 1950 y que coincide con el conflicto de Corea, en medio del cual inicia sus labores. te de las bases sociales que supuestamente les sustenta y legitima como representantes de la sociedad civil. Todo esto, en última instancia, viene a evidenciar la caducidad de los supuestos elementos distintivos que contiene el sentido clásico y originario de la denominación "ONG"; y no sin algo de razón, han surgido otras formas de llamar al conjunto de organizaciones no gubernamentales: "tercer sector", "sector no lucrativo", entre otros; no obstante, esta es una discusión que nos reservaremos para un apartado más adelante.

\section{Diversas perspectivas acerca de los orígenes y la historia de las ONG}

Haciendo la salvedad de que pueden haber excepciones -como el caso de Cruz Roja Internacional (fundada en 1863)-, la generalidad de autores y autoras que se han ocupado del tema de las ONG afirman que estas organizaciones emergen con mayor notoriedad en las postrimerías de la II Guerra Mundial, a propósito de colaborar en la atención de las calamidades que sufrían las poblaciones víctimas de esta gran conflagración.

Picas (2001) citando a Ferré (1995), refiere que en aquel momento histórico, el mayor protagonismo lo tuvieron, por un lado, las organizaciones religiosas norteamericanas (católicas y protestantes) ${ }^{12}$; y por otro, organizaciones laicas vinculadas a grupos de "hombres de negocios", empresarios, comerciantes, algunos intelectuales y artistas ${ }^{13}$. En el continente europeo, por su parte, la primera gran organización que se reconoce como ONG se creó en Inglaterra en 1942 y lleva por nombre, al día de hoy, de Oxford Committee for Famine Relief (OXFAM), agrupación que tuvo como propósito inicial socorrer a la población griega víctima de la hambruna originada por la conflagración bélica. Y en general, de modo similar, entre 1940 y mediados de los 60, otras organizaciones surgirán en toda la Europa Occidental, siendo destacables el Comité Catholique contre la Faim et pour le Développement en Francia; Terre des Hommes, en Suiza; Brot für die Welt, en Alemania; y Cáritas, en España.

Los datos expuestos anteriormente hacen las veces de -podríamos decir"supuestos teóricos" sobre el tema, y son de generalizada aceptación por parte de la mayoría de autores y autoras que hacen alusión, en alguna medida, a los orígenes de las ONG. Este aspecto del fenómeno sin embargo es, por cierto, algo en lo que no se suele profundizar mucho, por lo que tales datos, efectivamente, aparecen como una afirmación a la que con frecuencia se hace referencia en la mayor cantidad de la bibliografía física o electrónicamente ubicable. 


\section{Perspectiva histórica o de contenido}

Distanciándonos de la tendencia antes descrita y deteniéndonos un poco más en el análisis de este aspecto del fenómeno, nos percatamos de que fijar sin más la génesis de las ONG exclusivamente en esa época histórica, sería perfectamente válido si el universo de estas se redujera al grupo de organizaciones mayormente articuladas a la cooperación para el desarrollo, y a solo una parte o una generación de aquellas otras que trabajan en el campo de ayuda humanitaria. En otras palabras, sería un origen histórico aplicable únicamente a una parte de las ONG que hoy existen, las cuales aunque son las que predominan, no agota el universo de las ONG que coexisten en la cotidianidad de las complejas sociedades contemporáneas.

Si bien las ONG vinculadas a la cooperación para el desarrollo y a cierto sector de la acción humanitaria son en la actualidad las que tienen mayor protagonismo (sobre todo a nivel mediático), otro grupo de organizaciones de la sociedad civil -consideradas también con frecuencia "ONG"- hacen eco en el imaginario de la ciudadana o el ciudadano común en alguna dimensión de su existencia social, y cobran legitimidad y reconocimiento a lo interno de grupos de población con intereses, problemas y necesidades particulares.

Hablamos aquí, por ejemplo, de asociaciones científicas; comités; asociaciones de profesionales; grupos cívicos; agrupaciones orientadas al rescate y preservación del patrimonio cultural o natural; grupos promotores del arte, la recreación o el deporte; sociedades temáticas y en fin, organizaciones cuya naturaleza data de épocas incluso bastante más antiguas que la primera o segunda guerra mundial; sea que se mantengan bajo el mismo nombre y formas de operar (como el caso de la Cruz Roja), o que hayan evolucionado a estructuras más complejas e institucionalizadas, pero que en cualquier caso claramente surgen en un plano y con un alcance internacional.

Estas otras organizaciones a las que hemos hecho referencia son entidades que a primera vista poco o nada tienen que ver directamente con proyectos de desarrollo o con la acción humanitaria tal cual se concibe hoy, y que en cuya aparición es poco probable que mediaran mecanismos de estimulación, por ejemplo, un sistema institucionalizado de cooperación internacional como la Organización para la Cooperación Internacional y el Desarrollo Económico (OCDE). Son organizaciones que estuvieron -y siguen estando en la actualidad- más orientadas a la gestión de intereses particulares y muy puntuales; que llegaron a existir y a tomar protagonismo -permanente o coyunturalmente- ya sea por los límites objetivos de la acción gubernamental en un área temática y/o un momento histórico determinado, sea por la negligencia o por la contraposición abierta de intereses políticos e ideológicos, pero que han ejercido influencia en las tradiciones organizativas o asociativas voluntaristas y solidarias, en términos generales. 
Así entonces, hablamos de organizaciones también consideradas hoy día como organizaciones no gubernamentales, que aparecieron primero -muy claramente- en el plano internacional debido a los espacios que empezaron a crear y a gestionar (demandando, impulsando o exigiendo) o a los círculos a los que se integraron y muy tempranamente influenciaron. Son organizaciones, por tanto, que debido precisamente a ello, llamaron más la atención de profesiones y disciplinas como Relaciones Internacionales o el Derecho Internacional; y solo muy recientemente han empezado a ser foco de estudio de ciencias sociales clásicamente consideradas como la sociología, antropología, ciencias políticas, las ciencias de la comunicación, entre otras, o profesiones como trabajo social o administración pública.

Debido a lo anterior, cabe preguntarse: si pareciera que es un hecho que las ONG aparecieron primero en el plano internacional y solo después en el ámbito local o nacional; ¿por qué no nos detenemos lo suficiente para entender cuáles fueron los factores o causas que determinaron su aparición en dicho escenario internacional? Y si esta interrogante es aceptable y razonable, cabe también preguntarse ¿no será lógica y ontológicamente más consecuente realizar -aunque sea por asomo- una revisión de lo que al respecto se ha investigado desde otros ámbitos de estudio más relacionados y/o especializados, como es el caso de las relaciones internacionales?

Siendo afirmativa nuestra respuesta, consideramos que para el estudio crítico de las ONG, es necesario adoptar una perspectiva histórica que se nutra de las aportaciones de otras disciplinas o especialidades como las ya mencionadas; a efectos de contar con mayores posibilidades de recuperar elementos menos convencionales -pero más ricos- a partir de los cuales comprender en la complejidad real, las características actuales, la cambiante funcionalidad y el respaldo social que reciben las ONG hoy día en la mayoría de sociedades.

Así las cosas, queremos tan solo dejar planteado que desde una perspectiva historiográfica y de mayor amplitud podemos encontrar autores y autoras que demuestran que las ONG tienen su antecedente inmediato y sus orígenes en las llamadas "asociaciones u organizaciones internacionales privadas"; un viejo actor de las relaciones internacionales modernas -gestadas desde el mismo momento de surgimiento y expansión capitalista- que estaban constituidas por grupos de ciudadanos y ciudadanas que decidían organizarse (al margen de los poderes públicos) para velar por sus intereses particulares. Intereses principalmente de tipo filantrópicos, religiosos, humanitarios, culturales, científicos, profesionales y gremiales (Serrano, 1999).

Al respecto de esto, se sabe que hacia finales del siglo XIX -con inspiración basada principalmente en corrientes filosóficas ligadas a la caridad cristiana y al liberalismo político (sobre todo en el mundo anglosajón y Occidente en general)- estas protoformas de las ONG comenzaron a tener mayor influencia e 
impacto en la gestión de sus intereses; los cuales se hacían prevalecer básicamente en una o varias de las siguientes circunstancias:

1. Cuando dichos intereses se contraponían al orden jurídico establecido por el gobierno: caso típico de agrupaciones de comerciantes o mercaderes en los inicios del capitalismo, o asimismo, las misiones de órdenes religiosas en contextos y momentos de marcada y deliberada secularización.

2. Cuando el gobierno, abiertamente, no quería cumplir alguna misión debido a los costos políticos que le acarreaba o los riesgos estratégicos que podría significarle: ilustrado de manera espectacular por la causa de la abolición del comercio de esclavos y la de la esclavitud como tal.

3. Cuando los gobiernos no podían emprender ciertas misiones, en tanto que no tenían la posibilidad de tomar la iniciativa en ese campo específico: ejemplificado en época de conflictos bélicos, cuando ninguno de los bandos que se enfrentan se hace de instrumentos eficaces de negociación ni de las condiciones de confianza para poder hacer una tregua y recuperar heridos y caídos en el campo.

Al parecer, las asociaciones internacionales privadas se ganaron desde entonces una reputación positiva a nivel internacional, ya que en su accionar llegaron a convertirse incluso en agentes propulsores de algunos de los primeros organismos intergubernamentales que precedieron a la Organización de Naciones Unidas (ONU) - por ejemplo, la antigua Sociedad de Naciones-; algunos de los cuales, incluso, se mantuvieron y luego fueron adscritos a esta bajo otros nombres, en calidad de entes especializados (oficinas, programas, fondos) en áreas como educación, ciencia, cultura, trabajo, turismo, comercio, alimentación y agricultura; en tal sentido:

Si se considera el vasto abanico de objetivos que persiguen las ONG, se comprenderá fácilmente que, durante la historia de las organizaciones internacionales no gubernamentales, su papel en la relaciones internacionales ha sido a menudo considerable e incluso decisivo. Así, gracias a los esfuerzos que llevaron a cabo las ONG se solucionó el problema de la abolición de la esclavitud. También el papel representado por las ONG feministas fue fundamental en la conquista del sufragio para la mujer. La lucha contra la discriminación y los prejuicios raciales no adquirió pleno sentido hasta que las ONG se involucraron en ella. La enseñanza obligatoria es en gran 
14. En términos generales, varios autores coinciden en recordar, por ejemplo, que "cooperación privada o solidaria" (la de las ONG internacionales), existió mucho antes que la "Cooperación o Ayuda Oficial al Desarrollo" (multilateral y bilateral). Para esta autora, la primera ONGs que se fundó fue Cáritas Internacional, una organización Alemana creada en 1895; seguida de Save the Children, Red Berna, en 1919. parte obra también de las ONG. Sin lugar a dudas, numerosos organismos intergubernamentales deben su nacimiento a la acción de las ONG internacionales; por ejemplo la Oficina Internacional de Educación, la Oficina Internacional del Trabajo, la Organización Mundial del Turismo, la Organización Mundial Meteorológica y el Instituto Internacional del Frío son el resultado del desarrollo de ONG internacionales, mientras que la Unión Internacional de Protección de Obras Literarias y Artísticas y la Unión Internacional de Protección de la Propiedad Industrial y el Instituto Internacional de Agricultura son el resultado de las demandas de diferentes grupos privados (Serrano, 2004, p. 31-32).

Siendo esto así, es claro que no sería del todo aceptable si fijásemos la génesis de las ONG exclusivamente en los años posteriores al final de la II Guerra Mundial. Y si bien la mayor parte de la literatura reconoce que hubo excepciones (la Cruz Roja Internacional, específicamente), casos como este se podrían encontrar en mayor cantidad de lo que nos imaginamos (O' Neill, $2004)^{14}$, tan solo si nos situáramos por un momento en el dominio de las relaciones internacionales y su perspectiva histórica más amplia (Mesa, 1980). Para esto, obviamente, sería necesario animarse a adoptar un marco analítico bajo un enfoque consecuentemente más ontológico y dialéctico, que supere tanto las generalizaciones frecuentemente sesgadas y focalizadas, así como las posturas unilaterales y unilateralizantes que rechazan de plano casi sin consideración crítica alguna- cualquier "beneficio de la duda" respecto del papel de las ONG en otro tiempos, en otras latitudes y en general, en otros contextos.

\section{Enfoque formalista o jurídico-institucional}

Es evidente que otra cosa sucede si optamos por posicionarnos en un ángulo más formalista y conceptual, que terminaría por darle a esta dimensión del fenómeno un enfoque más de tipo jurídico-legal. Desde una óptica tal, el término o denominación "ONG" aparecerá únicamente hacia finales de la década de los 40; cuando por primera vez es utilizado de manera formal en documentos de la ONU (Biagosch, 2004). Sobre este punto, es frecuente encontrar en la literatura sobre el tema que el primer documento oficial que hace referencia al término o denominación -y que reconoce públicamente la existencia y función de estas organizaciones- es la Carta de las Naciones Unidas 
(capítulo X, artículo 71); documento que faculta al Consejo Económico y Social (ECOSOC, por sus siglas en inglés) a "celebrar consultas con organizaciones no gubernamentales que se ocupen de asuntos de la competencia del Consejo".

Cabe resaltar, sin embargo, que en esta primera definición oficial, el significado del término "ONG" será en extremo amplio y ambiguo, ya que, como afirma Picas (2001), dentro de ella se podía incluir cualquier organismo privado de servicios con finalidad no lucrativa; y además de esto, el término quedaba restringido a organizaciones de carácter internacional. Precisamente por esto último, quizás, es que en posteriores documentos del ECOSOC (resoluciones 288 B (X) de 1950, 1296 (XLIV) de 1968 y 1996/31 de 1996) y de otros organismos especializados de la ONU (FAO; OIT; UNESCO; OMS, entre otros), las ONG serán definidas con mayor precisión; garantizándoles siempre la participación -mediante mecanismos de colaboración y cooperación- en la mayor parte de las actividades de las Naciones Unidas (Serrano, 1999; Rabotnikof, Riggirozzi y Tussie, 2000).

En todo caso, desde esta perspectiva, ya para la época del apogeo del desarrollismo y finalizada la etapa de "institucionalización" de la Cooperación Internacional para el Desarrollo (fines de los años 60), la denominación "ONG" empezó a delimitarse a partir de un enfoque más sociológico y menos jurídico; siendo un caso típico, por ejemplo, la Organización para la Cooperación y el Desarrollo Económico (OCDE), entidad que adopta una definición en la que se enfatizan los supuestos propósitos filantrópicos y el origen privado de los fondos con que se financian estas organizaciones. Es así como, siguiendo con el ejemplo, para la más grande agencia intergubernamental de cooperación internacional: "La ONG es una organización fundada y gobernada por un grupo de ciudadanos privados, con un declarado propósito filantrópico y sostenida por contribuciones individuales privadas" (OCDE, 1988, b; citado en Murguialday y Valencia, 1999, p. 13). (cursivas nuestras)

Desde la misma consideración de la cooperación para el desarrollo, pero en la óptica de una agencia más bien bilateral -la Agencia Vasca de Cooperación para el Desarrollo- las organizaciones no gubernamentales son definidas incluso en términos más precisos, aunque con igual o mayor amplitud de aplicación:

Las ONG tienden, en general, a financiar, alentar, asesorar y administrar una serie de actividades económicas y sociales cuyos destinatarios suelen ser los sectores menos favorecidos de la sociedad, constituyendo un espectro organizacional que cubre prácticamente todos los ámbitos de inquietud por las condiciones de vida de la humanidad, desde los más variados enfoques filosóficos. Buen número 
de ellas opera sólo a escala nacional o local; otras lo hacen a nivel internacional ya que los problemas que abordan trascienden las fronteras. Aunque la amplitud y ambigüedad del término ONG permite englobar a una diversidad de organismos ajenos a lo gubernamental, su uso corriente excluye a entidades privadas de tipo empresarial (Mirguialday y Valencia, 1999, p. 14).

Así las cosas, desde la perspectiva que aquí hemos llamado formalista, es notable que en la medida en que las organizaciones no gubernamentales fueron orientándose progresivamente hacia objetivos cada vez más amplios y variados, en esa misma medida los organismos intergubernamentales -como el Banco Mundial- empezaron a adoptar una comprensión de la denominación tomando como punto de partida la descripción más precisa de las actividades concretas que estas organizaciones venían desarrollando. De esta manera, para este organismo financiero internacional, las ONG son " organizaciones privadas sin ánimo de lucro, que trabajan en los países en vías de desarrollo para aliviar el sufrimiento, dar a conocer la situación de los más pobres, proteger el entorno, proporcionar servicios sociales básicos o impulsar el progreso de la comunidad" (Banco Mundial, 1996; citado en Petras, 1997a; p. 50) (cursivas del original).

Tal y como puede apreciarse, el significado formal originario del término "ONG" es tan amplio y ambiguo que en él se podría incluir una cantidad considerable de organizaciones que irían desde organizaciones de tipo religioso, asociaciones profesionales, clubes de ocio, grupos culturales, asociaciones cívicas, organizaciones de cooperación y ayuda al desarrollo, universidades, centros de investigación, partidos políticos, organizaciones gremiales, instituciones deportivas privadas, instituciones de beneficencia, etc. Aunado a esto, "los intereses, las motivaciones, las estructuras, la financiación, el tipo de acciones, los objetivos que persiguen, el alcance geográfico o la ideología " (Palladino, 2006) y la filosofía que les inspira son variables que cambian -a veces drásticamente- entre una y otra organización que se suele nombrar o autonombrar bajo las siglas ONG.

Si a esto le sumamos el notable hecho de que el uso de la denominación (y las organizaciones que así se nombran, desde luego) hoy día parece mostrar una tendencia a identificarse, diluirse, confundirse o considerársele como "contenida en" o "parte de" otras expresiones tales como: "tercer sector"; "organizaciones sin fines de lucro" (OSL); "organizaciones de la sociedad civil" (OSC); "organizaciones sin ánimo de lucro" (OSAL); "sector no lucrativo o sin fines de lucro"; y "sector voluntario"; el panorama es aún más turbio y complejo. En tales condiciones, pues, no es de extrañar que con frecuencia la denominación actúe más como un término "paraguas" que como un concepto 
en sí (Pi i, 1998), bajo el cual se identifican y agrupan una variedad significativa de organizaciones que en apariencia, incluso, pueden resultar muy diferentes y hasta contrapuestas entre sí.

En primera instancia, es preciso reconocer que tal tendencia podría estar asociada -al menos en parte- a la falta de homogeneidad jurídica bajo la cual se constituye una ONG en cada país (Sánchez, 1998), así como a la categoría bajo la cual -al fin y al cabo- legalmente quedará inscrita la organización ante el correspondiente registro oficial. Por otra parte, es igual o aún más necesario reconocer que tal situación sin duda responde a las transformaciones que en la práctica van experimentando estas organizaciones; transformaciones que se van gestando, en buena medida, a partir de la pauta de interacción que en cada momento histórico establecen las ONG con otros actores sociales, tanto en el plano nacional como internacional (Serrano, 2004). No debemos olvidar que esto último será lo que determinará el papel específico que juegan estas organizaciones en cada sociedad concreta, en cada momento histórico determinado y en cada tema o área en la que se involucran especializadamente.

Pero cualesquiera que sean los factores de fondo que determinen los usos que se hacen de la denominación "ONG" en la actualidad, es evidente que se trata de un término que hoy por hoy se aplica a organizaciones que aún comparten (o por lo menos se considera que así es) algunos elementos comunes mínimos que permite agruparlas en un mismo conjunto. Por otra parte, más allá de esta discusión -que por cierto es muy contemporánea- es primordial reconocer que las ONG no aparecieron de la nada; ni han existido siempre; ni en todas las sociedades; ni en todo lugar donde existen son iguales; ni tuvieron permanentemente la misma forma o accionar.

\section{Hacia una definición crítica, amplia y plural}

Con las consideraciones que hemos esbozado hasta el momento, podemos ensayar una definición operativa que sea lo suficientemente amplia y plural y que no ignore los elementos aquí discutidos; así las cosas, proponemos entender a las ONG a partir de los siguientes elementos, según Morales (2010):

- $\quad$ Son entidades de carácter público, con diferentes fines y objetivos humanitarios y sociales definidos por sus integrantes, formalmente creadas independiente respecto a los gobiernos locales, regionales y nacionales; y en principio, también, de organismos internacionales.

- $\quad$ Desde el punto de vista jurídico, son entidades que adoptan diferentes estatus, que van desde las fundaciones y asociaciones hasta las corporaciones y cooperativas, entre otras formas. 
- $\quad$ Al conjunto del sector o al colectivo al que se adscriben se le denomina de diferentes formas, coexistiendo términos en castellano tales como: "organizaciones de la sociedad civil"; "sector voluntario"; "sector no lucrativo"; "sector solidario"; "economía social"; "tercer sector" y "sector social".

- La composición del recurso humano de estas organizaciones lo constituyen, por lo general, personas voluntarias, así como -predominantemente- trabajadores/(as) contratados(as).

- Internamente pueden tener un bajo o alto grado de organización y el financiamiento de las actividades que desarrollan proviene de diversas fuentes: personas particulares, Estados y otras administraciones públicas, organismos internacionales, empresas, otras ONG (del Norte), etc.

- $\quad$ El radio de acción de estas organizaciones abarca desde un nivel local a uno internacional. Cubren una gran variedad de temas y ámbitos que definen su trabajo y desarrollo.

- Dichos temas están relacionados con ayuda humanitaria, salud pública, investigación, desarrollo económico, desarrollo humano, cultura, derechos humanos, transferencia tecnológica, ecología, etc. No tratan de reemplazar las acciones de los Estados u organismos internacionales en sus correspondientes países sino de cubrir y ayudar en aquellas áreas en las cuales no existen políticas sociales o económicas, o bien cuando estas políticas resultan insatisfactorias para algunos grupos de la sociedad. También denuncian las infracciones de los gobiernos, la corrupción y los abusos.

\section{Las clasificaciones y tipologías en el universo de las ONG}

Las fronteras que con la denominación ONG se pretenden trazar respecto a otras organizaciones e iniciativas asociativas son cada vez más difusas, sino del todo inexistentes. Debido a esto, se han realizado esfuerzos por establecer algún tipo de clasificación o tipificación, partiendo del reconocimiento de que la heterogeneidad de la esfera de las ONG es innegable, por lo que resulta insuficiente cualquier intento de generalización, encasillamiento o explicación universalista de su naturaleza y funciones; no obstante esto, aquí nuevamente los criterios de clasificación y/o diferenciación varían tanto como las posiciones político-ideológicas de cada autora o autor que se aventura a realizar tal ejercicio de categorización. A este respecto, Rabotnikof (2001) afirma: 
En la literatura se encuentran varias clasificaciones que parecen agrupar desde grupos de autoayuda hasta fondos de caridad, grupos de investigación, iglesias, grupos de presión y asociaciones profesionales. A veces se distingue entre ONG operativas (operational) y de cabildeo (advocacy) para diferenciar a aquellas centradas en el diseño y ejecución de proyectos de las orientadas a defender o promover una determinada causa. Otras veces se distingue entre las ONG de servicios capaces de competir con el sector privado y público en el suministro de servicios o en la ejecución de contratos, de las participativas, tendientes a fortalecer la organización y las destrezas de los destinatarios de los proyectos (p. 18). (cursivas del original).

En términos generales, es posible identificar propuestas de clasificación que se encuentran estrechamente vinculadas a los diferentes momentos del "desarrollo" como paradigma del cambio social, y que proponen un esquema que es aplicable principalmente -aunque no exclusivamente- a la subcategoría conocida como Organizaciones No Gubernamentales de Desarrollo (ONGD). Otras clasificaciones, por el contrario, tienen un sentido más endógeno y pragmático, por lo que sus criterios están en función más bien de los campos de acción o las áreas de intervención de las organizaciones. Finalmente, se pueden localizar en la bibliografía clasificaciones considerablemente más específicas y abarcadoras, donde los patrones de clasificación van en función de variables autodefinidas o proclamadas por las propias organizaciones (observables en sus estatutos fundacionales), o que responden a la interpretación que se realiza de manera externa en torno al trabajo que desarrolla en la práctica cada organización; hablamos aquí de variables tales como: objetivos; misión, visión, filosofías; poblaciones meta; orientación político-ideológica; y proyecto de sociedad al que aspiran.

\section{Clasificaciones de acuerdo al país de origen}

Una de las primeras clasificaciones de las ONG que sale al paso en la literatura tiene que ver con la diferenciación que se realiza con respecto a la condición del país del que proceda la organización. Si bien esta es una clasificación que no necesariamente aparece explícita ni ocupa un apartado especial en la literatura relacionada, gran cantidad de autores y autoras parten de ella a la hora de realizar alguna diferenciación; por lo que es muy 
común que se refieran a las ONG del Norte - del mundo desarrollado o de Primer Mundo- y las ONG del Sur, sea, de países subdesarrollados, o del "Tercer Mundo" (Pi i, 1998). Sobre esto, desde el contexto costarricense -y coincidiendo en parte con García (2011)- Prado y Calderón apuntan:

Las relaciones entre el Norte y el Sur también se reflejan en el mundo de las ONG. La visión del Norte respecto del desarrollo es llevada a cabo coherentemente por sus diferentes ONG. La caracterización más precisa de ello son las organizaciones conservacionistas ortodoxas, en las cuales la protección ambiental predomina, sin importar el costo social o económico. Los que pagan este costo siempre son los pobres del Tercer Mundo que quedan inhabilitados para aprovechar [de manera sostenible, claro está] los recursos disponibles. Resulta paradójico que Europa, en donde los bosques han desaparecido hace más de doscientos años, pongan condiciones al aprovechamiento de los recursos de los países más pobres, incluso a la posibilidad del aprovechamiento sostenible, por privilegiar la conservación. Si bien existen Organizaciones del Norte comprometidas con el desarrollo humano sostenible, esta visión no es compartida por la mayoría. La gestión de estas organizaciones en los países del Tercer Mundo se limitó a acciones puntuales de escasa efectividad y alto costo (...) muchas de ellas han desarrollado formas de colaboración con organizaciones del Sur (...) sin embargo, en la mayoría de los casos las relaciones no son equitativas en la distribución de los recursos ni de las tareas (1996, p.410-411).

Es de destacar, por tanto, que esta clara delimitación que se establece a primera vista en términos semánticos, es a menudo trasladada a otros ámbitos, siendo que de una delimitación por criterio geográfico que mantiene el esquema bipolar, se pasa fácilmente a la reproducción de sesgos que no escapan del etnocentrismo, el eurocentrismo y el norteamericanismo. 


\section{Clasificaciones vinculadas al desarrollo de la cooperación internacional}

Se reconocen esfuerzos por clasificar a las ONG también en función de la época en que hayan sido fundadas, diferenciándose así al menos cuatro generaciones a partir de la década de 1950. Según este enfoque, cada una de estas generaciones de ONG están determinas por algo así como un cierto "espíritu organizativo, asociativo o solidario" que sería característico de momentos históricos específicos, por lo que cada organización nacida en dichos momentos comparte ciertos rasgos específicos, que estarían formando parte de su razón de ser y determinarían los objetivos concretos que perseguirían con el trabajo que desarrollan. En esta línea de clasificación, Pi i menciona que una de las clasificaciones más reconocidas sería la propuesta por David Korten; pero también es una forma de clasificar que se observa en autores/as ligados/as al estudio de la cooperación internacional tales como: Ortega, 1994; Murguialday y Valencia, 1999; Unceta y Yodi, 2000; Álvarez, 2012; Cuesta y Calabuig, 2010; y Morales, 2010.

Así las cosas, se puede constatar una primera generación de las ONG a la que pertenecerían aquellas organizaciones que surgieron en los 50 y 60 como consecuencia de situaciones de emergencia, y cuyo objetivo sería proporcionar acción inmediata, efectiva y humanitaria, enfocándose de manera casi exclusiva a la transferencia de dinero y actividades orientadas a incrementar el bienestar de los beneficiarios con una visión claramente asistencialista.

Habría una segunda generación cuya génesis se puede fijar entre los años 60 y 70, y estas estarían dedicadas -por su interés restricto- a la satisfacción de las necesidades básicas de poblaciones pobres y a la búsqueda de mecanismos de autoayuda. Son las organizaciones pertenecientes a esta generación a las se les conocerá como ONGD -o simplemente, organizaciones desarrollistas- y su característica principal será la implementación de programas a pequeña escala orientados a la prevención de problemas y a la transferencia tecnológica dentro de proyectos que buscaban el desarrollo de la autogestión.

Siguiendo con este esquema clasificatorio, la tercera generación de ONG refiere a las grandes organizaciones que predominaron a lo largo de los años 80. Dichas agrupaciones destacarían por su especialización en algunas áreas de desarrollo social, especialmente en la provisión de servicios y en la facilitación del desarrollo de otras ONG locales, regionales o nacionales (que generalmente serán sus contrapartes).

Finalmente, se tendría que mencionar una cuarta generación de ONG, fundadas en su mayoría a partir de los años 90, que estarían fuertemente influenciadas por el neoliberalismo, y en menor medida por la tendencia socialcristiana. A esta generación de ONG se les verá con mayor frecuencia involucradas en programas destinados a la producción, en pequeña escala, de pro- 
ductos para el mercado. Aunado a esto, serán organizaciones que se plantean temas como la intervención política y comprenden entre sus objetivos influir en las élites gobernantes responsables de las actuales políticas económicas desde una perspectiva relacionada con la pobreza.

Clasificaciones de acuerdo a la naturaleza, autodefinición y accionar operativo de las ONG

Existe, sin embargo, otra forma de clasificar a las organizaciones que forman parte del universo de las ONG a partir de variables que se consideran relevantes; un esquema que resulta de mayor concreción y flexibilidad y que encontramos en autores como García (1989) y Bombarolo et al, (1992), para quienes las organizaciones no gubernamentales se pueden clasificar, de manera general, de acuerdo a las siguientes variables:

- $\quad$ Según su Objetivo: con fines de lucro, orientadas a incrementar las ganancias económicas de sus miembros (asociaciones anónimas de producción o patrimoniales), cooperativas de ahorro y/o crédito, mutuales, asociaciones solidaristas, etc; o sin fines de lucro: donde la voluntad de sus miembros por agruparse pueden tener objetivos como el esparcimiento (clubes deportivos, centros de recreo, entre otros), de estudio (centros de investigación, de documentación, bibliotecas, etc.), defensa de intereses gremiales (sindicatos, asociaciones patronales) o de promoción del desarrollo de sectores populares (las ONGD). Según los autores, este último tipo de organizaciones no excluye el hecho de que, eventualmente, sus miembros puedan tener como meta de trabajo su propio desarrollo y sustentabilidad económica y laboral; sin embargo, no es esta la principal motivación para organizarse.

- $\quad$ Según el sentido de su trabajo: se trata, por una parte, de organizaciones que se caracterizan de acuerdo a las problemáticas particulares de los grupos sociales que atienden, siendo que se identifican las que están orientadas a la provisión de servicios sociales o atención de problemas personales o colectivos de grupos de clase media y/o alta (uniones, ligas o cámaras de productores -industriales y comerciales-; asociaciones o colegios profesionales; asociaciones de banqueros; etc.). Por otra parte, estarían las organizaciones destinadas de manera predominante a la atención de problemas surgidos en diversos grupos de personas o sectores sociales desprotegidos (en situación de pobreza, con problemas de salud -individualizados o colectivos-, educacionales -como el analfabetismo-, en condición de calle, desempleados/as) 
- $\quad$ Según las poblaciones destinatarias de sus acciones: las que actúan en beneficio propio (pero no de rentabilidad) o en beneficio de otro grupo social. Dentro de los primeros podrían contarse los clubes deportivos de barrio o comunitarios; asociación de propietarios de bienes inmuebles (condóminos/as); aficionados a algún deporte o actividad recreativa; etc.. Dentro del segundo tipo estarían las asociaciones voluntarias pero estructuradas (formalizadas legalmente o no) como las clásicas organizaciones de beneficencia o filantrópicas (religiosas o laicas).

- $\quad$ Según el carácter de sus programas o proyectos: se trata de organizaciones de carácter asistencial o benéfico; y organizaciones promotoras del desarrollo económico y social de grupos sociales. Las primeras se orientan a la prestación puntual de ayuda a grupos sociales específicos, que experimentan carencias elementales (salud, vivienda, educación, trabajo, vestido, entre otros), que enfrentan problemáticas más individualizadas (como es el caso de la adicción a drogas, la callejización, etc.), o colectivas (como el riesgo y la vulnerabilidad ante desastres naturales o ecológicos). El segundo tipo de organizaciones, según este criterio, se caracterizaría por su orientación hacia el desarrollo de actividades y tareas -que eventualmente contemplan la atención de necesidades puntuales pero que, sobre todo, las rebasan y superan- dirigidas a promover actitudes personales, familiares, comunales, o de clase a efectos de contribuir en los esfuerzos por impulsar determinados modelos de desarrollo social alternativo, basados en criterios de equidad, solidaridad, participación y democracia.

- $\quad$ Según el modelo social que buscan implementar: encontraríamos bajo este criterio, por un lado, a las organizaciones cuyo trabajo no pretende trascender las estructuras sociales y políticas del momento histórico determinado en el que están trabajando, por lo que tienden a la perpetuación del status quo y, por tanto, se les conoce también como organizaciones acríticas; generalmente creadas por los mismos gobiernos o agencias de cooperación o financiamiento con intereses particulares. Por otro lado, estarían las organizaciones críticas, que nacen principalmente como respuesta contestataria a realidades sociales o coyunturas políticas concretas y específicas; y que pretenden -al menos discursivamente- contribuir al proceso de cambio de estructuras sociales y ofrecer alternativas de cambio en los proyectos sociales de países, regiones o localidades.

Bajo un esquema o lógica similar a la que priva en este último criterio clasificatorio de ONG, Ángeles Diez Ramírez (del Instituto Español Ortega y Gasset) sostiene que posterior al boom de las ONG en los años 70 y 80, es posible identificar dos tipos de ONG, de acuerdo al sustrato ideológico que sub- 
yace en ellas: las vinculadas a planteamientos reivindicativos (justicia social, igualdad, etc.) y las centradas en acciones asistencialistas (ayuda de emergencias, proyectos sociales conservadores, etc.); a este respecto la autora precisa:

En el contexto de las ONG de los 70 estaba el peso ideológico de la revolución cubana y las guerrillas latinoamericanas, que alentaron la aparición y desarrollo de movimientos sociales radicales; y también la reacción internacional que se dirigió a impedir la expansión revolucionaria y a hacer "políticamente viable" el modelo capitalista para el Tercer Mundo, por lo que en esa línea se creó, para la región latinoamericana, la Alianza para el Progreso, el Banco Interamericano de Desarrollo y las "políticas sociales alternativas" con la intención de implementar la filosofía de la autoayuda y los cambios moderados que corrigieran los desequilibrios del sistema (...) También la iglesia, que hasta ese momento se había conformado con las clásicas acciones caritativas y misioneras, inspirada por el Concilio Vaticano II, inauguraba un discurso de mayor contenido social. Con el Papa Pío XII, que solicitó a las iglesias europeas la colaboración mediante fondos y personal a los esfuerzos misioneros, se abrió un ambiente progresista en la iglesia católica que daría lugar, en el caso latinoamericano, a la Conferencia del Episcopado latinoamericano en Medellín (1968) y a la "opción por los pobres" de la Teología de la Liberación. En esos años, surgieron ONG ligadas a los movimientos reivindicativos que no solo se nutrían ideológicamente de éstos, sino que les proporcionaban soporte organizativo y económico; otras, seguían desarrollándose ligadas a organismos internacionales centrándose en la asistencia social y la ayuda de emergencia (Diez, 2009).

\section{Reflexiones preliminares}

Una aproximación inicial al estado de la investigación académica costarricense sobre las ONG -a partir de la revisión y el análisis del catálogo de Trabajos 
Finales de Graduación de la Universidad de Costa Rica, así como de la literatura física y electrónica que es posible ubicar con algo de esfuerzo-, nos permite sostener la hipótesis de que el tema de las organizaciones no gubernamentales no ha recibido a la fecha la atención que merece en relación con la presencia de estas organizaciones en el país y la desregulación y poca fiscalización de las fuentes de financiamiento que estas mantienen.

Si bien en cuanto objeto de investigación académica, las ONG empezaron a ser estudiadas en nuestro país desde finales de la década de los 80 , y tuvieron un pico entre los años 90 y el primer lustro del siglo XXI; en la actualidad, no parecen constituir un objeto de mayor interés; y solo a partir de 2008 han empezado a aparecer trabajos que tienen una intencionalidad crítica frente al tema.

El tipo de abordaje que caracteriza a casi la totalidad de las investigaciones que se registran en el Sistema de Bibliotecas, Documentación e Información (SIBDI) de la Universidad de Costa Rica muestra una clara tendencia hacia los análisis descriptivos; al tiempo que cuando los estudios intentan trascender a investigaciones de mayor profundidad, los esfuerzos se orientan a aspectos operativos de la gestión interna de las organizaciones, la captación de recursos, las metodologías de trabajo, entre otros, con un claro enfoque eficientista.

Más allá del estado de la investigación, el discurso oficial acerca de las ONG no parece haber variado mucho desde el momento en que se publicó el último de los escasísimos trabajos colectivos dedicado exclusivamente a este tema. Con excepción, por un lado del número especial que publicó la Revista Parlamentaria sobre las ONG -y algunos trabajos realizados en el marco del proceso de integración regional a partir de los acuerdos de Esquipulas I y II, relacionados con la Concertación- no se identifica existencia alguna de debates en torno a esta temática. Esto último pese a que el país, incluso, haya figurado como sede de varios eventos internacionales relacionados con el tema; tal es el caso de la IV Conferencia Regional de ISTR, celebrada en la ciudad de San José en el año 2003. Mientras tanto, el discurso político nacional respecto al tema, no presenta mayor diferencia con el de los organismos de financiamiento internacional, donde de manera natural se considera a las ONG como agentes aliados en la gestión de la pública y como potenciales sustitutas.

Finalmente; si bien es innegable que con respecto al resto de Centroamérica, Costa Rica no tiene el mismo nivel de presencia e impacto de estas organizaciones, ni tampoco pareciera que capte la misma cantidad de recursos financieros; eso no quiere decir que la cantidad y el papel de las ONG que operan en el país no amerite el estudio profundo, sistemático y permanente del fenómeno. La cantidad de organizaciones de esta naturaleza directamente vinculadas a áreas como la asistencia social, niñez y adolescencia, o conservación ambiental y biodiversidad presentan dimensiones lo suficientemente justifica- 
bles para volcar la mirada investigativa desde el ámbito académico y especialmente desde las ciencias sociales.

\section{Bibliografía}

Aguayo, S. (1992). Del anonimato al protagonismo: los organismos no gubernamentales y el éxodo centroamericano. Foro Internacional, Enero-Marzo, 1992, no.3, vol. XXXII, pp. 323-341.

Agurto, I y Piña, C (1988). Las Organizaciones No Gubernamentales de Promoción y Desarrollo Urbano en Chile: una propuesta de investigación. Material de Discusión \# 110. Programa FLACSOSantiago. Santiago, Chile. FLACSO.

Alpízar, L; Mora, S. Carvajal Evelyn y Cedeño, A. (2003). Los métodos de intervención de las organizaciones no gubernamentales en la formación y capacitación laboral de adolescentes en riesgo social. Tesis para optar por el grado de licenciatura en Trabajo Social. Escuela de Trabajo Social, Facultad de Ciencias Sociales, Universidad de Costa Rica. San José, Costa Rica.

Álvarez, S. (2012). Una introducción a la cooperación internacional al desarrollo. Revista REDUR, 10; 285-309.

Arango, M.; Pérez, G. y Sepulveda, L. (2011). Las organizaciones no gubernamentales -ONG-: hacia la construcción de su significado. Ensayos de Economía, 38;243-260.

Arato, A. (1996). Emergencia, declive y reconstrucción del concepto de sociedad civil. Isegoría 13; 5-17.

Araya, B y Jiménez, M (2005). El enfoque de derechos desde las ONG que trabajan con personas adultas mayores en Costa Rica. Tesis para optar por el grado de licenciatura en Trabajo Social. Facultad de Ciencias Sociales. Universidad de Costa Rica. Costa Rica. San José, Costa Rica.

Arellano-López, S. y Petras, J. (1994). La ambigua ayuda de las ONGs en Bolivia. Revista Nueva Sociedad, 131;72-87.

Arias, A. (1993). Las Organizaciones No Gubernamentales en Costa Rica: análisis y diseño organizacional. Tesis sometida a consideración del Programa de Estudios de Posgrado en Administración Pública para optar por al grado de Maestría. Universidad de Costa Rica. Sistema de Estudios de Posgrado. San José, Costa Rica. 
Ayllón, B. (2014). La Gobernanza de la Cooperación y el rol de las Organizaciones de la Sociedad Civil en la Cooperación Sur-Sur. Revista Internacional de Cooperación y Desarrollo. 1(2); 33-46.

Balbis, J. (2001). ONGs, gobernancia y desarrollo en América Latina y el Caribe. Documento base del Seminario Regional de América Latina y el Caribe "ONGs, Gobernancia y Desarrollo en América Latina y el Caribe", noviembre de 2001, Montevideo http://www.lasociedadcivil.org/uploads/ciberteca/balbis.pdf

Bejarano, G y Víquez, R. (1996). Organizaciones no gubernamentales ante el nuevo rol del Estado. Revista Parlamentaria, 4( 2).

Beltrán, J. (2006). Entre sueños globales y condiciones materiales: la otra cara de las ONG. Las ONG, un mundo heterogéneo. Revistateína 11. http://www.revistateina.es/teina/web/teina11/dos2.htm. Recuperado en fecha 13/07/2013.

Bolandi, R; González, M y Hidalgo, J. (1995). La intervención de las ONG's en la promoción de la participación de la mujer rural en grupos asociativos femeninos para la producción: la perspectiva de las mujeres. Tesis para optar por el grado de licenciatura en Trabajo Social. Escuela de Trabajo Social, Facultad de Ciencias Sociales, Universidad de Costa Rica. San José, Costa Rica.

Bombarolo, F y Pérez, L. (1998). Cambio y fortalecimiento institucional de las ONGDs: El caso Argentino. En: Valderrama, M y Pérez, L. (comps.). Cambio y fortalecimiento institucional de las Organizaciones No Gubernamentales en América Latina. Buenos Aires, Argentina. Ediciones FICONG-ALOP.

Bombarolo, F; Pérez, L y Stein, A (1992). El rol de las Organizaciones No Gubernamentales en América Latina y el Caribe. Buenos Aires, Argentina: FICONG.

Boza, E. y Monge, L. (2008). Análisis del vínculo entre el Estado y las ONG de asistencia social en su relación con las transformaciones históricas del capitalismo en Costa Rica: 1978-2008. Tesis para optar por el grado de Licenciatura en Trabajo Social, Universidad de Costa Rica, San José.

Boza, E. y Monge, L. (2010). La función política ideológica de las ONG en el escenario de la (contra) reforma estatal. Reflexiones, 89 (1), 77-86.

Brenes, M. y Chacón, M.S. (2009). Intervención con personas en situación de indigencia: Un análisis crítico a cuatro Organizaciones no Gubernamentales. Tesis para optar por el grado de Licenciatura en 
Trabajo Social. Facultad de Ciencias Sociales. Universidad de Costa Rica. Costa Rica. San José, Costa Rica.

Calabuig, C y Gómez-Torres, M. (2010). Cooperación Internacional para el Desarrollo. Cuadernos de Cooperación para el Desarrollo $N^{\circ} 1$. Editorial de la Universitat Politècnica de València, Centro de Cooperación para el Desarrollo. Valencia, España.

Calvo, M; Chinchilla, M; Coto, G. y Pacheco, E. (1993). Las Organizaciones No Gubernamentales y su Participación en la Gestión de la Política Social Costarricense. Informe de Seminario de Graduación presentado para optar al título de Licenciatura en Trabajo Social. Universidad de Costa Rica. Facultad de Ciencias Sociales, Escuela de Trabajo Social. San José, Costa Rica.

Campos, L y Salazar, R (1987). Los organismos no gubernamentales de protección de los derechos humanos. Tesis para optar por el grado de Licenciatura en Derecho. Facultad de Derecho, Universidad de Costa Rica. San José, Costa Rica.

Cañas, A. (2008). Estatus Jurídico de las Organizaciones No Gubernamentales Internacionales. Tesis para optar por el grado de Licenciatura en Derecho. Facultad de Derecho, Universidad de Costa Rica. San José, Costa Rica.

Casaburi, G., Riggirozzi, M. y Tuozzo, M. (2000). El Banco Interamericano de Desarrollo, el Banco Mundial y la sociedad civil: Luces y sombras de una nueva relación. Buenos Aires: Facultad Latinoamericana de Ciencias Sociales.

Casey, J. (1996). Las organizaciones no gubernamentales: su papel en las políticas públicas. Revista Gestión y Análisis de Política Pública (GAPP) 5-6. 175-188. Instituto Nacional de Administración Pública, Gobierno de España. Madrid, España. http://revistasonline.inap.es/index.php? journal=GAPP\&page =article \&op=view\&path\%5B\%5D=76\&path\%5B \%5D=76 Recuperado en fecha 18/11/2014.

Catalán, C. (1987). Las ONGs y la investigación en comunicaciones en Chile: una aproximación preliminar. Documento de Trabajo \# 402. Programa FLACSO-Chile. Santiago, Chile. FLACSO.

Comisión para la Defensa de los Derechos Humanos en Centroamérica CODEHUCA (1994). Los Horizontes del éxodo: el proceso de reincorporación de los retornados salvadoreños y guatemaltecos. San José, Costa Rica. 
Contreras, M. A. (1997). Organizaciones No Gubernamentales: realidad y reto. En: Derechos Humanos, Órgano Informativo de la Comisión de Derechos Humanos del Estado de México. Gaceta No. 28. VII Doctrina. Diciembre de 1997. CODHEM. Toluca, México.

Cordero, C. (1996). Incógnitas de una ecuación. Revista Parlamentaria, 4(2).

Carrales, J; Machado, A. y Salgado, C. (1995). Relaciones ONGs y Estado en Desarrollo Sostenible en Colombia. Seminario-Taller Internacional. Bogotá, Colombia. CINEP-IICA.

Cuesta, I. y Calabuig, C. (2010). La Cooperación No Gubernamental (Capt. IV). En: Boni y otros (2010). Cuadernos de Cooperación para el Desarrollo. Núm.1. Centro de Cooperación para el Desarrollo. EDITORIAL UNIVERSITAT POLITĖCNICA DE VALÈNCIA. Valencia, España.

Chateu, J y Martinic, S. (1989). Educación para Adulto y Educación Popular en la última década. Documento de Trabajo \# 400. Programa FLACSOChile. Santiago, Chile. FLACSO.

Defensa de Niños Internacional-Costa Rica (2004). COSECODENI: ¿quiénes somos y qué hacemos? En: www.dnicostarica.org/.../01-12-2004\%20quienes-somos-hacemos.pdf.

Derechos Humanos (1997). Organizaciones no gubernamentales pro derechos humanos. Gaceta No. 28 Órgano Informativo de la Comisión de Derechos Humanos del Estado de México. Toluca, México.

Diez, A. (1999). Voluntariado, ONGs y sociedad civil en la reordenación globalizadora. Tercer Sector y Participación Juvenil. Revista Estudios de Juventud. 45; 93-102.

Diez, A. (2009). Organizaciones no-gubernamentales: Las ONGs en el marco del nuevo orden mundial. En: Reyes, Román (Dir.). Diccionario Crítico de Ciencias Sociales. Terminología científico social. $\left(3^{\circ}\right.$ Ed.) Universidad Complutense de Madrid y Plaza y Valdés, Editores. Madrid, España.

Enríquez, A. (1997). Desarrollo y ONG en El Salvador: retos y perspectivas. Alternativas para el Desarrollo, 44; 1-11.

Enríquez, A. (1998). Desarrollo y ONG en El Salvador: retos y perspectivas. Alternativas para el Desarrollo, 55; 32-39.

Fernández, A. R. (2003). Las ONG entre lo público y lo privado. Revista Foro, 47; 57-61. 
Fonseca C; Salazar M y Valerio, C. (2009) El accionar de las Organizaciones no Gubernamentales desde el componente atención de la política pública contra la Explotación Sexual Comercial de Niños, Niñas, y Adolescentes (ESCNNA). Tesis para optar por el grado de Licenciatura en Trabajo Social. Facultad de Ciencias Sociales. Universidad de Costa Rica. Costa Rica. San José, Costa Rica.

Foro Internacional de ONGs y Movimientos Sociales (1992). Construyendo el futuro: tratados alternativos de Río 92. Editorial Porvenir -CECADE. San José, Costa Rica.

Furche, C. (1982). Los organismos no gubernamentales y el desarrollo rural en Ecuador: apuntes para una discusión. Revista EURE, X(29); 67-86.

Gadea, P. y Gómez, C. (1999). El debate sobre las ONG's en España: el caso de los servicios sociales. Revista de Servicios Sociales, 36; 34-42.

García, A. (2011). EL "OENEGEISMO", ENFERMEDAD INFANTIL DEL DERECHISMO (O cómo la "reconducción" del Proceso de Cambio es la restauración neoliberal). Vicepresidencia del Estado Plurinacional, Presidencia de la Asamblea Legislativa Plurinacional. La Paz, Bolivia.

García, A. (2012). GEOLOPÍTICA DE LA AMAZONÍA. Poder hacendalpatrimonial y acumulación capitalista. Vicepresidencia del Estado Plurinacional, Presidencia de la Asamblea Legislativa Plurinacional. La Paz, Bolivia.

García, J. E. y Martinic, S. (1984). Las instituciones privadas y la educación popular: el caso de Chile. Ponencia presentada en la Reunión Regional de Educación Para Adultos. Programa Regional de Desarrollo Educativo, PREDE. 25-30 noviembre de 1985. San José, Costa Rica.

García, J. E. (1989). La contribución de las organizaciones no gubernamentales de desarrollo a la educación para adultos. UNESCOOREALC. Santiago, Chile.

Gerstenfeld, P y Fuentes, A. (2005). Caracterización del Tercer Sector en las políticas públicas de formación de capital humano en Uruguay. CEPAL. Montevideo, Uruguay.

Gómez, C. (2004). Las ONG en la sociedad global: estrategias de las ONG frente al Estado en la era de la globalización. Cuadernos BAKEAZ, 65.

Gómez, S. (1987a). Experiencias no gubernamentales de desarrollo rural en Chile. Diseño de Investigación Documento de Trabajo \# 01. Programa FLACSO-Santiago de Chile. Santiago, Chile. FLACSO. 
Gómez, S. (1987b). Organismos Privados de Desarrollo Rural: algunas características básicas. Documento de Trabajo \# 349. Programa FLACSO-Santiago de Chile. Santiago, Chile. FLACSO.

Gómez, S. (1988). ¿Nuevas formas de desarrollo rural en Chile? Un análisis de los ONG. Documento de Trabajo \# 393. Programa FLACSO-Chile. Santiago, Chile. FLACSO.

Gómez, S. (1992a). Dilemas de los ONGs rurales en el contexto democrático. Documento de Trabajo \# 41. Programa FLACSO-Chile. Serie Estudios Sociales. Santiago, Chile. FLACSO.

Gómez, S. (1992b). Desarrollo Rural. Catastro, Organismos No Gubernamentales. Santiago, Chile. FLACSO-Fundación Andes.

Gutiérrez, D; Mora, P. y Vargas, K (2002). Análisis de la gestión de las organizaciones no gubernamentales orientadas a la atención de la niñez y su relación con el Estado. Memoria de Seminario de Graduación para optar por el grado de licenciatura en Administración Pública. Facultad de Ciencias Económicas, Universidad de Costa Rica. San José, Costa Rica.

Herrera, M. (1997). ¿Cómo funcionan las organizaciones del Tercer Sector? Un análisis de la estructura y las dinámicas organizativas. Revista Gestión y Análisis de Política Pública 9; 69-94.

Hidalgo, M y Largaespada, S. (2009). La Respuesta de las Organizaciones No Gubernamentales a los Derechos y Necesidades de la Niñez y Adolescencia en Condiciones de Exclusión Social en Costa Rica. Tesis para optar por el grado de Licenciatura en Trabajo Social. Facultad de Ciencias Sociales. Universidad de Costa Rica. Costa Rica. San José, Costa Rica.

Hilhorst, J. (1983). Organizaciones No Gubernamentales y el Desarrollo Rural Integrado. Revista EURE, 10(29); 9-22.

INBAS y Lrsocialresearch (2005). Evaluación del rol de ONG como socios de la Cooperación Austriaca para el Desarrollo en Nicaragua y su contribución en la erradicación de la pobreza. Viena, Australia I Coatepec, México.

Irías, G. (1996). Ajuste Estructural e Inversión Social. La participación de las ONGs en los FIS. San José, Costa Rica. Departamento Ecuménico de Investigaciones (DEI).

Jiménez, A. (1996). Personalidad jurídica de las organizaciones no gubernamentales. Tesis para optar por el grado de Licenciatura en 
Derecho. Facultad de Derecho, Universidad de Costa Rica. San José, Costa Rica.

Jiménez, R (1995). Captación de recursos para una organización no gubernamental. Proyecto de graduación para optar por el grado Master in Business Administration. Unational University. Heredia, Costa Rica.

López, J. A. (2004). Luces, cámaras e... acción solidaria. A influencia mediática na cooperación internacional. Actas de los talleres para el V Congreso Portugués de Sociología. www.aps.pt/cms/docs_prv/docs/DPR46151dc009cd2_1.pdf. Recuperado en fecha 30/07/2013.

López, J. A. (2006 a). Los medios de comunicación y ONGDS: la conformación de una nueva cultura corporativa en el sector solidario. Monografía. Caritas. Documentación Social No. 140. Págs. 39-55. Recuperado en fecha 30/07/2013. http://www.caritas.es/imagesrepository/CapitulosPublicaciones/521/04\% 20LOS\%20MEDIOS\%20DE\%20COMUNICACI\%C3\%93N\%20Y \%20LAS\%200NGDS.pdf.

López, J.A. (2006 b). Los medios de comunicación y las ONGDs: la conformación de una nueva cultura corporativa en el sector solidario. En: Caritas. Documentación Social. No. 140. Revista de Estudios Sociales y Sociología Aplicada. Comunicación y Sociedad Civil. Monografías. Págs. 39-45. Cáritas. Madrid, España. http://www.caritas.es/imagesrepository/CapitulosPublicaciones/521/04\% 20LOS\%20MEDIOS\%20DE\%20COMUNICACI\%C3\%93N\%20Y \%20LAS\%200NGDS.pdf.

López, J. A. (2006 c). El tercer sector y el mercado: conflictos institucionales en España. Centro de Investigaciones Sociológicas. Madrid, España. Siglo XXI, Editores.

Lucatello, S. (2014). La cooperación internacional y medio ambiente: tendencias y desafíos para Latinoamérica. Revista Internacional de Cooperación y Desarrollo. 1(2); 33-46.

Lladser, M. T. (1986). Centros Privados de Investigación en Ciencias Sociales en Chile (CESOC). Academia de Humanismo Cristiano-FLACSO. Santiago, Chile.

Mesa, R. (1980). "Ecologia" de las Relaciones Internacionales. En: Cid, lleana (Comp) (2001). Lecturas básicas para la introducción al estudio de las Relaciones Internacionales. Facultad de Ciencias Políticas y Sociales (UNAM), Ciudad Universitaria, México, D.F. 
Monge, H. (1999). Centroamérica: La sociedad civil, protagonista del proceso de integración. Editorial Porvenir ALOPCECADE. San José, Costa Rica.

Morales, H. (2010). La cooperación Internacional en Centroamérica. Una mirada crítica de los sujetos políticos de la región. MUGARIK GABE. Guatemala.

Murguialday, C. y Valencia, I. (1999). Las organizaciones no gubernamentales para el desarrollo. Cooperación para el Desarrollo, Manual de Formación No. 2. Valencia, España. Servicio Central de Publicaciones del Gobierno Vasco. Vitoria-Gasteiz.

O' Neill, S. (2004). En el mundo hay dos países mimados por la cooperación y uno es Nicaragua. Charla con la Revista Envío sobre ideas y experiencias de trabajo en la cooperación con los países del Sur, con Centroamérica y Nicaragua. En: Revista Envío [en línea]. No. 268 (2004). <http://www.envio.org.ni/articulo/2171>

Ortega, M. L. (1994). Las ONGD y la CRISIS del desarrollo. Un análisis de la cooperación con Centroamérica. Colección Cooperación y Desarrolla No. 10. Editorial IEPALA. Madrid, España.

Padrón, M (1981). El papel de las Organizaciones no Gubernamentales: Desarrollo y Participación Popular. En: Roca, S (comp). La autogestión en América Latina y el Caribe. Lima, Perú. Ediciones CLA e IICA.

Palladino, J. P. (2006). El delgado hilo entre la asistencia social y la despolitización de conflictos. Las ONG, un mundo heterogéneo. Revistateína; 11.

Patronato Nacional de la Infancia PANI (2013). Informe de Gestión Institucional 2013. San José, Costa Rica.

Patronato Nacional de la Infancia PANI (2014). Informe de Gestión: Por la mejora de la calidad de vida de niños, niñas y adolescentes en comunidades protectoras de sus derechos. San José, Costa Rica.

Patronato Nacional de la Infancia PANI (2015). Liquidación presupuestaria 2014. Informe Evaluación Anual, Metas del Plan Operativo Institucional 2014. San José, Costa Rica. http://www.pani.go.cr/files/Fina-Pres2011/liquidacion_presupuestaria_2014.pdf. Consultado en fecha $18 / 03 / 2015$

Patronato Nacional de la Infancia PANI-Fondo de Naciones Unidas para la Infancia UNICEF (2009) Política Nacional para Niñez y la Adolescencia de Costa Rica 2009-2021. San José, Costa Rica. 
Petras, J y Veltmeyer, H. (2004). Las dos caras del imperialismo: Vasallos y Guerreros. México, DF. Editorial LUMEN.

Petras, J. (1997.b). Neoliberalismo en América Latina: La Izquierda Devuelve el Golpe. Buenos Aires, Argentina.: Homo Sapiens.

Petras, J. (1997.c). Imperialismo y ONGs en Latinoamérica. Monthly Review, 9; 10-27.

Petras, J. (1997a). El posmarxismo rampante. Crítica a los intelectuales y a las ONG's. Viento Sur 31; 35-46.

Petras, J. y Veltmeyer, H. (2002). El imperialismo en el siglo XXI. La globalización desenmascarada. Madrid, España. Ediciones Popular

Petrone, F. (2013). El humanitarismo es la continuación del capitalismo con otros medios. Revista Internacional de Ética y Política; 2.

Picas, J. (2001). El papel de las Organizaciones no Gubernamentales y la Crisis del Desarrollo. Una crítica antropológica a las formas de cooperación. Tesis para optar por el grado de Doctor en Antropología Social. Departament d'Antropologia Social i d'Història d'Amèrica i Àfrica. Facultat de Geografia i Història; Universitat de Barcelona. Barcelona, España. http://diposit.ub.edu/dspace/handle/2445/35192. Recuperado en fecha 22/11/2013.

Picas, J. (2003). Las ONG y la cultura de la solidaridad: la ética mínima de la acción humanitaria. Revista Papers; 71; 65-76.

Picas, J. (2006). Los límites de la solidaridad. Las ONGs y el mercado de 'bienes simbólico.'Revista Gazeta de Antropología; 22.

Pi i, A. (1998). Breve panorama de las organizaciones no gubernamentales. Revista Este País; 87.

Pi i., A. (2006). Las ONG como nuevo actor social. Dirigentes y Beneficiarios: ¿Visiones e Imágenes encontradas? Tesis para optar por el grado de Doctora en Ciencias Antropológicas. Universidad Autónoma Metropolitana. Unidad de Iztapalapa, División de Ciencias Sociales y Humanidades. México, D.F.

Prado, M. y Calderón, P. (1996). Las Organizaciones no gubernamentales ante el nuevo rol del Estado. Revista Parlamentaria. 4;(2).

Piña, C. (1989). Las ONGs en el ámbito local urbano. Desafíos y potencialidades. Documento de Trabajo \# 433. Programa FLACSOChile. Santiago, Chile. FLACSO. 
Rabotnikof, N. (2001). La caracterización de la sociedad civil. Perspectiva de los bancos multilaterales de desarrollo. Nueva Sociedad; 171.

Rabotnikof, N.; Riggiorozzi, M. y Tussie, D. (2000). Los organismos internacionales frente a la sociedad civil: Las agendas en juego. En: Tussie, Diana (Comp.) (2000). Luces y sombras de una nueva relación: el Banco Interamericano de Desarrollo, el Banco Mundial y la Sociedad Civil. FLACSO-Temas Grupo Editorial. Buenos Aires. Argentina.

Reuben, W. (1988). Las organizaciones no gubernamentales (ONGs) en el desarrollo rural de América Latina y el Caribe. San José, Costa Rica. IICA.

Reuben, W. (1991). El papal de las ONG en la cooperación europea hacia Centroamérica. En: Ruben, R. y Van Oord, G. (Edts). Más allá del Ajuste: la contribución europea al desarrollo democrático y duradero de las economías centroamericanas. San José, Costa Rica. Departamento Ecuménico de Investigaciones (DEI).

Rocha, J. L. (2011). Los jinetes del desarrollo en tiempos neoliberales Las ONG. Revista Envío, No. 354; 35-44.

Rodríguez, W (2007). Formulación de un programa de formación organizacional para el mejoramiento de la interacción social, orientado a mandos medios de una organización no gubernamental. Proyecto de tesis (para optar por el grado de Licenciatura en Psicología. Facultad de Ciencias Sociales. Universidad de Costa Rica. 2007. Costa Rica. San José, Costa Rica.

Rojas, M. C. (2000). Las Fundaciones Empresariales en Colombia. En: Lo Público: una pregunta desde la sociedad civil. Ciudad: Ed. Quebecor Impreandes Ltda.

Rossel, C. (2013). Te amo, te odio, dame más: ONG, participación y representación en el primer gobierno de izquierda de Uruguay. Ciudad Autónoma de Buenos Aires, Argentina. CLACSO.

Rossel, C. (2010). Tercer sector y prestación de servicios públicos: la "caja negra" de la participación ciudadana en la gestión pública y su impacto en los regímenes de bienestar corporativos. Revista Reforma $y$ Democracia, 47.

Ruiz, D. (2005). Marco Institucional de Atención a la Niñez y la Adolescencia en Costa Rica: El Patronato Nacional de la Infancia en su vínculo técnico y financiero con las ONG. Un asunto de política pública. Tesis para optar por el grado de Licenciatura en Trabajo Social. Escuela de Trabajo Social, Universidad de Costa Rica. San José, Costa Rica. 
Ruiz, J.I.; Jiménez, A.; Anheir, H. y Salamon, L (2001). XVIII. España. En: Salamon et al (Coord). La sociedad civil global: dimensiones del sector no lucrativo. Proyecto de Estudio Comparativo del sector no lucrativo de la Universidad Johns Hopkins. Fundación BBVA. Madrid, España.

Salamon, L; Anheier, H; List, R; Toepler, S; Sokolowski, W., y colaboradores (2001). La sociedad civil global: dimensiones del sector no lucrativo. Proyecto de Estudio Comparativo del sector no lucrativo de la Universidad Johns Hopkins. Fundación BBVA. Madrid, España.

Sánchez, S. (1998). Costa Rica. En: Fundación Arias para la Paz y el Progreso Humano (Comp.). Marco Jurídico que regula a las Organizaciones Sin Fines de Lucro en Centroamérica. Serie: El Derecho y la Sociedad Civil No. 3. San José, Costa Rica.

Sauma, K (2011). La posibilidad de las organizaciones costarricenses sin fines de lucro de acceder a los mecanismos de resolución de controversias del Derecho internacional de inversión. Tesis para optar por el grado de Licenciatura en Derecho. Facultad de Derecho, Universidad de Costa Rica. San José, Costa Rica.

Serbin, C. (1997). Globalización y sociedad civil en los procesos de integración. Revista Nueva Sociedad, 147. 44-55.

Serrano, E. (1999). Las ONG como actores de las relaciones Internacionales. Tesis Doctoral. Universidad Complutense de Madrid, Facultad de Ciencias Políticas y Sociología, Departamento de Derecho Internacional Público y Relaciones Internacionales. Madrid, España. http://eprints.ucm.es/2019/1/S1038801.pdf. Recuperado en fecha $17 / 07 / 2014$

Serrano, E. (2004). Organizaciones internacionales no gubernamentales. Fundamentos para una teoría. Senado de la República. México, D.F.

Spoerer, S. (1988, 03 de junio). Las ONG, escuelas de ciudadanía en América Latina. El País. Recuperado de: http://elpais.com/diario/1988/06/03/internacional/581292015_850215.ht $\mathrm{ml}$

SustainAbility (2005). La ONG del siglo XXI: En el mercado, por el cambio. (Edición en Español) Fundación Ecología y Desarrollo.

Torres-Rivas, A. (2001). La sociedad civil en la construcción democrática: notas desde una perspectiva crítica. Revista Instituciones y Desarrollo, 8 y $9 ; 143-170$. 
Tussie, D. (1997). El BID, el Banco Mundial y la sociedad civil: nuevas modalidades de financiamiento internacional. Buenos Aires: Facultad Latinoamericana de Ciencias Sociales.

Tussie, D. y Tuozzo, M. F. (1997). Introducción. En: Tussie, D. (compiladora). El BID, el Banco Mundial y la sociedad civil: nuevas modalidades de financiamiento internacional. Buenos Aires: Facultad Latinoamericana de Ciencias Sociales.

Unceta, K. y Yoldi, P. (2000). La cooperación al desarrollo: surgimiento y evolución histórica. Vitoria-Gasteiz: Servicio Central de Publicaciones del Gobierno Vasco.

Valverde, A. (1996). Organizaciones no gubernamentales ante el nuevo rol del Estado. Revista Parlamentaria, 4(2).

Vargas, L. y Vega, O (2005). Organizaciones no gubernamentales en Costa Rica: un andamiaje para la atención y protección de la población menor de edad. Tesis para optar por el grado de Licenciatura en Ciencias Políticas, con énfasis en Gobierno y Políticas Públicas. Facultad de Ciencias Sociales, Escuela de Ciencias Políticas. Universidad de Costa Rica. San José, Costa Rica. 
Revista Rupturas, Volúmen 5 Número 2 Centro de Investigación en Cultura y Desarrollo (CICDE)

Universidad Estatal a Distancia (UNED)

San José, Costa Rica

Julio-Diciembre 2015 


$\begin{array}{llrlll}\text { Apuntes relativos a } & \text { la } & \text { Outlines } & \text { Related to the } & \text { Artículo recibido: } \\ \text { producción del conocimiento } & \text { Production } & \text { of } & \text { Scientific } & 4 \text { de noviembre del } 2014 . \\ \text { científico, } & \text { dilemas } & \text { y } & \text { Knowledge, Dilemmas and } & \text { Evaluado: } \\ \text { posibilidades } & \text { en } & \text { la } & \text { Possibilities in Social Research } & \text { 28 de noviembre del } 2014 . \\ \text { investigación social } & & & & \text { Aceptado: } \\ \end{array}$

RESUMEN

En este trabajo los autores desarrollan una introducción a la investigación en las ciencias sociales como consecuencia de una serie de preguntas y reflexiones acerca de cómo es el proceso de elaborar una investigación. Los investigadores también sugieren algunas ideas y consejos para elaborar un trabajo de investigación, con la idea clara de que cada investigación también es una artesanía más que un manual. Por último, algunas de estas ideas se pueden cambiar y ser deconstruidas a lo largo del tiempo.

Palabras Clave

Investigación; introducción; ciencias sociales; elaboración de proyecto de investigación

\section{ABSTRACT}

In this paper, the researchers develop an introduction to research in Social Sciences, this as a result of a number of questions and reflections on the process of building a research project. The researchers also suggest some ideas and give advice on how to shape a research paper, clearly stating that every research project is a product of careful craftsmanship more than just a following a manual. Finally, some of this ideas can be changed and deconstructed through time.

\section{KEY WORDS}

Research; introduction; social sciences; how to make a research paper

Licenciado en Ciencias Políticas por la Universidad de Costa Rica. Máster en Estudios Latinoamericanos con énfasis en Cultura y Desarrollo de la Universidad Nacional de Costa Rica. Investigador del Centro de Investigación en Cultura y Desarrollo de la Universidad Estatal a Distancia de Costa Rica (UNED).

Correo electrónico: abadillas@uned.ac.cr

Sociólogo por la Universidad Nacional de Heredia, Costa Rica. Egresado de la Maestría Centroamericana de Sociología de la Universidad de Costa Rica. Investigador y docente del Centro de Investigación en Cultura y Desarrollo (CICDE) de la Universidad Estatal a Distancia de Costa Rica (UNED).

Correo electrónico: jsolis@uned.ac.cr

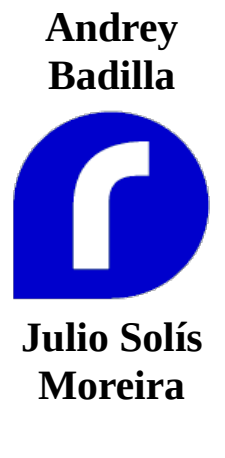




\section{Apuntes relativos a la producción del conocimiento científico, dilemas y posibilidades en la investigación social}

La ciencia emerge como una práctica, con el tiempo y la formación se convierte en una actividad cotidiana, puede estar al alcance de todos (as) y esto refleja la necesidad humana de interrogarnos, poner en duda a nuestro entorno, las relaciones con los demás y con los fenómenos que nos rodean. Siguiendo el aporte de Badilla (2011), ha de tenerse en cuenta que la ciencia en su origen es un reflejo de la experiencia humana y de la sumatoria de las capacidades personales de muchos investigadores y pensadores que han ido desarrollando prácticas metódicas, que en el tiempo han derivado en un nosotros, en una comunidad científica que sostiene un conjunto de conocimientos; de esta forma el saber y la investigación científica se reconocen como una herencia humana.

En referencia a lo expuesto, el saber en las ciencias sociales implicaría una característica profundamente humana, referida al sentido y el significado de nuestras vidas, señalaría Berger (1967, p.230) como la realidad es en parte "comedia humana", pues se entrecruzan aspectos simpáticos de nuestras vidas que han sido marcadas desde niños (as), influenciadas por un sentido compartido o común, por un mundo que se nos aparece como objetivo, por instituciones compartidas, por reglas que nos hacen humanos. La diferencia radica en que la ciencia busca conseguir algún grado de certidumbre sobre esa experiencia humana mediante un método, buscando comprender y definir lingüísticamente el saber para compartirlo en textos, útiles e instrumentos. Actualmente también la virtualidad está tomando importancia a modo de especio compartido o accesible.

Como obra humana el saber también tiene algo de arte, de artesanía intelectual, esto implicaría hacer cosas que son particulares a cada una y uno de nosotros. La artesanía nos relaciona con las obras materiales e intelectuales 
que se hacen sin emplear técnicas de reproducción en masa o de montaje. Si vemos la investigación y la ciencia como una artesanía, aunque busquemos hacer un producto parecido al anterior, tendrá siempre sus peculiaridades, pues tendrá impresa la vitalidad de su creador, como diría Sennett (2009): "El artesano representa la condición específicamente humana del compromiso" (p.32).

Manteniendo la reflexión anterior, hay que tener en cuenta que la implicación humana en el saber de las ciencias sociales también envuelve un punto de discusión clásico, como es, el de la objetividad, condición de difícil resolución pues la neutralidad o distanciamiento sobre los fenómenos que observamos se limita pues están incorporados en nuestra experiencia, son sentimientos, vitalidades y acervos personales que hacen dificultoso que el investigador no se involucre personalmente en sus estudios, esto no tiene por qué ser un sesgo, eso sí, tiene que hacerse explícito, como un requisito para la investigación crítica, que se ha de sustentar en posturas metodológicas, conceptuales, contextuales y teóricas claras para avanzar en la ciencia social.

A lo largo de la historia humana, hemos acumulado experiencias, logros y fracasos que con el pasar de los años se han convertido en conocimientos, experiencias importantes y valiosas para el saber actual. Sin embargo, dada las limitaciones humanas somos incapaces de abordar todos los campos del saber, a lo que debemos sumarle las motivaciones subjetivas, predilecciones y cercanías con nuestra vida cotidiana, estos condicionantes son centrales en la escogencia de un tema, estas inquietudes y preferencias nos ayudan en la escogencia de un tema de investigación o de trabajo final de graduación.

Bajo lo planteado, conocemos de muchas maneras, por ejemplo, a través de la experiencia y la tradición, conocemos mediante la(s) ciencia(s) y también por medio de nuestra experiencia sensible del mundo (es decir mediante el arte) y todas estas formas de aprender y comprender son igualmente válidas y necesarias. Sin embargo, parece existir algún grado de jerarquización de estas, por ejemplo, colocando al método científico (entendido este desde la concepción positivista tradicional) como superior e invalidando las otras formas, esta es una noción de herencia moderna bajo la comprensión de un mundo como lógico, lineal, progresivo, medible mediante leyes que pretenden ser generalizables a todo el universo, con una intención hetero normativa y occidentalizadora.

En relación con lo anterior, deseamos presentar de manera preliminar que si bien conocer y aprehender es un proceso de carácter complejo, es decir habrán tantas formas de conocer como personas existan; en el método científico algunos elementos son esenciales, por ejemplo: la presentación de la información de una forma ordenada, lógica y argumentativamente sostenible. En el caso de las ciencias sociales el contexto de significación histórica es esencial, dado que nos permite entender los fenómenos, procesos u objetos 
1. Por su siglas en inglés western, educated, industrialized, rich and democratic. de estudio, como elementos integrales y concomitantes a un entorno y no como elementos aislados. A su vez se acompaña con conceptos, es decir nociones teóricas y operativas, así como con la formulación de objetivos o propósitos y una explicación metodológica-operativa, en otras palabras del uso de las técnicas, fuentes, su tratamiento, calendarización y los productos o metas esperados.

Sabemos además que la(s) ciencia(s) tiene(n) un componente político, en otras palabras una intencionalidad que tenderá a beneficiar a determinados grupos de poder, clases sociales o grupos de persona. Ejemplo de lo anterior lo constituyen los estudios WEIRD ${ }^{1}$ (es decir estudios desde países occidentales, con altos niveles educativos, industrializados, ricos y democráticos).

Un análisis reciente de las principales revistas en seis sub-disciplinas de la Psicología en 2003-2007 reveló que el 68\% de los investigadores proviene de los EE.UU., y un total de $96 \%$ de los sujetos eran de países industrializados y occidentales, especialmente de Norteamérica, Europa, Australia, e Israel. La composición de estas muestras parece reflejar en gran parte a los autores residentes de dichos países del país de, el 73\% de los autores en primer lugar de las publicaciones provienen de universidades en Estados Unidos, en conjunto el 99\% estaban en universidades de los países occidentales. Esto significa que el $96 \%$ de las muestras psicológicas provienen de países con sólo el 12\% de la población mundial (Henrich, Steven y Norenzayan, 2010, p.5).

Lo anterior, nos sirve para evidenciar la importancia de reconocer lo que se denomina el locus de enunciación, en otras palabras el lugar desde el cual se enuncia, se formula y se promueve ciencia, esto implica en primera instancia el reconocimiento del carácter político de la ciencia y por tanto de los intereses de la práctica científica. Un ejemplo de ello consiste en reconocer como la investigación y los resultados obtenidos pueden variar si se realizan desde: oriente u occidente, desde la teoría feminista, desde el mainstream económico mundial o bien desde una perspectiva crítica y contrahegemónica como la keynesiana, la marxista, los estudios de género, las metodologías como la investigación-acción participativa. Los ejemplos abundan.

Luego de lo anterior se puede agregar que parte de los objetivos de la ciencia de frontera no gira solamente en adquirir nuevo conocimiento, sino en comprender y aprender mejor. Hemos aprendido que el objetivo de la ciencia ha girado en torno a los descubrimientos y la innovación. Sin embargo estos 
dos últimos elementos tienen un componente económico utilitario; si bien adquirir nuevo conocimiento es sumamente importante, no es el objetivo único de la ciencia, comprender y aprender mejor también son pasos vitales en la producción científica. Por lo que tal vez esta sea la justificación más importante de la investigación en Ciencias Sociales, pero esto requiere de un para y un quién.

Necesitamos de las ciencias sociales para comprender mejor, comprender que la realidad es social y culturalmente construida, y por tanto puede ser destruida, transformada y reconstruida. Para comprender mejor las formas en que socialmente creamos y nos recreamos, esto nos trae algún grado de certeza y hace más fácil y llevadera la experiencia de la vida. Pero y sobre todo para comprender las estructuras del poder y como estas nos condicionan, condicionan el goce del sexo, el cuerpo, el empleo, la forma en la que nos relacionamos y explican las contradicciones de la vida en sociedad y las vicisitudes de las personas en su fuero interno.

En referencia a lo que se ha señalado hay un punto fundamental en las ciencias sociales, el aporte a la sociedad, en el tanto se posiciona con una mirada crítica sobre los procesos y fenómenos, buscando producir un conocimiento alternativo al defendido por el status quo o los grupos de poder establecido. Ese espíritu crítico ha de movilizar ciertas expectativas, la producción del conocimiento ha de tener un sustento comprobable para su puesta en la discusión pública, esa es la diferencia entre la intuición y la opinión, debido a que sobre la estructura del saber científico predomina la rigurosidad en la presentación de las evidencias para favorecer la comunicación en una comunidad de investigadores.

En la búsqueda del avance y aporte crítico al conocimiento ha de ampliarse en lo posible el saber a la población en general, buscando que la información surgida de las investigaciones sea de fácil acceso, sea comprensible, sea didáctica y pedagógica, esto con un fin concreto, el empoderamiento del público, tal condición se acerca a una reflexión sobre el valor público de la investigación en el análisis de los problemas, buscando colaborar con las cuestiones sociales y con aquellos que han sido marginados y discriminados.

A manera de resumen de la sección anterior, queremos señalar los siguientes elementos:

Hay muchas formas de conocer, comprender y aprender, el conocimiento científico es una de esas formas pero no es la única. Sin embargo, debemos señalar que desde cierto punto de vista la ciencia aporta lo que ningún otro conocimiento aporta, por ejemplo: los satélites artificiales o el internet. La ciencia no es enteramente diferente a otras formas de conocimiento en lo que hace, al hecho de que puede tener consecuencias negativas y consecuencias positivas. La diferencia está en que, por su carácter sistemático y 
crítico, la ciencia tiene un potencial superior: tanto para lo positivo como para lo negativo.

1) Entre lo positivo, la ciencia aporta un principio anti-dogmático. No quiere decir que los científicos no puedan ser dogmáticos ni niega que a veces se haga ciencia de forma dogmática, como cuando justifica sistemas de dominación. Pero en su concepción de base la ciencia supone un ejercicio permanente de confrontación crítica con los dogmas. En general, los otros conocimientos no operan de esa forma. De hecho, el conocimiento tradicional en sus diversas expresiones supone validez incuestionable de sus afirmaciones. Tienden a ser, en general, conocimientos dogmáticos.

La ciencia no es axiológicamente neutral, en otras palabras responde a intereses, enfoques y necesidades de las personas que realizan la investigación, puesto que todo científico es un ser humano de su tiempo, de su sociedad y su cultura. Sin embargo debemos hacer la aclaración de que lo anterior no es necesariamente así si de las teorías científicas de algunas de las ciencias físicas y naturales se trata. No es claro ni evidente que detrás de la antimateria, las partículas subatómicas, las placas tectónicas haya alguna ideología e intereses políticos.

2) En cuanto a algunas formas de cómo se articula la producción científica, se plantea que al escribir un documento científico usualmente utilizamos la tercera persona singular y plural, por ejemplo: no escribimos "yo pienso", sino, "el autor o los autores plantean que...", esto porque reconocemos que la investigación científica es el resultado de una empresa colectiva a lo largo de los años de experiencias acumuladas de conocimiento de la que todos somos parte. Sin embargo debemos señalar que en altos niveles académicos y de investigación, los y las científicos(as) e investigadores(as) suelen utilizar otra clase de estilos narrativos y discursivos.

3) También hacemos uso del presente histórico, esto significa escribir en presente eventos que ocurrieron en el pasado, acá algunos ejemplos: "Napoleón muere desterrado en la Isla de Santa Elena. En el año 800, Carlomagno es coronado. El día 15 de abril de 1912 se hunde el Titanic. En 1492 Cristóbal Colón descubre América." (Gramáticas, 2012)

4) Toda la producción científica tiene un locus o lugar (el cual no es necesariamente físico, sino también simbólico, estructural y desde el poder) desde el cual se produce y se elabora la producción científica, por lo tanto los resultados obtenidos tienen un alcance mucho más modesto que las pretensiones universales adquiridas desde la modernidad. Esto es válido para las ciencias sociales al menos en gran par- 
te de su producción y trabajo pero mucho menos para las ciencias naturales. En particular, eso tiene poco sentido para la física y otras ciencias naturales y exactas, por ejemplo: ¿la tierra no gira alrededor del sol según la cultura? ¿Las partículas subatómicas existían en ciertas épocas pero en otras no? Incluso en el caso de la biología: ¿es que en el antiguo testamento de la biblia en esas sociedades si regía el creacionismo y solo después adquirió vigencia el evolucionismo?

\section{Hacia la elaboración de un proyecto de investigación}

Luego de lo anterior, queremos abordar algunas nociones básicas para hacer un proyecto de investigación. Si bien existe algún grado de consenso en el ámbito costarricense sobre las partes que debe tener una propuesta de investigación, no es cierto que exista un único método científico. Sin embargo en el ámbito académico la tradición se basa en al menos los pasos que veremos a continuación. Antes de iniciar por el método debemos entender el camino, los pasos que los y las investigadoras utilizarán para llevar a cabo su investigación, estos pasos deben estar debidamente señalados e identificados, de manera tal que nos permitan comprobar que estamos frente a información relevante y fidedigna y que las conclusiones sean derivaciones de las premisas planteadas.

\section{Elementos necesarios de todo proyecto de investigación académica}

\section{Problematizando el tema}

Esta es una etapa central y preliminar de toda investigación, es un tipo de instrumentalización, buscando el acercamiento preliminar a los factores que se van a investigar. Para lograr lo anterior se hace especial énfasis en la búsqueda de fuentes de información en el denominado estado de la cuestión o estado del arte, que tiene como proceso el ir recopilando primero información del objeto. La problematización es a su vez una herramienta central que ha de ser afinada e interiorizada por el investigador con el tiempo, con miras a facilitar los diseños de investigación para delimitarlos y dar cuenta de lo que ha sido investigado.

En ese proceso habría una tríada básica necesaria en una problematización: la presentación de los datos (lo empírico), el contexto (la historia y los antecedentes de investigación) y los conceptos que se han utilizado de forma básica en las investigaciones esta condición es preliminar y luego habría de ser profundizada en el marco teórico, y en el desarrollo de la investigación para contrastarla con las evidencias. 
La problematización es, en sí misma una investigación de carácter bibliográfico (libros, artículos, tesis y otros textos) que permitan identificar las tendencias académicas, las discusiones conceptuales, las investigaciones previas, los antecedentes, los datos estadísticos, las metodologías y los posicionamientos desde los cuales ha sido abordado el tema.

A su vez la revisión bibliográfica o revisión de la producción académica del tema seleccionado tiene dos grandes rasgos, etapas o momentos:

1) El primero de carácter heurístico, en otras palabras de búsqueda o investigación de documentos y fuentes históricas. Esta etapa suele llamarse estado de la cuestión o estado del arte. Esta es una etapa de descubrimiento de fuentes de información, por ello se le denomina heurística, porque se refiere a los hallazgos de conocimiento e información que serán pertinentes en la problematización del tema seleccionado.

2) Un segundo momento que corresponde a una etapa hermenéutica es decir del análisis e interpretación de esos textos, esta sería la etapa de revisión en profundidad de las fuentes de carácter bibliográfico, en cuanto a su pertinencia conceptual, metodológica y contextual para aportar generalmente al estado de la cuestión, que se desarrolla en el primer nivel de la investigación, esta es una búsqueda de carácter exploratorio en la que se avanza en las primeras inquietudes e interrogantes.

\section{Diagrama 1}

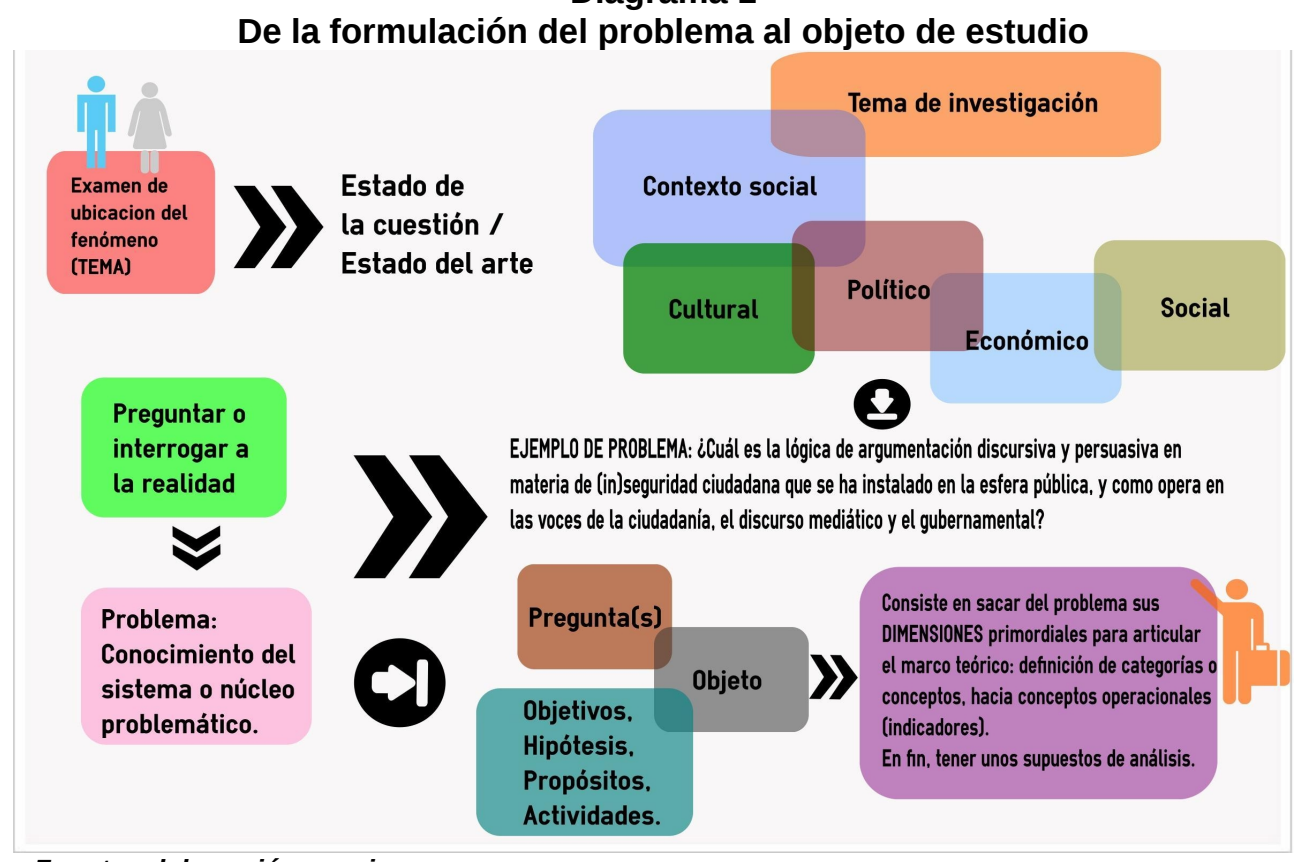

Fuente: elaboración propia. 
En referencia a Badilla (2011), se señala que una de las metas finales del planteamiento de problema es crear una interrogante o pregunta cuyo resultado es pasar de problematizar o poner en duda los antecedentes e información que se encontró, buscando delimitar el campo de estudio y a su vez pasar al diseño de los objetivos y la estrategia metodológica. Solís (2011) al respecto nos señala lo siguiente:

Puntos básicos para la definición de un problema son: Relación entre dos o más conceptos observables; seleccionar regularidades empíricas o variables que sean operacionalizables, que sean observables a través de categorías en el caso de investigaciones de corte cualitativo, y variables e indicadores si es una investigación de corte cuantitativo. El problema ha de ser planteado como pregunta. Que sea posible aplicarle prueba empírica a los conceptos y las unidades de análisis. Ejemplos de unidades de análisis: discursos, actores, organizaciones, políticas, territorios, barrios, ciudades, etc. La problematización en sí misma sirve para justificar el valor de la investigación y el aporte que se quiere hacer (p.4).

\section{La justificación}

Toda proceso investigativo requiere de una justificación, esta consiste en la creación de un línea argumentativa que le permita entender al lector la importancia del objeto o tema de estudio. En esencia en este apartado se justifica la validez y la pertinencia, así como la importancia que tiene la investigación desde el punto de vista metodológico y epistemológico, y sus posibles aportes. También se permiten justificaciones de orden personal, es decir las motivaciones del o la investigador(a). Por otra parte, la justificación es un elemento que sólo adquiere sentido en su vinculación con otras partes del proyecto de investigación, principalmente con el contexto y los elementos histórico-factuales.

Una parte fundamental de la problematización se da con la justificación del estudio propuesto, en este apartado se recomienda hacer señalamientos precisos, enfocados a evidenciar las finalidades del estudio, estos señalamientos pueden ser sobre la importancia social del estudio (aportar a la resolución de un problema práctico, a la colaboración con algún grupo en particular, al empoderamiento o visibilización de poblaciones excluidas o marginadas), también habría un rubro enfocado a la validez y pertinencia dentro del espacio académico (delimitación temática, disciplinaria, teórica, metodológica) es- 
2.Una investigación puede incorporar elementos cuantitativos sin por ello ser positivista, ni buscar resultados presuntamente exactos. tos serían aportes que justifican un estudio en el marco del conocimiento científico (epistemología) y el conocimiento en general (gnoseología).

\section{Objetivos}

En esta revisión, cuyo fin es reseñar los procesos de la estructura de un proyecto de investigación, hay que hacer un énfasis principal en los objetivos, cuyo diseño tiene un fin concreto, articular el objeto de estudio hacia actividades y metas dirigidas a la producción de conocimiento. Así, el objetivo general contiene una cercanía con la problematización, con la condición de que necesariamente ha de tener los conceptos del marco teórico, los cuales se desarrollarán en profundidad en la investigación y el trabajo de campo.

Como señala Badilla (2011), un objetivo "es un enunciado afirmativo de la proposición interrogativa realizada en la etapa de la problematización. Para ello se utilizan verbos que respondan a la pregunta ¿cómo?, mediante el uso del infinitivo, ejemplos de este tipo de verbos son: caracterizar, categorizar, contrastar, evaluar, entre otros" (p.2).

Los objetivos específicos tienen una intención operativa e instrumental, son el camino para descomponer las dimensiones de análisis surgidas de la teorización y la problematización, y nos dan la vía de inicio, para definir la metodología o el camino para llevar a cabo la investigación, entiéndase esto como el norte sobre el cual vamos a dirigir las expectativas investigativas en el objeto.

También hay un reto interesante que está en la posibilidad de plantear investigación sin objetivos, pero con propósitos o actividades, es decir enunciado lo que se desea conseguir con la investigación. Habría de señalarse en estos casos la importancia de contar con un diseño metodológico-operativo muy claro que explique la forma en que se lograría alcanzar los propósitos y actividades.

En la investigación por propósitos, los enunciados o preguntas desde los que parte el investigador son referentes con cierto grado de flexibilidad. En lo fundamental la investigación por propósitos parte de una postura epistemológica y metodológica de origen cualitativa, un poco distinta de la investigación de tipo más estadística que tienee un enfoque más hacia las hipótesis, objetivos, uso de indicadores y variables comparadas con la idea de obtener información de grandes muestras y que busca resultados muy delimitados a modo de extracción de información, lo que fomenta una escisión entre el objeto de la investigación y lo subjetivo (sujeto) ${ }^{2}$.

Pensando en esa reflexión debemos señalar que esa escisión no es determinante pues hay investigaciones mixtas que hacen uso de modelos cualitati- 
vos y cuantitativos buscando precisar todavía más la creación de conocimiento. A su vez, algunos enfoques críticos como la concepción metodológica dialéctica, la etnometodología, la fenomenología, la teoría fundamentada, se plantean sobre el hecho de que la realidad humana es un proceso inseparable e irreductible. Sobre tal fundamento se buscaría articular elementos de corte epistemológico y metodológico, de lo particular a lo general, de lo general a lo particular y de lo inductivo a lo deductivo y a la inversa, en un proceso concatenado, en el que la realidad es cualitativa y cuantitativa simultáneamente y por ello no sería posible pensar en una forma de aproximación a la realidad a partir del uso exclusivo de uno de sus paradigmas, o de la separación dual, por ejemplo del sujeto frente al objeto, restándole valor a la complejidad de la realidad social.

La investigación por propósitos es de uso común en investigaciones de tipo teórico-prácticas, con metodologías como la investigación-acción participativa, aunque no es de uso exclusivo. Asímismo se encuentran referentes en el posicionamiento epistemológico y metodológico de la Grounded Theory. Recordemos que dicha teoría parte en lo fundamental de una inversión de la investigación tradicional en las ciencias sociales, es decir, se parte primero de la recolección de datos de lo que se desea investigar, para posteriormente analizarlos y categorizarlos y concluir. En la tradición clásica de la investigación, primero se plantean hipótesis que son contrastadas con las realidades, mientras que la Grounded Theory es simplemente un método inductivo, con cierto sesgo empirista, ya que parte de los datos mismos, de la llamada codificación abierta que significa categoriza la información conforme se va haciendo el análisis, por eso sigue la lógica del análisis hermenéutico.

Luego de lo anterior, los propósitos o las preguntas generadoras son guías, referentes, de un proceso que puede estar sujeto a cambios. Generalmente, se enuncia primero la población, es decir las personas o grupo de personas con quienes se trabajará y su relación, luego lo que interesa o se persigue con la investigación, y se finaliza con el motivo o las razones de la investigación (Morales, R. 2014).

En relación con la anterior Gurdián (2007) nos señala lo siguiente:

La investigadora y el investigador cualitativos parten de una situación particular para elaborar, provisionalmente, un problema de investigación o pregunta generadora, y elegir el método apropiado. Un proyecto de investigación cualitativa, lejos de ser la aplicación ciega de técnicas específicas, exige de la investigadora y del investigador una actitud y un comportamiento reflexivo: cada decisión debe ser justificada en la perspectiva de producir los conocimientos válidos y 
útiles posibles. Desde esta perspectiva, los pasos de investigación cualitativa se pueden considerar como un caso particular del proceso de resolución de problemas. Resolver un problema de investigación, consiste en encontrar los medios de suprimir la separación entre el actual -no satisfactorio- y el saber buscado (p. 189).

\section{Taxonomía de Bloom}

La taxonomía de Bloom se refiere a un intento de ordenación de herramientas, formas e intenciones de aprender y conocer, formulada en 1948 por Benjamin Bloom a partir de discusiones e intercambios entre colegas de la Asociación Americana de Psicología, la taxonomía ha sido revisada, rechazada y reformulada en numerosas ocasiones. Su utilidad central radica en la formulación de los objetivos y propósitos de la investigación. Debemos entender que la taxonomía no es jerárquica y que habrá procesos cognitivos o de conocimiento que tenderán a solaparse.

Tal y como nos señala Munzenmaier y Rubin (2013):

(...) debido a que habilidades como la comprensión puede ejercerse en muchos niveles, los formuladores permiten que las categorías se solapen. Por ejemplo, entender es técnicamente inferior en la jerarquía de aplicar. Sin embargo, la habilidad de explicar es cognitivamente más compleja que la ejecución, a pesar de que la habilidad está asociada con una categoría superior (p.23).

En la versión crítica y revisada de la taxonomía realizada por Munzenmaier y Rubin (2013) plantean dos dimensiones, la primera relacionada con el tipo de conocimiento que se persigue, y una segunda relacionada con los procesos cognitivos. En relación con la primera dimensión las autoras nos plantean:

Conocimiento factual, el cual es el conocimiento más básico para un área de estudio, el cual se refiere a los hechos esenciales, la terminología, detalles o elementos que los participantes deben saber o estar familiarizados con el fin de comprender una disciplina o resolver un problema dentro de un campo de estudio. Conocimiento conceptual, este se refiere al conocimiento de las clasificaciones, los principios, generalizaciones, teorías, modelos o estructuras pertinen- 
tes a un área disciplinaria particular. Conocimiento procedimental, este se refiere al conocimiento que ayuda a los estudiantes a hacer algo específico dentro de un área de estudio. También se refiere a los métodos de investigación, a habilidades específicas, algoritmos, técnicas y metodologías particulares. Este conocimiento es a menudo objeto de trabajos específicos. Conocimiento metacognitivo, se refiere a la conciencia del propio pensamiento y el crecimiento personal. Esta categoría se añadió porque la investigación reciente nos ha dado una nueva comprensión de cómo monitorear los alumnos y regulan sus propios procesos cognitivos (Munzenmaier y Rubin, 2013, p.19).

Ilustración 1

Taxonomía de Bloom según Santiago

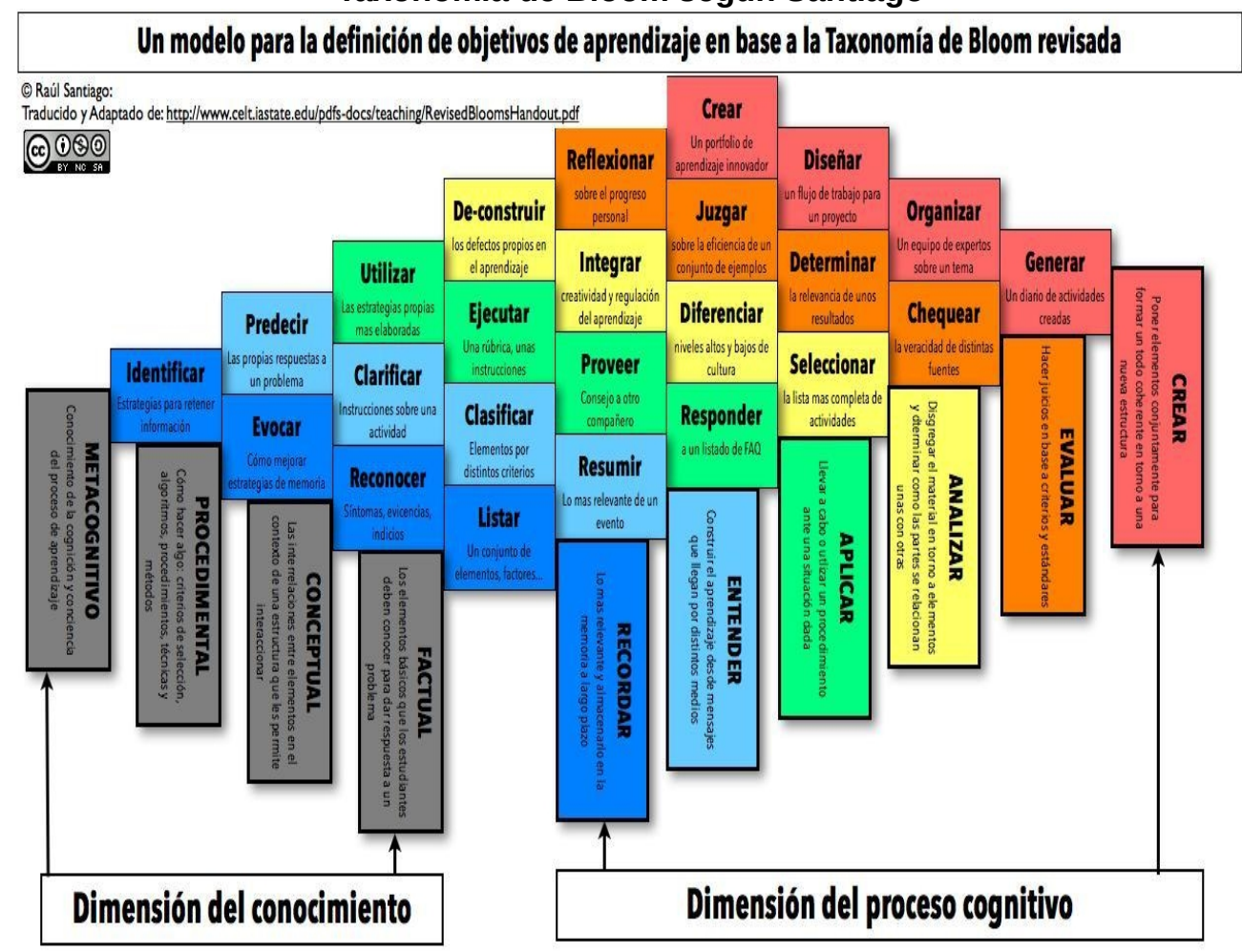

Fuente: Santiago (2013)

En relación con la segunda dimensión, estas nos señalan cómo los procesos cognitivos pueden separarse en al menos las siguientes categorías: recordar, entender, aplicar, analizar, evaluar y crear. En otras palabras el o la investiga- 
3. Hay que señalar que toda investigación tiene procesos de conceptualización, desde conceptos referenciales (contextuales, antecedentes, políticos, institucionales). No obstante, es en el marco teórico donde se hace un esfuerzo por profundizar con mayor cuidado las concepciones mediante reflexiones surgidas de escuelas de pensamiento, movimientos analíticos y epistemológicos. dor(a) aplica algún tipo de proceso cognitivo para obtener algún tipo de contenido-conocimiento ya sea esta factual, conceptual, procedimental o metacognitivo. En la siguiente ilustración mostramos los entrecruzamientos de la dimensión cognitiva y la dimensión del conocimiento, así como algunos de los verbos utilizados según el objetivo que se persiga.

\section{Perspectiva teórica y marcos interpretativos}

La perspectiva teórica constituye la etapa en la cual se desarrolla una construcción conceptual en profundidad del problema de investigación ${ }^{3}$. Tal etapa implica un proceso de elaboración intelectual que puede tener uno o varios fines: explicar, comprender, establecer relaciones e interrelaciones, jerarquizar.

Asimismo hay que señalar que el marco teórico parte de reflexiones abstractas y generalizaciones que han de ser asociadas a evidencias, con la intención de verificar, contrastar o bien de replantear conocimientos. Lo expuesto se refiere a condiciones analíticas que cada disciplina ha ido desarrollando con el tiempo para el entendimiento del mundo, mediante marcos conceptuales y teóricos que son formalizados hasta convertirse en grupos de conceptos que representan sintéticamente una serie de hechos y fenómenos observables, por ejemplo: para la psicología la conciencia, el carácter; en la sociología conceptos como clase social, estatus y estratificación; para la economía el mercado, el capital, la producción; para la ciencias políticas el poder, el Estado y la organización, entre muchas otras que son fundamentales para los disciplinas expuestas.

Las perspectivas teóricas también buscan contrastar los elementos conceptuales según distintos niveles de formalización, entre ellos, los metadiscursos, las generalizaciones, las matemáticas, la lógica, la praxis, la evidencia empírica, la realidad concreta, la vida cotidiana, elementos y condiciones en la que están insertos los problemas de investigación

A su vez, se ha de reafirmar que las perspectivas teóricas (o marcos interpretativos) son parte de un proceso de construcción que se busca sustentar a partir de la crítica (puesta en duda) y de la validación los conceptos teóricos importantes para el objeto de estudio. Para ello se vale de teorías de carácter general y de alcance medio que son aquellas teorías que explican una porción específica de la realidad y no su totalidad. Las perspectivas teóricas en un diseño de investigación también tienen un fin práctico e instrumental, ayudan en la investigación a entender ciertos conceptos y categorías que serán necesarias para la interpretación de la realidad, y tienen consecuencias en cómo se entenderán los fenómenos, procesos o hechos observados mediante los instrumentos 
En concreto, esta etapa es central pues ayudará a interpretar las pruebas surgidas de las evidencias del diseño metodológico, en un ir y venir entre el trabajo empírico y la reflexión teórica donde es central la construcción de dimensiones para el denominado objeto de investigación este paso se da cuando el problema se deconstruye, esto significa que se enfrentan los conceptos iníciales sugeridos por las lecturas y el estado de la cuestión, frente a un modelo o marco teórico, para así lograr una mayor generalidad analítica sobre el problema y para que este no quede en el mero fenómeno.

Esa deconstrucción se da mediante el dimensionamiento, que implica el paso final en la construcción del objeto de estudio, este es un postulado que integra los intereses teóricos en dimensiones analíticas surgidas de la problematización y que se observarán mediante una metodología.

Finalmente, y como señala Solís (2011), los marcos teóricos se estructuran en el proceso de la problematización del tema. Seguidamente se construiría un objeto de estudio como principio que articula los conceptos generales que se operacionalizarían mediante objetivos e hipótesis. Posteriormente se define la metodología y la aplicación de las técnicas que serían los útiles para indagar las pruebas que buscamos para sustentar las tesis y presupuestos de nuestras investigaciones.

\section{Operacionalización y metodología}

Esta etapa es fundamental pues se define de la escogencia de un conjunto de procedimientos instrumentales básicos para llevar a cabo la investigación. El diseño del marco metodológico implicaría trabajar sobre diversos pasos prácticos como son: (a) se delimita el tipo de estudio, donde se señala sí será exploratorio, descriptivo, relacional, sincrónico, diacrónico; (b) se define la población y las unidades de análisis (grupos sociales, espacios, comunidades, instituciones, organizaciones, entre otras); (c) se establecen los procedimientos de operacionalización y se puntualizan las categorías y las variables del estudio (Tabla 2).

Hay que recordar que en el proceso de operacionalización es vital hacer un énfasis en el origen de las fuentes de información que buscan responder a los conceptos (Tabla 1 y 2), y son necesarias para pasar a la etapa ulterior de la investigación, la selección de las técnicas de investigación.

Luego de lo anterior se procede a determinar cuáles son las fuentes que van a darle contenido a los distintos posibles indicadores, el tipo de técnica mediante la cual se van a tratar (análisis documental, de 
contenido, análisis estadísticos, censos, focus groups, entre otras.)

(Badilla, 2011, p.5).

La metodología consiste en explicar el camino a seguir durante la investigación, es decir la forma en que la información y los datos serán recolectados, según técnica a utilizar, como se sistematizará la evidencia, ya sea a través de una forma, cualitativa, cuantitativa o dialéctica. Toda metodología está compuesta por una serie de técnicas y herramientas, seleccionadas con la intención de responder a los objetivos planteados o bien de atrapar la evidencia necesaria para llevar adelante nuestro análisis. Debemos recordar lo señalado anteriormente, la metodología debe seguir un orden coherente, comprensible y responder al objetivo o meta planteado.

En la Tabla 1 mostramos un ejemplo de fuentes según la técnica a utilizar, y en la Tabla 2 a manera de ejemplo las partes del contenido de una matriz de operacionalización de variables (etapa en la que se instrumentalizan los conceptos con miras a la medición de nuestros objetivos).

Tabla 1

Ejemplos para el tratamiento de las fuentes según técnica a utilizar

\begin{tabular}{|c|c|}
\hline Fuente & Técnica \\
\hline Ley 8555 y su reglamento & Análisis documental \\
\hline Estatuto del Servicio Civil y su reglamento & Análisis documental \\
\hline Registro Artístico & $\begin{array}{l}\text { Análisis documental y } \\
\text { estadístico }\end{array}$ \\
\hline $\begin{array}{l}\text { Programas, planes, festivales, temporadas } \\
\text { teatrales del MCJ }\end{array}$ & $\begin{array}{l}\text { Análisis documental y } \\
\text { estadístico }\end{array}$ \\
\hline Datos presupuestarios del MCJ & $\begin{array}{l}\text { Análisis documental y } \\
\text { estadístico }\end{array}$ \\
\hline Plan anual operativos del MCJ & Análisis documental \\
\hline $\begin{array}{l}\text { Planes de gobierno y planes de campaña de la } \\
\text { Administración Arias y Pacheco }\end{array}$ & Análisis documental \\
\hline Expertos, funcionarios, artistas. & $\begin{array}{l}\text { Entrevistas, cuestionarios, } \\
\text { grupos focales. }\end{array}$ \\
\hline Contratos realizados por el MCJ & $\begin{array}{l}\text { Análisis documental y } \\
\text { estadístico. }\end{array}$ \\
\hline
\end{tabular}

Fuente: Badilla (2013, p.26). 
Tabla 2

Ejemplo de una matriz de operacionalización de variables

\begin{tabular}{|c|c|c|c|c|c|c|}
\hline $\begin{array}{l}\text { Unidad de } \\
\text { Análisis }\end{array}$ & Variable & Indicador & Aspectos & Fuentes & $\begin{array}{l}\text { Localizaci } \\
\text { ón }\end{array}$ & Técnica \\
\hline \begin{tabular}{|l|} 
Las \\
políticas \\
públicas \\
culturales \\
del MCJ en \\
la coyuntura \\
establecida
\end{tabular} & $\begin{array}{l}\text { Independient } \\
\text { La formulación } \\
\text { y decisión de } \\
\text { as políticas } \\
\text { públicas de } \\
\text { cultura del } \\
\text { MCJ }\end{array}$ & $\begin{array}{l}1 . \\
\text { Articulación } \\
\text { del personal } \\
\text { artístico con } \\
\text { a política } \\
\text { cultural. }\end{array}$ & $\begin{array}{l}\text { a) Grado de } \\
\text { nvolucramiento en la } \\
\text { formulación de las } \\
\text { políticas públicas de } \\
\text { cultura. } \\
\text { b) Grado de } \\
\text { nvolucramiento de } \\
\text { os artistas con el } \\
\text { proceso de } \\
\text { planificación de la } \\
\text { actividad cultural. } \\
\text { c) Nivel de influencia } \\
\text { artística en la } \\
\text { decisión de las } \\
\text { políticas culturales. }\end{array}$ & $\begin{array}{l}\text { a) Plan anual } \\
\text { operativo del MCJ } \\
\text { b) Plan Nacional } \\
\text { de Gobierno } \\
\text { apartado de } \\
\text { cultura. } \\
\text { c) Memorias } \\
\text { Institucionales. } \\
\text { d) Planes de } \\
\text { campaña de la } \\
\text { administración } \\
\text { Arias y Pacheco. } \\
\text { e) Expertos y } \\
\text { funcionarios de la } \\
\text { institución. }\end{array}$ & $\begin{array}{l}\text { a) Oficina } \\
\text { de } \\
\text { Planificación } \\
\text { del MCJ. } \\
\text { b) Mideplan } \\
\text { en línea. } \\
\text { c) Plan de } \\
\text { campaña } \\
\text { del PUSC } \\
\text { en línea. }\end{array}$ & $\begin{array}{l}\text { a) Análisis } \\
\text { documental } \\
\text { b) } \\
\text { Entrevistas } \\
\text { c) Grupos } \\
\text { Focales. }\end{array}$ \\
\hline \begin{tabular}{|l|} 
El régimen \\
artístico de \\
contratación \\
del $\mathrm{MCJ}$
\end{tabular} & $\begin{array}{l}\text { Dependiente } \\
\text { El aumento de } \\
\text { control de las } \\
\text { autoridades } \\
\text { del Ministerio } \\
\text { para con el } \\
\text { sector artístico } \\
\text { contratado }\end{array}$ & $\begin{array}{l}\text { 2. Políticas } \\
\text { de } \\
\text { selección } \\
\text { del personal } \\
\text { artístico. }\end{array}$ & $\begin{array}{l}\text { a) Método de } \\
\text { selección de } \\
\text { elegibles(Concursos } \\
\text { públicos, carteles } \\
\text { públicos) } \\
\text { b) Personal } \\
\text { requerido según } \\
\text { actividad. } \\
\text { c) Criterios de } \\
\text { selección. }\end{array}$ & $\begin{array}{l}\text { a) Contratos } \\
\text { ealizados entre el } \\
\text { MCJ y artistas o } \\
\text { asociaciones de } \\
\text { artistas. } \\
\text { b) Estatuto del } \\
\text { servicio civil. } \\
\text { c) Expertos y } \\
\text { funcionarios del } \\
\text { MCJ. }\end{array}$ & \begin{tabular}{|l|} 
a) Oficina \\
de \\
Proveeduría \\
del MCJ.
\end{tabular} & \begin{tabular}{|l|} 
a) Análisis \\
documental \\
b) \\
Entrevistas. \\
c) Análisis \\
estadístico. \\
d) Grupos \\
focales.
\end{tabular} \\
\hline
\end{tabular}

Fuente: Badilla (2013, p.28)

Este artículo se busca poner en evidencia que la investigación en ciencias sociales no puede comprenderse como una fórmula, ni una receta, sino que debe entenderse como un proceso riguroso de búsqueda de conocimiento, acompañado de creatividad y flexibilidad. Si bien existen algunas tradiciones en la elaboración de un proyecto de investigación, estas no son taxativas, ni infalibles.

En esencia, la producción de cualquier investigación implica rigurosidad, creatividad y contrastabilidad (es decir que la evidencia pueda ser localizable, contrastada y comparable, lo que implica que la construcción argumentativa del texto sea sólida) y al menos, en las ciencias sociales, se debería comprender el lugar de enunciación, este último aspecto es central, puesto que reposiciona la importancia considerar que el conocimiento tiene implicaciones e intereses políticos que le son subyacentes. De este modo, el método científico y la elaboración de los proyectos de investigación también responden a un contexto de significación sociohistórico, cultural y humano.

Igualmente, en este artículo se expusieron diversos procesos y recomendaciones sobre los diseños de investigación, con una centralidad en la problematización, un fundamento que reafirma la complejidad de los temas sobre 
los que hay una interrogación o una puesta en duda. Tal cualidad está inmersa en el desarrollo de la imaginación en cada proyecto. Por eso también hay una importante reflexión sobre el aprender haciendo, sobre la artesanía como metáfora para la definición de los objetos de estudio, en sus contextos, escenarios, procesos y posibilidades.

Si bien a lo largo del texto elaboramos una serie de recomendaciones y sugerencia sobre como elaborar un documento científico, estas pautas son abiertas, tienen una intención didáctica y orientadora (con el propósito de acompañar o facilitar) más que una intención recetaria, en un proceso de construcción que avanza conforme estudiamos en profundidad los temas que nos interesan investigar.

\section{Bibliografía}

Badilla, A. (2013). Cultura y poder: el caso de la Ley 8555 (2002-2006). Tesis para optar por el grado de Licenciado en Ciencia Política. Universidad de Costa Rica. San José, Costa Rica.

Badilla, A. (octubre de 2011). Ciencia ¿cuál ciencia? Recuperado el 13 de 02 de 2015, de CICDE: http://investiga.uned.ac.cr/cicde/images/ciencia.pdf

Berger, P. (1967). Introducción a la sociología. Una perspectiva humanista. México: Limusa.

Gramáticas. (2012). Ejemplos de Presente Histórico. Recuperado el 13 de Febrero de 2015, de http://www.gramaticas.net/2012/05/ejemplos-depresente-historico.html

Gurdián, A. (2007). El paradigma cualitativo en la investigación socioeducativa. San José, Costa Rica. Coordinación Educativa y Cultural Centroamericana, Agencia Española de Cooperación Internacional.

Henrich, J. Steven, H. Norenzayan, A. (2010). The weirdest people in the world?. Behavioral and Brain Sciences, 33, p. 61-83.

Morales, R. (2014). Comunicación personal. 3 de junio.

Munzenmaier, C. Rubin, N. (2013). Bloom's Taxonomy: What's Old Is New Again. USA. The eLearning Guild.

Santiago, R. (2013). La taxonomía de bloom en detalle. The Flipped Classroom. Recuperado 16 de julio, 2014 de: http://www.theflippedclassroom.es/la-taxonomia-de-bloom-en-detalle/ 
Sennett, R. (2009). El artesano. Barcelona: Editorial ANAGRAMA.

Solís, J. (octubre de 2011). Los colores que no vemos... Recuperado el 02 de 13 de 2015, de CICDE: http://investiga.uned.ac.cr/cicde/images/colores.pdf 
Revista Rupturas, Volúmen 5 Número 2 Centro de Investigación en Cultura y Desarrollo (CICDE)

Universidad Estatal a Distancia (UNED)

San José, Costa Rica

Julio-Diciembre 2015 


\section{Reseñas}

Reseñas es una sección de Rupturas en la cual se reúnen valoraciones comentadas de libros o artículos ubicados dentro de la cobertura temática de esta revista. La participación en dicha sección se da principal aunque no exclusivamente mediante una invitación expresa del Consejo Editorial a una persona académica cuyo conocimiento sobre un tema sea respaldado por su trayectoria sostenida de trabajo. La otra modalidad es que uno de nuestros lectores o lectoras decida proponer una reseña. Tanto en este último caso como en el anterior se exige además rigurosidad en el manejo de la información así como demostrar desenvolverse con seguridad y estilo propio entre los contenidos del texto a reseñar. 
Revista Rupturas, Volúmen 5 Número 2 Centro de Investigación en Cultura y Desarrollo (CICDE)

Universidad Estatal a Distancia (UNED)

San José, Costa Rica

Julio-Diciembre 2015 


\section{Luis Paulino Vargas Solís}

\section{¿Hacia un capitalismo rentificado y patrimonializado? A propósito del libro "El capital en el siglo XXI" de Thomas Piketty}

Resumen: "El capital en el siglo XXI", obra del economista francés Thomas Piketty, presenta una amplia investigación sobre el tema de la desigualdad, centrada fundamentalmente en los países ricos del capitalismo contemporáneo, pero con una rica sustentación histórica que proporciona datos empíricos que, para algunos países, se remontan varios siglos atrás. Es un trabajo cuya fundamentación teórica es cuestionable, porque maneja un concepto de capital elaborado de modo desprolijo y porque se sustenta en ciertas "leyes" que, en realidad, son más bien simples relaciones contables cuando no meras tautologías. Sin embargo, la información empírica que se aporta es muy rica, ha sido trabajada con cuidado y rigor y ha alimentado un debate mundial de la mayor relevancia. Asimismo el libro sugiere tendencias de desarrollo en el capitalismo, que el autor a veces pasa por alto o apenas analiza, y las cuales, sin embargo, abren interesantes vías para nuevas investigaciones potencialmente muy valiosas.

Summary: "Capital in the twenty-first century" is a book whose author is the French economist Thomas Piketty. It offers a wide research on the issue of inequality, mostly in the richest countries of contemporaneous capitalism. This work is based on very rich historical and empirical information, which in case of some countries, has extended within several centuries. From a theoretical point of view, this work has several problems, not just because its concept of capital is unsatisfactory, but because it formulates some "laws of capitalism", that in fact are no more than countable relations or mere tautologies. But, in any case, Piketty gathers a lot of very useful empirical information, which is elaborated with care and rigor, and has fed a very important debate all over the world as well. At the same time, this book suggests some tendencies of the developing of the capitalism, and even thought the author doesn't analyze them, or just try them in a superficial way, all of that generates new and very interesting possibilities for future research.

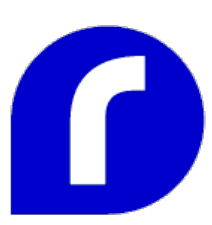

Luis Paulino
Economista y Máster en relaciones internacionales. Doctor en gobierno y políticas públicas. Catedrático Universitario. Actualmente es Director a.i. del Centro de Investigación en Cultura y Desarrollo (CICDE) de la Vicerrectoría de Investigación de la Universidad Estatal a Distancia (UNED). Ganador del Premio Nacional Aquileo Echeverría 2011 por su libro "La llave y el candado. Realidad e ideología de la propiedad intelectual" (Editorial UNED, 2010). Correo electrónico: Ipvaso@gmail.com 


\title{
¿Hacia un capitalismo rentificado y patrimonializado? A propósito del libro "El capital en el siglo XXI" de Thomas Piketty
}

\begin{abstract}
"Moreover, the production function has been a powerful instrument of miseducation. The student of economic theory is taught to write $0=f(L, C)$ where $L$ is a quantity of labour, $C$ a quantity of capital and 0 a rate of output of commodities. He is instructed to assume all workers alike, and to measure $L$ in man-hours of labour; he is told something about the index-number problem involved in choosing a unit of output; and then he is hurried on to the next question, in the hope that he will forget to ask in what units $C$ is measured. Before ever he does ask, he has become a professor, and so sloppy habits of thought are handed on from one generation to the next."

Joan Robinson, 1953
\end{abstract}

La obra de Piketty "El capital en el siglo XXI" (México: Fondo de Cultura Económica 2014) es un libro de enormes dimensiones (cercano a las 700 páginas en su edición en español), que ha logrado lo que muy pocos libros sobre economía: convertirse en best seller y dar lugar a un acalorado debate mundial sobre el tema de la desigualdad. Es una obra meritoria en muchos sentidos que, sin embargo, tiene también sus facetas débiles y cuestionables. Habiendo sido objeto de análisis y discusión en muchos idiomas y en los foros y contextos más diversos, este artículo que aquí presento tan solo intenta llamar la atención sobre algunos detalles que, quizá, han recibido poca atención, y los cuales se desprenden de este trabajo, incluso siendo a veces cuestiones que escapan a lo que parecen haber sido los objetivos explícitos del propio Piketty. Acaso él no estaría de acuerdo con tales conclusiones, y hasta podrían no gustarle $\mathrm{y}$, sin embargo, son derivaciones plausibles que surgen del planteamiento y análisis que desarrolla.

\section{Los aportes más positivos}

El libro de Piketty tiene, sin duda, aspectos sumamente valiosos, tanto en términos de sus contenidos e intencionalidad, como por sus impactos sociales y políticos. 
Primero, Piketty trae a la luz y pone en el centro del debate el tema de la desigualdad, en una época donde el capitalismo ha evolucionado hacia una profundización abismal de las diferencias entre un pequeño grupo excesivamente rico y el resto de la sociedad, todo lo cual ha sido justificado desde una filosofía presuntamente meritocrática, que exalta la competencia como si fuese un valor apreciable por sí mismo. Desde ahí se alimenta la idea de que los muy ricos lo son como premio a su arrojo para asumir riesgos y por su capacidad para la innovación y el trabajo tenaz. Esa hipótesis podría tener alguna dosis de verdad, y acaso esa sea una de las fuerzas revolucionarias del capitalismo que en su momento Marx aplaudió. Sin embargo, la atribución a esta construcción ideológica de una validez generalizada, siendo altamente improbable, es efectivamente confrontada y cuestionada a fondo por parte de Piketty, como igualmente su trabajo obliga a reflexionar acerca de si realmente basta -como los apologetas del sistema quisieran- con crecer y aumentar la riqueza, aún si esta se distribuye de forma cada vez más inequitativa, ya que, de cualquier forma, y según su planteamiento, incluso los más pobres saldrían entonces beneficiados. El caso es que, hasta en el mejor de los casos, los abismos sociales abiertos, y los excesos ofensivos de riqueza, tienen un efecto disolvente sobre los lazos de la convivencia social y un terrible poder de subversión que debilita las democracias. Sobre ello advierte Piketty y los datos que aporta lo respaldan de forma brillante y elocuente. Ciertamente el mundo se vuelve inhóspito cuando la desigualdad excede ciertos límites, pero no tan solo por ese poder disruptivo que ello conlleva, sino porque el ahondamiento de los abismos sociales comporta un fallo ético y humano sustantivo. Miserable es la sociedad donde tal cosa ocurre y, por ello mismo, turbio e incierto se vuelve su futuro.

Segundo, Piketty se desmarca, muy claramente, de la visión reduccionista que imagina la economía como una ciencia que existe al margen de las otras ciencias sociales, para la cual el hecho económico sería entonces un universo autocontenido, por completo ajeno de la sociedad en general, su cultura y su historia. Para este autor las ciencias sociales se mueven sobre un terreno compartido e indivisible, en el cual se hace imposible trazar líneas divisorias. Este es un elemento, de significativa importancia, que pone en cuestión ciertas críticas, más bien simplistas y maniqueas, que descalifican a Piketty como un economista neoclásico más dentro del ejército de economistas convencionales del mainstream económico. Es ciertamente más que eso, y su esfuerzo por dialogar con la historia, como también la claridad con que asume la necesidad de una relación de complementación y mutua polinización entre la economía y las otras ciencias sociales, así lo atestigua. Resulta particularmente claro su posicionamiento crítico frente a una tendencia central en la economía ortodoxa: las teorizaciones abstractas y altamente matematizadas, carentes de todo contenido de realidad e, incluso, de toda relevancia y significado económico. Si Schumpeter admiraba y promovía ese tipo de formulaciones teóricas abstractas -hasta llegar incluso a hablar de una "econo- 
mía exacta"- Piketty, muy por el contrario, denuncia esa pretensión como una ambición a la vez ilusa y castrante.

Al combatir tales formalizaciones matemáticas abstractas, Piketty busca apoyarse en la evidencia empírica e histórica, y lo hace con extraordinaria riqueza y especial rigor y cuidado. Hay algunos casos nacionales que son estudiados con notable amplitud, principalmente Francia y Reino Unido; secundariamente Estados Unidos y Alemania. También Australia, Canadá, Japón, Suecia, la Europa continental en su conjunto. Así como algunos de los países que Piketty llama "emergentes": India, Indonesia, China, Sudáfrica, Argentina, Colombia. Sigue siendo, como es evidente, una visión predominantemente euro-céntrica y occidentalizada, en la cual queda escaso lugar para el sur y para oriente. Y aunque ello constituye una limitación, ésta resulta sin embargo comprensible. En primer lugar, es cierto que Piketty es europeo y escribe como tal; o sea, es un hombre y un científico que mira el mundo desde Europa Occidental. Pero, en fin, ese es un problema común a todos y todas quienes hacemos ciencia social, desde siempre condenados a una mirada que nace desde nuestro peculiar lugar socio-histórico. Corresponde a quienes leamos a Piketty, el cobrar conciencia de tal condicionamiento y desde ahí enriquecer la interpretación que hagamos y el provecho que eventualmente obtengamos de la investigación que se nos ofrece. Cuando, por otra parte, es seguramente cierto que en el mundo no rico o no occidental no existe, en general, la misma riqueza de fuentes a las cuales recurrir para desarrollar una investigación con similares características y alcances. De modo que, más allá del locus de enunciación o de las taras epistemológicas que cada quien cargue consigo, hay limitaciones objetivas que dificultan poder realizar una indagación comparable en los países del sur.

Por otra parte, resulta a la vez desafiante y sugerente la visión de muy largo plazo que Piketty desarrolla en su libro, algo que recuerda a Braudel entre los historiadores y a Wallerstein entre los sociólogos. Piketty navega así sobre movimientos económicos que se prolongan a lo largo de varias generaciones e incluso varios siglos. Esto es provocativo desde un punto de vista: nos advierte acerca de los grandes procesos y fuerzas que se mueven en el muy largo plazo, influyendo y modelando, a menudo de modo imperceptible, el devenir de las comunidades humanas y la vida de la gente. Mirar y comprender estos grandes procesos puede incluso ser una buena vacuna contra dogmatismos y redentorismos que imaginan que es posible provocar rupturas cataclísmicas a partir de las cuales hacer emerger mundos completamente nuevos. La mirada al muy largo plazo nos permite advertir que los grandes cambios tienden a ser, sobre todo, procesos que se prolongan a lo largo de períodos muy extendidos, a menudo jalonados por acontecimientos traumáticos y violentos estremecimientos, pero de una forma tal que incluso esos mega sismos históricos, no obstante dejar una impronta que perdura largamente, al cabo se hacen parte de procesos de mucho mayor alcance. Sobre todo es claro que no es posible hacer tabula rasa de la historia y del pasado, de forma tal que ninguna sociedad se transforma de golpe, como si repentinamen- 
te lograra borrar toda su historia, para entonces, y desde las cenizas, nacer como un mundo completamente nuevo. En realidad, las sociedades nunca dejan de ser lo que alguna vez fueron, o, en todo caso, si lograran efectivamente desprenderse de ese pasado remoto, solo lo logran como resultado de evoluciones lentas, prolongadas y complejas. Y, sin embargo, y pensando en esos larguísimos períodos sobre los que Piketty nos provoca reflexionar, es imposible no recordar, como decía Keynes, que "en el largo plazo todos (y todas) estamos muertos". Y en el muy largo plazo de Piketty, todavía más: incluso los tataranietos habrán muerto. Vale decir: la vida concreta de las personas se resuelve en una cotidianidad que, día a día, actualiza el reclamo por una vida digna. He ahí -vuelvo a Keynes- la dimensión central de la economía como una ciencia moral, es decir, una ciencia que, políticamente orientada e imbuida de un compromiso de solidaridad y justicia, debe esforzarse por aportar respuestas eficaces ante esas justas demandas por una vida que merezca vivirse. Tal es un criterio ético, de respeto a la vida concreta de las personas, que invalida las diversas propuestas -tanto de izquierda como de derecha- que promueven el sacrificio de la vida en el hoy y el ahora, con la promesa de una "sociedad perfecta" en el futuro...un futuro que, de tan indefinido, resulta asimismo inasible. A la vez, esto plantea una advertencia necesaria ante la propuesta analítica del larguísimo plazo pikettiano. Vale decir: el largo -o larguísimo- plazo aporta una perspectiva para la indagación teórica e histórica que resulta rica y provechosa en muchos sentidos, especialmente para la comprensión de los grandes movimientos de las sociedades humanas. Pero nunca debería dar motivo ni pretexto para olvidarse como lo hicieron los proyectos del socialismo real o lo hace el neoliberalismode la realidad cotidiana de la gente y de su derecho a una vida digna y decente.

\section{Problemas y limitaciones en el planteamiento de Piketty}

El trabajo de Piketty adolece, en efecto, de algunas fallas, que conviene considerar y analizar.

\section{Concepciones sobre trabajo y capital}

El concepto de capital es obviamente central en este libro; ya desde su propio título se desprende que así ha de ser. Y, sin embargo, es un concepto que Piketty coloca y maneja en un plano más bien intuitivo, con escasa -prácticamente nula- hondura y rigor teóricos. Es como si Piketty optase por un atajo: elude cualquier discusión teórica de fondo, al punto que incurre en algo que no se sabe si es un gazapo en toda la regla, una distracción realmente inexplicable o una simple tergiversación, dada su desatinada referencia (Pp. 253256) a la célebre controversia "Cambridge versus Cambridge". Según Piketty la controversia versaba sobre si existía o no inestabilidad en el sendero de reconoce el artículo de la crecimiento de largo plazo, según ello se reflejaría en los modelos formula- profesora Robinson dos por Domar y luego por Solow. Esto es simplemente falso; la controversia (Robinson 1953) como el -que desde su lado crítico fue liderada por el Cambridge británico con Joan marcha el debate. 
2. Como ironizaba Joan Robinson (1953) con su característica agudeza en relación con la educación que se imparte en los cursos introductorios de economía: "Before ever he [the student Ipvs] does ask, he has become a professor, and so sloppy habits of thought are handed on from one generation to the next".
Robinson, Piero Sraffa y Luigi Passinetti a la cabeza- ${ }^{1}$ versaba sobre el significado del concepto de capital, y dejó en claro que la teoría económica neoclásica manejaba un concepto de capital inconsistente en lo teórico e irrelevante frente a la realidad económica concreta. Cuatro aspectos destacados de esa controversia son los siguientes:

- $\quad$ Para medir el capital es necesario conocer su precio, es decir, la tasa de interés, la cual, de acuerdo con la propia teoría neoclásica, se determina con base en la productividad marginal...del propio capital. El razonamiento se vuelve entonces circular y tautológico.

- $\quad$ El qué es y cómo se mide el capital, viene a ser una especie de acertijo para la teoría económico neoclásica, pero con reminiscencias que llevan hasta economistas contra-ricardianos de los decenios de los veinte y treinta del siglo XIX, en particular Nassau Senior. Esos autores sentaron las bases para el desarrollo posterior de la teoría económica generalmente designada como neoclásica, fundada por Jevons, Menger y antes que estos Gossen, la cual compartía, ya desde su nacimiento, ese mismo problema: en sus elaboraciones teóricas el concepto de capital constituye una especie de balbuceo nunca claramente inteligible. Ya fuese la idea de capital como "espera" o "abstinencia" -que se remonta a Senior- o, con Bhöm-Baerk como tiempo de producción y como producción indirecta, y, por lo tanto, como instrumento -nunca claramente definido, siempre nebuloso y hasta metafísico- que permitía elevar la productividad. O bien, tal cual acontece con los austriacos, la mera enumeración descriptiva de los diversos tipos de activos identificados como capital, lo que haría imposible ninguna teoría de la determinación del precio de este "factor" y, por lo tanto, convertiría la teoría neoclásica de la distribución en una imposibilidad teórica. Hasta culminar con el desatinado intento de Samuelson imaginando el capital como una especie de arcilla, un tipo de material maleable de indefinible textura e improbable entidad física. En todo caso, más pareciera que Piketty opta por el mismo atajo que intentó Solow: eludir la discusión de fondo y hablar de capital con total despreocupación del significado y fundamentación teórica del concepto. Lo cual también recuerda el planteamiento de la escuela austriaca, cuando opta por la simple enumeración descriptiva.

- $\quad$ En la práctica, y según demanda el sentido común dominante que, en su versión más vulgarizada, se les impone a los estudiantes de economía ya desde sus cursos introductorios, el capital viene a ser cualquier cosa: maquinarias, herramientas, equipos, vehículos...lo que sea. ${ }^{2}$ Con lo que teóricamente viene siendo nada, o por lo menos nada susceptible de ser reflexionado teóricamente.

- $\quad$ Esto cuestiona tanto la noción neoclásica de función de producción, usualmente construida a partir de la ficción teórica de dos "factores de la producción" (trabajo y capital), cuando también la pro- 
puesta según la cual el "precio o retribución de los factores" se determina por su productividad marginal. Una parte fundamental del edificio teórico neoclásico queda así gravemente falseado. Su teoría de la distribución se cae aparatosamente, pero con ella entra en cuestión también uno de los aspectos centrales de su teoría de los precios, puesto que uno de los componentes necesarios de esta última (Dobb, 1985) atiende a la determinación del pago de los factores con arreglo a su productividad marginal. Este último es el a priori, generalmente no explicitado, que define la distribución, por tanto el ingreso de cada consumidor y, en consecuencia, su función de demanda.

El Cambridge estadounidense -de filiación neoclásica y liderado por los mencionados Samuelson y Solow- se quedó sin ninguna respuesta satisfactoria. Sus diversos intentos fueron sucesivamente derrotados, incluida la propuesta de Samuelson (1962) para la construcción de una "función de producción subrogada" y sus "parábolas neoclásicas", de las cuales Sraffa dio cuenta en forma devastadora en su clásico libro Producción de mercancías por medio de mercancías (Sraffa, 1960; véase también Roncaglia, 2000; Fiorito s.f. y Mora Plaza, 2011).

\section{La cosificación de las relaciones sociales}

Piketty, como he comentado, hace como si este debate jamás se hubiese dado, y de hecho confunde los términos bajo los que se dio, atribuyéndole contenidos que jamás tuvo. $\mathrm{Y}$, sin embargo, hay razones para creer que, en parte al menos, da por válida la noción neoclásica de capital, al menos en cuanto opta por una conceptuación estrictamente descriptiva. Así, nuestro autor parece privilegiar una salida alterna, al modo de un atajo: trabaja el concepto de capital procurando borrar del mapa toda discusión teórica sobre ese particular. No le parece necesario precisar qué entiende por capital y, de hecho, no lo hace del todo. Al final está claro que para Piketty capital parece 3. Un detalle ilustrativo: en ser todo aquello que el sentido común de los economistas neoclásicos acos- su crítica a Marx,

tumbra reconocer como tal, o sea activos de cualquier tipo, sean estos de vocación realmente productiva o no ${ }^{3}$. Por ello mismo, en el contexto de su trabajo las rentas y los beneficios o ganancias empresariales aparecen indiferenciados e igualmente identificados como "rendimientos del capital".

Schumpeter -que nace como economista bajo el paraguas de la escuela austriaca- reiteradamente recurre a ese concepto de capital como simple Pero también podría interpretarse que en Piketty capital es sinónimo de pro- instrumentos o herramientas piedad: tiene capital quien posee una propiedad, la cual concede el poder (véase Schumpeter, 1983). para ser receptor de un rendimiento. Sin mayor dilación ni matiz, capitalista y propietario son aquí términos sinónimos: lo mismo da si se posee bonos del gobierno; acciones de una empresa; edificios de apartamentos o de oficinas o grandes extensiones de tierras incultas. Y, sin embargo, sigue siendo cierto que todo capitalista es propietario, pero no todo propietario es necesariamente capitalista. Esto ya aparecía bastante claro entre los fisiócratas franceses 
del siglo XVIII, y más aún en los economistas clásicos Smith y Ricardo quienes, en su propósito por entender la emergente sociedad capitalista, asimismo procuraron diferenciar teórica y conceptualmente la figura y el rol socioeconómico del burgués, por oposición al propietario rentista tradicional. Piketty, en una perspectiva que lo aproxima al universo teórico neoclásico, elude estos matices teóricos y opta por una visión que, aunque politizada en mucho de sus aspectos, preserva lo que es esencial al neoclasicismo: su negativa a reconocer la organización en clases sociales que caracteriza al capitalismo, lo cual no quiere decir que esa organización clasista se resuelva en un binarismo simplista burguesía-proletariado, cuando seguramente la estructura de clases del capitalismo contemporáneo es mucho más compleja que eso.

Una derivación interesante de este análisis de Piketty, y conforme a los términos que utiliza, es el tratamiento que él desarrolla en relación con el hecho de que las empresas -en particular las grandes empresas- en general no están bajo la dirección de sus propietarios capitalistas. Más bien quedan en manos de gerentes o gestores que, en su condición de tales, actúan, de acuerdo con Piketty, como trabajadores -si bien trabajadores sobrepagados- no como capitalistas. Y si bien esta idea no es novedosa -ya de ello nos hablaba John Kenneth Galbraith hace muchos años, desde su concepto de tecnoestructura (Galbraith, 1980)- sí hay una implicación que no es posible pasar inadvertida, cuando Piketty asimila esos "súper ejecutivos" con cualesquiera otros trabajadores o trabajadoras. Ello ratifica, nuevamente, su proximidad al enfoque neoclásico, en cuanto esto claramente nos sugiere ligereza en la forma como se conceptúan las clases sociales. El caso es que el concepto de clases sociales aparece en el libro de Piketty, aun cuando prácticamente no se le menciona y, en particular, sin ninguna problematización teórica respecto de su significado. Es un concepto que circula a lo largo del trabajo, pero siempre subterráneo e invisible. Eso, como se sabe, es usual en el enfoque neoclásico, el cual, en su tendencia a cosificar las relaciones sociales, habla del trabajo y del capital exclusivamente en cuanto que factores de producción por lo tanto como cosificaciones carentes de contenido sociohistórico. En correspondencia con lo anterior, hay en Piketty, como ya indiqué, una identificación entre propiedad y capital, y, correspondientemente, una tendencia a considerar como trabajo todo aquello que los seres humanos ejecutan haciendo uso de su capacidad muscular e inteligencia. De tal modo los "súper-ejecutivos" aparecen insertos como parte de una misma categoría -el trabajo- igual que trabajador o trabajadora sin calificación que desempeñan funciones muy simples ubicadas en el fondo de todas las jerarquías sociales. Para hacer tal cosa, Piketty ha debido desechar la teoría del capital humano, lo cual hace de forma explícita. $Y$, sin embargo, incurre en un error similar al que es propio de esta última: cuando asimila lo disímil para considerar que realidades cualitativamente diferentes puedan ser consideradas "trabajo" en pie de igualdad, aplica un procedimiento similar -e igual de forzado- que el que es propio de la mencionada teoría cuando esta supone que el trabajador y trabajadora pueden incorporar en su corporeidad un capital que debería ser gestionado como lo hace cualquier capitalista con el capital de su empresa (véase Biagi- 
ni y Fernández Peychaux, 2015). Hay aquí, pues, una fijación en los objetos y una difuminación de las relaciones sociales, particularmente respecto del carácter asimétrico de éstas y, por lo tanto, en vinculación con las complejas relaciones de dominación-subordinación que caracterizan la organización económica capitalista, jerarquizanda en múltiples estratos.

El manejo que él realiza de esos conceptos de capital y trabajo, seguramente advierte acerca de la importancia de recuperar la noción de capital como relación social y, en particular, como una que implica asimetría y dominio, lo cual conlleva, necesariamente, un retorno a algunos de las elaboraciones de Marx sobre el capital. Y, sin embargo, y a diferencia del común de los economistas neoclásicos, Piketty sí reconoce -no obstante estas imprecisiones teóricas y conceptuales- que el conflicto está presente en los procesos distributivos entre las diversas clases y estamentos que conforman las sociedades capitalistas, y que, por lo tanto, la remuneración de los llamados factores de la producción no es un asunto técnico determinado por productividades marginales que son, a su vez, resultado de determinados coeficientes tecnológicos, sino que, antes bien, sobre todo está determinado por esa tensión social y política.

Otra implicación importante sobre la que ya advertí: renta y ganancia capitalista se vuelven en Piketty categorías indiferenciadas; obtener ganancias como propietario de una empresa que produce determinado bien o servicio y que compite en un determinado mercado, recibe similar tratamiento que obtener una renta a partir de un bono gubernamental o del alquiler de una casa. Es cierto que esto no afecta los resultados fundamentales que derivan de la investigación de Piketty, conforme a los objetivos analíticos que él parece haber privilegiado. $\mathrm{Y}$, sin embargo, el homogenizar de tal forma categorías que ya aparecían bien deslindadas en el propio Adam Smith, y más claramente en David Ricardo, imposibilita profundizar -como luego lo indicaré- en la caracterización de algunos rasgos, acaso de importancia central, que caracterizan al capitalismo actual.

\section{Los mecanismos económicos de la desigualdad y la importancia de la política}

El concepto de capital en Piketty resulta entonces insatisfactorio, excepto, quizá, para los efectos prácticos que este autor persigue. De lo que se trata es de mostrar cómo ese capital -es decir, esos activos que implican propiedad y generan rendimiento- van acumulándose a la vez que su propiedad va concentrándose de modo que el flujo incrementado de los rendimientos va quedando cada vez en menos manos. Piketty trata de sustanciar su tesis a partir de algunas reglas básicas, en particular la siguiente: la que postula que existe una determinada relación entre el crecimiento de la economía, la tasa de ahorro y la magnitud del capital acumulado (medido por la relación entre el valor de mercado de todos los activos acumulados -de cualquier tipo que fueren- respecto del valor de la producción o ingreso nacional), algo que se- 
guramente lo emparenta con los modelos teóricos de crecimiento equilibrado, en la versión de Kaldor y otros autores neoclásicos. Piketty aduce que los datos históricos ratifican que el rendimiento anual del capital tiende a situarse en los alrededores del 4-5\%, cuando las tasas de crecimiento de la economía escasamente han excedido a lo largo de decenios y siglos del $1 \%$-tan solo escalaron algo por encima del 3\% durante la época dorada del período posterior a la Segunda Guerra Mundial- todo lo cual determina condiciones estructurales de muy largo plazo propicias a una profundización tendencial en el proceso de concentración del capital o patrimonio y, en consecuencia, de ahondamiento de las desigualdades.

Hay aquí una sugerencia interesante: la de que el sistema -y en particular el capitalismo- se mueve en el muy largo plazo hacia una concentración y desigualdad crecientes, excepto que por vías políticas se frene ese proceso y se reviertan las tendencias concentradoras, o bien que ocurran acontecimientos traumáticos -del tipo de los acaecidos con las dos guerras mundiales del Siglo XX y la Gran Depresión de los treintas- que permitan destruir una parte significativa del capital acumulado (patrimonio y activos acumulados) y, por lo tanto, corten, al menos por algún tiempo, el circuito automático de la concentración de la riqueza.

Con un aditamento igualmente interesante: el de que -según el propio Piketty y con arreglo a sus categorías- las desigualdades tienden a ser más abismales al interior de los poseedores de capital (según él los categoriza y conceptúa), que al interior de quienes obtienen ingresos a partir del trabajo (según, asimismo, la conceptuación poco afortunada que él hace de esta categoría). Vale decir: incluso la brecha enorme entre las retribuciones a los "súper-ejecutivos" y los trabajadores manuales menos calificados, son menos pronunciadas que las existentes entre los individuos y las familias situadas en la cúspide más elevada y exclusiva de la riqueza, y el resto de los propietarios. Las diferencias se detectan -y así lo demuestra Piketty- incluso en el estamento más alto, ya que el 1 por mil de los más ricos, es mucho más rico que el $1 \%$ más rico e incomparablemente más rico que el $5 \%$ más rico.

Todo esto tiene una implicación teórica central, que para Piketty pasa inadvertida o por lo menos no mencionada, en relación con lo siguiente: si históricamente se demuestra que el rendimiento del capital (o, más precisamente, el rendimiento derivado de la propiedad de diversos formas de activos) se sitúa en los alrededores del 4-5\% anual, y que eso es así incluso cuando el crecimiento de las economías se sostiene a lo largo del tiempo tres o cuatro puntos por debajo de ese nivel, cabe entonces preguntarse ¿cuáles son los mecanismos profundos, las fuerzas fundamentales subyacentes, que explican esto que, a primera vista, podría considerarse un oxímoron o, en todo caso, una situación que pareciera ser objetivamente insostenible? Un rendimiento del capital que, a lo largo de períodos muy largos, se sostiene por encima del crecimiento de la economía, conduciría inevitablemente a una concentración de la riqueza en manos de los propietarios -incluidos los capitalistas propiamente dichos- y en contra de las clases trabajadoras, pero puesto 
que esa concentración es mucho más aguda en la cúspide más elevada formada por una minúscula proporción de los propietarios mega-ricos, ello también entraña un relegamiento progresivo de los propietarios que conforman parte importante de las capas medias de la sociedad. Esto coincide -en forma indirecta pero muy clara- con las tesis marxistas sobre depauperización de la clase proletaria. Con la ventaja que proporciona la perspectiva de un siglo y medio de desarrollo capitalista desde que esa hipótesis fuera formulada, ésta parece resurgir, de forma no intencional, pero como una depauperización relativa -no absoluta como erróneamente lo anticipó Marx- asociada al ahondamiento abismal de las diferencias, incluso en contra de los capitales pequeños y medianos y los grupos medios de la sociedad, y no solo de las clases trabajadoras que viven de un salario. Ello asimismo plantea algunas sugerencias interesantes en el sentido de que la concentración patrimonial que hace que algunos individuos, familias y estratos sociales se vuelvan inmensamente ricos, es un movimiento paralelo, aunque generalmente invisible, que acompaña el proceso de oligopolización creciente de los mercados en manos de corporaciones de alcance planetario. El dominio que estos gigantes logran sobre mercados, economías nacionales y gobiernos tiene seguramente vínculos importantes, aunque difusos, complejos y subterráneos con esos otros procesos de enriquecimiento excesivo de una cúpula de individuos y familias, insignificante en su tamaño absoluto pero de inmenso poder económico.

Vuelvo sobre esa interpelación teórica fundamental antes formulada: ¿cuáles son las fuerzas subyacentes que propician que los rendimientos asociados a la propiedad de diferentes formas de activos se sostengan muy por encima del crecimiento mismo de la economía? No tengo una respuesta, puesto que evidentemente se trata de una pregunta que tiene implicaciones extremadamente complejas. Y, sin embargo, creo que también aquí Piketty resucita y actualiza sin proponérselo -aunque en una versión complejizada- a Marx como también a los economistas clásicos que le antecedieron -en especial Ricardo- ya que la respuesta seguramente habrá que buscarla, más que en fuerzas económicas "puras", en los arreglos institucionales, históricamente gestados a partir de la interacción -conflictiva, negociadora o colaborativaentre las clases sociales. Dicho de otra forma: los mecanismos económicos que ponen en marcha una especie de dinámica autónoma y automática desde la cual emerge una especie de "tasa de rendimiento garantizada" de los patrimonios, seguramente operan sobre el telón de fondo de una institucionalidad que propicia que esos mecanismos efectivamente funcionen de esa forma y con esos resultados. Esto nos reconduce de la economía hacia la política y hacia la dinámica social y cultural. O bien, dicho de otra forma, este acaso sea un rasgo asociado a la estructura de clases de nuestras sociedades, $y$, de hecho, ello mismo se desprende de los datos históricos que Piketty aporta. De ser esto correcto, ello advertiría que -excluyendo la posibilidad de grandes catástrofes económicas o militares que impliquen una masiva destrucción de patrimonios y activos acumulados- solo por medio del mecanismo político -a través de instituciones, normativas y, en general, decisiones y ac- 
ciones políticas ojalá democráticamente acordadas- es posible romper ese círculo auto-reforzado de la concentración y del ahondamiento de las diferencias. Eventualmente esa podría también ser la manera a través de la cual sea factible diseñar y poner en funcionamiento nuevos mecanismos económicos, más que simplemente políticos, que propicien una mayor equidad distributiva.

\section{¿El crecimiento económico como antídoto para la desigualdad?}

Por otra parte, según Piketty -y los datos que aporta parecen respaldarlo- el crecimiento económico viene a ser una especie de antídoto contra la desigualdad, o, al menos, contra las formas extremas de desigualdad. Ese es un resultado que deriva de la mecánica misma del sistema, que este autor identifica sin problematizarla ni explicarla, y con arreglo a la cual se plantea una determinada relación entre crecimiento económico, tasa de ahorro y magnitud relativa entre el capital acumulado (patrimonio o activos valuados a precios de mercado) y el ingreso o producto nacional. $Y$, de hecho, pareciera que el único período conocido donde el crecimiento fue suficientemente elevado como para compensar el rendimiento del capital y provocar una atenuación de la desigualdad, habría sido la etapa dorada posterior a la Segunda Guerra Mundial. Queda sin embargo una duda razonable en relación con los factores que explicarían ese elevado crecimiento del período de posguerra. En particular, cabe preguntarse si Piketty no estará mirando ahí una correlación espuria o, en todo caso, una correlación que induce a error. Ello por cuanto él, como ya vimos, omite cualquier discusión teórica que clarifique por qué el rendimiento del capital resulta tan elevado, tanto absolutamente como por comparación con el crecimiento de las economías, cuando por otra parte, su explicación del alto crecimiento en el período de la segunda posguerra mundial es principalmente atribuido, de nuevo, a fuerzas económicas que actúan mecánicamente -sobre todo a partir del proceso de reconstitución de los patrimonios tras la masiva destrucción que éstos habrían tenido a raíz de las guerras mundiales y el derrumbe económico de los treinta - sin apenas consideración de fuerzas sociales y factores políticos que, de una u otra forma, pudieron haber propiciado ese crecimiento así como la mayor equidad lograda.

Ese período está caracterizado por una suerte de pacto capital-trabajo (Amín, 1999) que propició tanto la emergencia y consolidación de los Estados de Bienestar -sobre todo en Europa- como la imposición de una tributación progresiva de alcances muy considerables, incluso en Estados Unidos, y en algunos casos (como lo muestra Piketty) más en este país que en otros. Es además un período donde el sistema financiero internacional fue estructurado con arreglo a una nueva arquitectura y un nuevo sistema monetario, todo ello reflejando en parte las ideas propuestas por Keynes. Hay en todo esto aspectos que se sitúan en el ámbito de lo económico pero sobre todo son cuestiones que atienden a procesos sociales y políticos. Todo lo cual, en medio de su innegable complejidad, en parte considerable está teñido por proce- 
sos interclasistas de conflicto y negociación. Se da así lugar a arreglos institucionales y, respectivamente, balances sociopolíticos que lograron estabilizarse de forma relativamente exitosa y lograron sobrevivir durante varios decenios, hasta dar sus primeras manifestaciones claras de descomposición hacia mediados de los años setenta del siglo XX.

Desde el tipo de correlaciones mecánicas que establece Piketty, nada de esto es importante o, en el mejor de los casos, tiene tan solo una importancia muy secundaria. De hecho, como ya indiqué, el alto crecimiento del período de la segunda posguerra mundial, es atribuido por este autor principalmente a los procesos de reconstitución de los capitales -los activos y patrimonios- a raíz de las devastaciones dejadas por las guerras mundiales, en especial la segunda, y la depresión de los treintas. Y, sin embargo, es por lo menos razonable considerar que buena parte del crecimiento alcanzado y una parte nada despreciable de la disminución en las desigualdades fue producto de tales procesos políticos y sociales, en cuanto estos gestaron condiciones de estabilidad y certidumbre, y potenciaron la expansión de los mercados, de una forma que resulta históricamente peculiar, posiblemente única. Ello podría sintetizare en una pregunta ¿acaso los procesos de reconstrucción de las economías y de reconstitución patrimonial habrían sido igualmente exitosos en ausencia de ese marco institucional y ese conjunto de políticas, tanto nacionales como internacionales, que de tal modo lograron crear condiciones de estabilidad propicias? Es difícil descartar que esto no haya tenido una influencia significativa en el desempeño del capitalismo mundial durante ese período, en cuyo caso las correlaciones que Piketty observa resultarían cuestionables en grado suficiente como para exigir una buena dosis de cautela.

Por otra parte, el considerar que el crecimiento económico es un mecanismo poderoso, si de prevenir o incluso reducir las desigualdades se trata, tiene una implicación evidentemente problemática, particularmente en esta época de cambio climático y crisis ambiental. Es claro que no es una posibilidad viable ni aconsejable, particularmente en lo que atañe a los países ricos. Pero incluso en el caso de los países pobres, aun reconociendo que necesitarán crecer para mejorar los niveles de vida y resolver problemas acuciantes en ámbitos esenciales como la salud, la educación, la nutrición, la vivienda y el 4. Crecimiento y consumo agua potable, en todo caso es necesario entender que su crecimiento no podría replicar los modelos del norte rico, puesto que ello es ambientalmente inviable $^{4}$. Y, sin embargo, también debe reconocerse que, en general, Piketty no está recomendando que se recurra al crecimiento como antídoto frente a la desigualdad. De hecho, y en lo que al siglo XXI se refiere, este autor susson, seguramente, las dos caras de una misma moneda. El consumismo, por su parte, es objeto de una crítica sugerente y lúcida por parte de Bauman cribe la tesis de que lo esperable es un crecimiento a largo plazo muy anémico y reducido, como consecuencia principalmente de dos factores: la caída de las tasas de natalidad y la ausencia de tecnologías e industrias puntas que posean capacidades dinamizadoras sustanciales. $Y$ aunque le presta muy poca atención, un tercer factor que Piketty admite como potencialmente limitante del crecimiento es la propia crisis ambiental. 
Teniendo en mente que, en efecto, el siglo XXI no será de elevado crecimiento económico, Piketty opta por el mecanismo político como antídoto frente al crecimiento de la desigualdad. Y aquí, nuevamente, disiente respecto del establishment de los economistas neoclásicos, particularmente aquellos de la versión más ortodoxa y conservadora. $\mathrm{O}$, de otra forma, podríamos decir que esto establece un acercamiento a algunas corrientes o expresiones del neokeynesianismo -en particular las que representan los premios nobel Stiglitz y Krugman- siempre dispuestos a promover mecanismos institucionales y políticos que atenúen las consecuencias negativas derivadas del automatismo de los mercados capitalistas. La propuesta que entonces Piketty nos presenta enfatiza el mecanismo tributario y alienta la coordinación internacional entre los estados como forma de controlar la evasión de impuestos, si bien, como es usual aunque comprensible, su énfasis se centra en Europa. Esa cooperación que se propone, siendo de difícil aplicación, es sin embargo esencial, como paso intermedio en el proceso de constitución de los que Morin (2010) ha llamado una sociedad y una ciudadanía planetarias, asentadas políticamente en una confederación democrática de estados, algo indispensable para rescatar y dar plena vigencia a los derechos de los pueblos, las ciudadanías y de las personas, cuando el capital efectivamente ha tendido a mundializarse. Aparte lo cual, Piketty centra su atención en tres tipos de impuestos: sobre las herencias y donaciones; sobre los ingresos y sobre el patrimonio. Idealmente esto debería ser fruto de la concertación entre los diversos gobiernos hasta llegar a ser, potencialmente, de aplicación mundial. El tributo sobre los ingresos, siendo progresivo, se propone que llegue a tener carácter confiscatorio en sus niveles más elevados, intentando así desincentivar los comportamientos predatorios e irresponsables de los "súper-ejecutivos". El impuesto sobre patrimonios operaria a partir de tasas mucho más reducidas (1-2\% según la cuantía de los patrimonios) y, según Piketty (acaso con un exceso de optimismo) constituiría un mecanismo regulador esencial, particularmente en esta época de efectiva globalización de los capitales financieros.

Estas propuestas han sido descalificadas como "utópicas" y quienes así lo indican son, en general, analistas de izquierdas (entre ellos Varoufakis, actual ministro de finanzas del gobierno de Syriza en Grecia). Aunque, por otra parte, para los sectores conservadores de filiación ideológica neoliberal, todo eso resulta más bien una amenaza terrible, una especie de puñal lanzado contra el corazón mismo del capitalismo. Por supuesto, es por lo menos paradójico que algunas izquierdas quieran aquí aplicar el apelativo "utópico", ya que ello necesariamente entraña una toma de posición más bien conformista. En cambio no tiene nada de extraño la respuesta visceral que esto provoca en los sectores conservadores y plutocráticos.

De mi parte, reconozco aquí algo como una especie de hoja de ruta que apunta en la dirección correcta: hacia la concertación de políticas -en este caso en materia tributaria- y, por lo tanto, hacia la concertación entre estados y gobiernos, con fines de cooperación en materia tributaria, intercambio de información y, eventualmente, el establecimiento de un sistema impositivo 
unificado. Y, sin embargo, es cierto que Piketty no toma en cuenta otras posibilidades, necesarias y potencialmente muy eficaces, si de promover una mayor equidad se trata. El fortalecimiento de los sindicatos y su coordinación y cooperación a nivel internacional es una de ellas, y de una importancia seguramente clave. La elevación de los salarios mínimos y, eventualmente, la implementación de las propuestas para una renta básica universal, son algunas otras posibilidades a considerar. Por otra parte, hay que reconocer que la dificultad de Piketty para dar espacios a ese otro tipo de alternativas, y, en particular, para pensar la participación y movilización ciudadana como instrumento político que provoque cambios en el orden institucional que hoy propicia la desigualdad, ratifica que hay aspectos en los cuales el autor francés no logra liberarse completamente de las anteojeras que imponen la cosificación característica de la teoría económica neoclásica. Por ello, sus propuesta tributarias -en principio correctas y bien orientadas- arriesgan degradarse en un ejercicio tecnocrático sin mayores consecuencias, en el tanto no se reconozca la importancia de la movilización ciudadana como requisito que les dé viabilidad política.

Dos últimos aspectos, que sugieren posibles vertientes de discusión teórica pero con interesantes consecuencias políticas, son los siguientes: primero, las implicaciones del larguísimo plazo pikettiano en relación con las usuales caracterizaciones teóricas neoclásicas que postulan equilibrios armoniosos a largo plazo; segundo, la naturaleza rentista del capitalismo del siglo XXI. Ninguno de estos aspectos es reconocido por Piketty $y$, sin embargo, de su libro parecen desprenderse consecuencias interesantes en ambos casos.

\section{El larguísimo plazo pikettiano y los "equilibrios virtuosos" neoclásicos}

Esa teoría económica convencional introduce el largo plazo a propósito de diversos asuntos: la teoría de la empresa (lo que remite a los aportes originales de Marshall); la del equilibrio de mercados competitivos, en relación, a su vez, con la teoría de la competencia perfecta (con sus raíces en Walras y sus extremas sofisticaciones matemáticas en Arrow, Debreu y Hahn y la crítica contundente de Ackerman y Nadal, 2013); también en el nivel macroeconómico, particularmente desde las formulaciones de la teoría de las expectativas racionales de Lucas y Sargent. Aun tratándose de problemáticas más o menos disímiles entre sí, en todos los casos las teorías reinciden en una misma conclusión: la capacidad del sistema de mercado para restablecer equilibrios virtuosos a largo plazo, cada vez que ese equilibrio ha sufrido alguna perturbación de corto plazo. En su forma teórica pura, cuando el tiempo adquiere un estatuto estrictamente lógico vacío de cualquier referente histórico, los procesos de ajuste son, en la abstracción matemática, instantáneos, lo cual supone conocimiento perfecto e infinita capacidad de adaptación. En ese contexto, pasado, presente y futuro se vuelven indistinguibles: todo se resuelve en un presente que posee un estatuto contradictorio: es instantáneo pero 
es eterno de forma que aprisiona en sí mismo el pasado y el futuro. Esto admite diversas adaptaciones -bien para fines didácticos o para persuasión de oyentes incautos- en cuyo caso el largo plazo viene a ser como al modo de una sucesión fluida y armoniosa de cortos plazos. Si en uno de estos acaeció alguna perturbación -por ejemplo, a raíz de una política fiscal expansiva- en los sucesivos cortos plazos ese trastorno será reabsorbido y neutralizado por el sistema, de forma que, "a largo plazo", habremos regresado al equilibrio armonioso que los mercados, en su infinita sabiduría, habrán establecido, sin que, al cabo, ocurra nada importante.

En los largos recorridos históricos -de décadas y siglos- que Piketty realiza en su libro, podría quizá observarse una confirmación de esa tesis neoclásica de los equilibrios armoniosos a largo plazo. Al menos ello podría desprenderse de una observación descuidada que se atenga tan solo a la tendencia del sistema, que Piketty evidencia, a crecer en muy largo plazo, sin bien a tasas relativamente modestas del orden del 1-2\% promedio anual. Lo cual no resulta demasiado novedoso, si recordamos que en Marx la tendencia a la acumulación incesante de capitales, al parecer vinculada a su vez a la búsqueda incesante de ganancias, aparece como un rasgo consustancial al capitalismo, idea que Schumpeter comparte pero reformula, asociándola más bien a la capacidad del capitalismo para la continua innovación tecnológica, en correspondencia con la bien conocida tesis del empresario schumpeteriano, acaso no tan diferente -como Schumpeter prefería creer- de la tesis de Marx acerca de la compulsión capitalista hacia la inversión. Esos movimientos de largo alcance enmascaran múltiples, y a veces agudas, perturbaciones de corto o mediano plazo e incluso, a veces, de duración relativamente extensa. Podría haber aquí un error derivado de la fijación excesiva en el bosque, con descuido de los árboles, lo que impide constatar que la realidad del capitalismo quizá su realidad inmanente- es la del desequilibrio e inestabilidad; un continuo ir y venir de empujones, saltos, frenazos y derrumbes. El sistema parece estable cuando se dibujan curvas que cubren decenios y siglos enteros, pero jamás es estable en términos de sus implicaciones para la vida concreta de la gente (de ahí la importancia de en el largo plazo todos estamos muertos de Keynes ya que, en el entre tanto, se acumulan sufrimientos y frustraciones en la cotidianidad de la vida de la gente). Dicho de otra forma: la ficción de los promedios estadísticos a lo largo de períodos muy largos, sugiere una estabilidad inexistente. En realidad, el capitalismo solamente existe como perturbación y desequilibrios permanentes, y mucho más si se le deja a su automatismo irrestricto. Podríamos entonces decir que, contario a las ficciones teóricas neoclásicas que postulan mercados perfectos, el capitalismo sigue existiendo porque los mecanismos políticos -y en particular la democracia- le han proporcionado el oxígeno que necesitaba. 


\section{¿Hacia un capitalismo patrimonializado y rentificado?}

Por otra parte, del estudio de Piketty podría desprenderse otra conclusión que pareciera pasar inadvertida para el autor francés: el capitalismo, según su análisis, se mueve hacia una modalidad patrimonialista y rentista. Es decir, estaríamos en presencia de un capitalismo patrimonializado y rentificado, ello en virtud de la acumulación de fortunas colosales, heredadas de generación en generación y las cuales, con el paso del tiempo, tienden a hincharse más y más, de forma mecánica y por efecto acumulativo del rendimiento que automáticamente generan. Lo cual, por otra parte, hace trizas la ilusión -tan cara para la economía- según la cual la mayor virtud del capitalismo es su capacidad para premiar y retribuir el riesgo y la innovación. En cambio, lo que estaría en proceso de consolidación es un sistema que coloca en la cúspide del poder y los privilegios, a una clase ociosa y muy rica, cuyos miembros nacerán siendo dueños de fortunas colosales y vivirán una existencia de disipación y despilfarro sin jamás tener que esforzarse por nada ni aportar nada a la sociedad ni a la humanidad. La dinámica nada brillante que la productividad registra en el nuevo siglo en la generalidad de los países capitalistas ricos, acaso confirme esa realidad subyacente. $Y$ siendo que esto implica poner en ralentí unos de los mecanismos básicos de dinamización del sistema, asimismo es algo que abre serias interrogantes en relación con su viabilidad desde el punto de vista político, puesto que, como debería ser obvio, estos excesos inútiles e injustificables inevitablemente generan furia, frustración y malestar.

La imagen de ese capitalismo rentificado y patrimonializado deriva coherentemente del análisis que desarrolla Piketty y de la abundante evidencia empírica que aporta. Pero el propio Piketty lo deja más como una insinuación, que como un planteamiento explícitamente debatido. Que no desarrolle en profundidad este aspecto tan esencial podría deberse a varias razones, incluso a la necesidad práctica de establecer límites a un trabajo de por sí muy voluminoso. Pero ello también podría ser un reflejo de la confusión que se presenta entre renta y ganancia o beneficio capitalista, ambas comprimidas por Piketty en la imprecisa noción de "rendimiento (o tasa de rendimiento) del capital". Esos dos tipos de ingresos -que ya Smith y sobre todo Ricardo supieron diferenciar como las remuneraciones de dos clases sociales distintasreflejan también lógicas económicas subyacentes muy distintas, y este es posiblemente el aspecto más importante de la cuestión, que en Piketty pasa inadvertido. Es el contraste entre la burguesía revolucionaria de que hablaba Marx, y el viejo orden feudal, estático y conservador. O, en el siglo XXI, vendría a ser la notable paradoja de un capitalismo gobernado, desde la cúspide más elevada del poder económico, por una clase ociosa, cada vez más y más rica y poderosa gracias al usufructo de sus rentas.

Cierto, por otra parte, que Piketty aporta datos que muestran que hacia finales del siglo XIX e inicios del XX, se había avanzado hacia extremos comparables de concentración de la riqueza y ahondamiento de las desigualdades, todo lo cual se habría frenado a raíz de los grandes cataclismos de las gue- 
rras mundiales y la Gran Depresión, durante el período 1914-1945. Y, sin embargo, algo nuevo hay seguramente en el actual siglo XXI, asociado a la capacidad de los capitales para mundializarse de forma efectiva, y establecer, por medio de corporaciones transnacionales, bancos y fondos especulativos, un control real sobre naciones, países y gobiernos. Lo cual plantea un desafío económico que se desdobla asimismo como una amenaza política cuyas consecuencias no es posible ignorar ni disminuir. Dicho de otra forma: las reformas que esto exige realizar son de un alcance mucho más amplio de lo que podría haberse pensado hace un siglo, en cuyo contexto las ideas del mismo Piketty sobre tributación, aun siendo insuficientes, seguramente apuntan en la dirección correcta.

Acaso esto podría abrirse hacia especulaciones -no carentes de fundamento- en relación con posibles procesos de mutación del propio sistema capitalista, en cuanto la dinámica automática que le caracteriza podría estar conduciendo hacia algo que implica su propia subversión, al tiempo que ella misma genera la obligación de introducir reformas institucionales que, destinadas a frenar ese problemático automatismo, tendrían sin embargo un alcance tal que, eventualmente, podrían implicar avanzar, efectivamente, hacia algo que deja de ser capitalismo y empieza a parecerse a algo diferente. Y, sin embargo, esta es una reflexión que dejo aquí tan solo sugerida.

\section{Una última consideración}

El trabajo de Piketty tiene una consecuencia práctica de enorme importancia para el caso de Costa Rica y, de seguro, para muchos otros países, en especial países pobres, en el sentido de que nuestras mediciones de la desigualdad son un monumento a la chapucería. El análisis que Piketty desarrolla, y la evidencia empírica que aporta, claramente sugieren que nuestros estudios sobre desigualdad con seguridad ocultan muchísimo más de lo que revelan. El desafío está planteado: ¿cómo desarrollar metodologías de investigación e instrumentos de recopilación, sistematización y análisis de la información que desnuden las reales dimensiones de las desigualdades que fracturan nuestra sociedad?

\section{Bibliografía}

Ackerman, F. y Nadal, A. (2013). Ensayos críticos sobre la teoría del equilibrio general. México: Siglo XXI Editores.

Amin, S. (1999). El capitalismo en la era de la globalización. Barcelona: Paidós.

Bauman, Z. (2010). Vida de consumo. Buenos Aires: Fondo de Cultura Eco- 
nómica.

Bauman, Z. (2014). ¿La riqueza de unos pocos nos beneficia a todos? Barcelona: Paidós.

Biagini, H.E. y Fernández Peychaux, D. (2015). El neuroliberalismo y la ética del más fuerte. Heredia: EUNA.

Mora Plaza, A. (2011). Viaje al interior de la producción de mercancías por medio de mercancías. Revista Crítica de Ciencias Sociales yJurídicas.

Dobb, M. (1985). Teorías del valor y de la distribución desde Adam Smith. Ideología y teoría económica. México: Siglo XXI Editores.

Fiorito, A. (s.f.). Piero Sraffa: la implosión de la economía neoclásica. Ediciones Cooperativas.

Galbraith, J.K. (1980). El nuevo estado industrial. Barcelona: Editorial Ariel.

Morin, E. (2010). ¿Hacia el abismo? Globalización en el siglo XXI. Madrid: Paidós.

Robinson, J. (1953). The production function and the theory of capital. Review of economic studies, 21(2), 81-106.

Roncaglia, A. (2000). Piero Sraffa: his life, thought and cultural heritage. New York: Routledge.

Samuelson, P.A. (1962). Parable and realism in capital theory: the surrogate production function. The Review of Economic Studies, Oxford University Press, 29(3).

Schumpeter, J.A. (1983). 10 grandes economistas: de Marx a Keynes. Madrid: Alianza Editorial S.A.

Sraffa, P. (1960). Production of commodities by means of commodities. A prelude to a critique of economic theory. London: Cambridge University Press. 